$5-11-2021$

\title{
Occupational Therapist Role in Post-Secondary Education Transition Program: Emphasis on Self-Advocacy Skills
}

\author{
Nikki K. Voorhees \\ University of St. Augustine for Health Sciences \\ DOI: https://doi.org/10.46409/sr.OOQC3665
}

Follow this and additional works at: https://soar.usa.edu/capstones

Part of the Accessibility Commons, Occupational Therapy Commons, and the Special Education and Teaching Commons

\section{Recommended Citation \\ Voorhees, N. K. (2021). Occupational Therapist Role in Post-Secondary Education Transition Program: Emphasis on Self-Advocacy Skills. [Doctoral project, University of St Augustine for Health Sciences]. SOAR @ USA: Student Capstone Projects Collection. https://doi.org/10.46409/sr.00QC3665}

This Capstone is brought to you for free and open access by the Student Research at SOAR @ USA. It has been accepted for inclusion in Student Capstone Projects by an authorized administrator of SOAR @ USA. For more information, please contact soar@usa.edu, erobinson@usa.edu. 
Occupational Therapist Role in Post-Secondary Education Transition Program: Emphasis on Self-Advocacy Skills

\author{
Nikki, K, Voorhees \\ Department of Occupational Therapy, University of St. Augustine for Health Sciences
}

A Capstone Presented in Partial Fulfillment

of the Requirement for the Degree of DOCTOR OF OCCUPATIONAL THERAPY

University of St. Augustine for Health Sciences

December 2020 
Occupational Therapist Role in Post-Secondary Education Transition Program: Emphasis on Self-Advocacy Skills

Nikki, K, Voorhees

Department of Occupational Therapy, University of St. Augustine for Health Sciences has been approved

December, 2020

APPROVED:

Susan MacDermott, OTD, OTR/L, Doctoral Coordinator

Becki Cohill, OTD, OTR/L, Doctoral Coordinator

Erin Schwier, EdD, OTD, OTR/L, Program Director

ACCEPTED AND SIGNED:

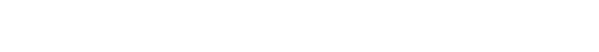

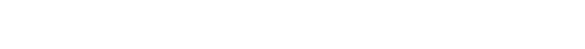

Susan MacDermott, OTD, OTR/L, Doctoral Coordinator

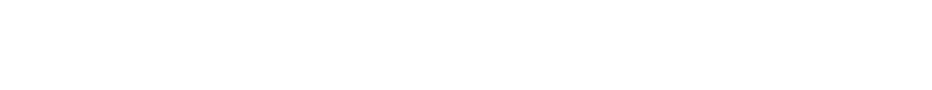

Becki Cohill, OTD, OTR/L, Doctoral Coordinator

\begin{tabular}{|c|c|}
\hline Erin Schwier & 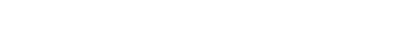 \\
\hline
\end{tabular}

Erin Schwier, EdD, OTD, OTR/L, Program Director 
Copyright (C) Nikki Voorhees, 2020 all rights reserved 


\section{Table of Contents}

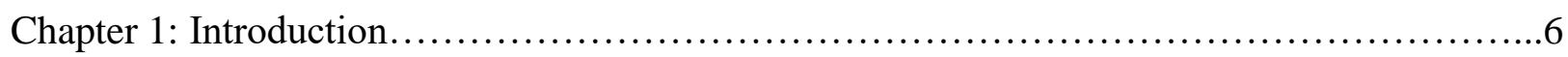

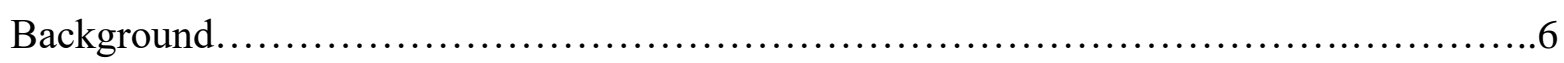

Statement of the Problem............................................................ 10

Purpose Statement.........................................................11

Rationale................................................................... 12

Significance................................................................. 12

Objectives................................................................. 13

Assumptions, Limitations, and Delimitations.....................................14

Definitions of Terms......................................................... 15

Chapter 2: Literature Review....................................................... 16

Student Experiences on Transition to Post-secondary education .......................... 16

The Role of Occupational Therapy in Transition Planning ............................17

Current Transition Programs..................................................... 18

Self-advocacy Framework....................................................20

Literature Review Summary.................................................21

Chapter 3: Project Description...................................................22

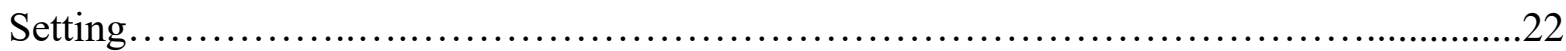

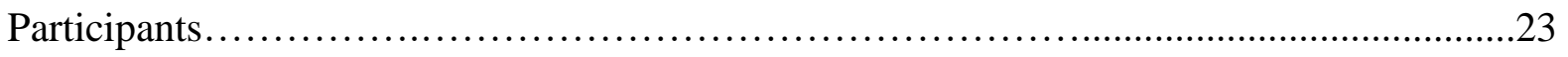

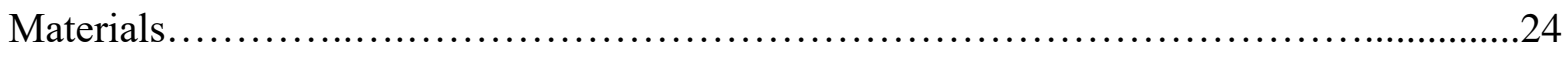

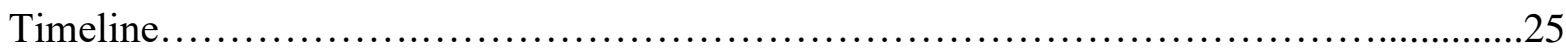

Program Description Conclusion.............................................. 31

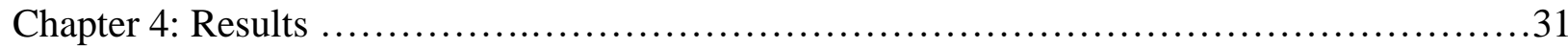


Chapter 5: Discussion......................................................... 50

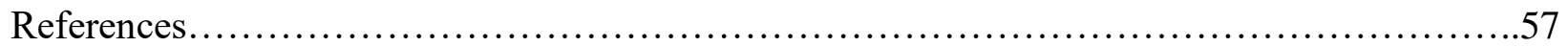

Appendix A - Staff Survey.....................................................64

Appendix B - Self-Advocacy Survey .............................................68

Appendix C - Self-Advocacy Post Survey ......................................... 72

Appendix D - College Readiness Survey............................................76

Appendix E - Lesson Plans in College and Career Readiness Course ........................8 80

Appendix F - Lesson Plans $8^{\text {th }}$ Graders........................................... 108

Appendix G - Staff Survey.................................................... 119

Appendix H - Self-Advocacy Survey ..........................................125

Appendix I - Self-Advocacy Post Survey .........................................137

Appendix J - College Readiness Survey...........................................147 


\section{Occupational Therapist Role in Post-Secondary Education Transition Program: Emphasis on Self-Advocacy Skills Chapter 1: Introduction}

The purpose of this capstone paper is to provide a brief outline of my occupational therapy (OT) capstone project, which is to help prepare students with learning differences for the transition from high school to post-secondary education. This project includes social skills, selfadvocacy, and self-determination skills essential for a successful transition.

\section{Background}

It is becoming increasingly important for individuals to obtain post-secondary education in order to gain employment (Alverson et al., 2019; Chandroo et al., 2018). This increased importance to attend post-secondary education makes it imperative for students who are graduating from high school to be fully prepared for the transition to post-secondary education (Rothman et al., 2008). The transition from high school to post-secondary education is difficult for any individual. However, it is even more difficult for students with learning differences, as they tend to have problems in the areas of social skills, communication, problem solving, selfadvocacy, and executive functioning (Alverson et al., 2019). Individuals with learning differences refers to students who learn in different ways or difference paces and it does not necessarily mean they have a formal diagnosis (The Winston School, n.d.). The transition from high school to post-secondary education poses concerns not only in the increased academic work intensity of post-secondary education, but also poses concerns in areas such as independent living skills, social interactions with peers, self-advocating to professors, requesting needed academic accommodations and navigating resources on a new campus (Novakovic \& Ross, 2015). 
High school students with learning differences tend to receive high levels of support throughout high school such as accommodations, modifications to curriculum, in-class support, and individualized teaching and assessment approaches (Chandroo et al., 2018). Those same levels of support are then expected by the students during their post-secondary education as well (Hotez et al., 2018; Lawson et al., 2016). The misperception that post-secondary education will provide the same level of support results in students being even more unprepared for their transition to post-secondary education. There are federal regulations in place through Americans with Disabilities Act for post-secondary students to receive disability-related accommodations such as individual assessment approaches, assistance with note-taking, and assistive technology, but modifications to the curriculum is not offered. However, unlike in high school, the students will need the self-advocacy skills to promote their own health literacy and request those needed accommodations themselves (Hotez et al., 2018). Entering post-secondary education is often the first time when students demonstrate self-advocacy and are accountable for independently requesting appropriate accommodations, promoting their own health literacy, knowing the laws related to their education and their rights as a student, as well as being accountable for developing the self-advocacy and communication skills needed to obtain those supports (Hotez et al., 2018).

Currently, there are federal regulations in place to ensure that high school students with disabilities receive proper guidance for their transition toward individualized post-secondary goals. However, these regulations do not take into account individuals with learning differences without a formal diagnosis. The Individuals with Disabilities Education Act (IDEA) of 2004 requires all students with a formal diagnosis qualified under IDEA between ages 16-21 to have a transition plan (Spencer et al., 2017). According to the National Center for Learning Disabilities 
(n.d.), if eligible under IDEA, the students, with the help of the high school team will develop an Individualized Education Plan (IEP). The IEP includes a section on transition planning that is individualized for each student based on his/her post-secondary goals (Chandroo et al., 2018). The IEP team determines the transition plan for each student and typically includes the student, parents, teachers, and other professionals involved in related services including OTs (Angell et al., 2019).

Occupational therapists can work in a variety of settings to help promote independence from activities of daily living to work/education. Occupational therapists can work with individuals to improve sensory modulation skills, self-awareness, time management, study skills, social skills, self-determination and self-advocacy, all of which are necessary for the transition to postsecondary education (Dirette, 2019; Spencer et al., 2017). Although OTs have an established role on the IEP team, OTs who are working in the school setting are increasingly reporting limited participation in transition planning due to other professions perception of OTs as "the people who work on handwriting and sensory integration" (Angell et al., 2019, p.129). There are limited OTs currently working in transition services as this is still considered an emerging practice area in the profession of OT (Spencer et al., 2017). The role of OT is to address areas of concern that affect students' occupations while in high school as well as occupations they enter into as an adult after graduation (Mankey, 2011). Mankey (2011) interviewed OTs regarding their level of involvement in secondary transition planning. They found that the OTs reported there is currently very little involvement of OTs in transition planning for students but felt that this is a critical area for OT intervention (Mankey, 2011).

Occupational therapists use various models to guide their critical reasoning. A model that will influence the development of this program will be Model of Human Occupation (MOHO). 
Kielhofner and Burke (1980) stated that MOHO focuses on volition (motivation of the individual), habituation (the individual's patterns or routines), and performance capacity (skills required to complete the task). It describes how individuals perform and adapt their occupations based on feedback from the physical and social environments (Kielhofner \& Burke, 1980). The MOHO will be used to help students as they transition to post-secondary education in order to maintain motivation to pursue post-secondary education, to assist with the establishment of healthy and effective routines and patterns, and to identify and improve the performance skills needed to succeed, such as self-advocacy. It will also guide each student in order to adapt and modify their occupations, such as post-secondary education, depending on feedback from the environment.

Using the Person, Environment, and Occupation Performance Model (PEOP), an OT can assess each student individually, the environment they are working in, the task or role of the student and how all three of those aspects affect a student's occupational performance (Baum et al., 2015). This model focuses on determining the ideal combination of person, environment and task to support optimal occupational performance (Baum et al., 2015). It separates intrinsic and extrinsic factors, meaning that it looks at factors that happen within the individual such as cognitive and psychological components as well as external factors such as the natural environment and federal regulations, as both have potential to affect occupational performance (Baum et al., 2015). The PEOP model is client-centered, indicating that the student will identify the post-secondary goals on which they wish to improve (Baum et al., 2015). Based on those needs, the OT can then find potential barriers in the student's occupational performance and break down those barriers by altering the student's environment and tasks in a way that supports positive occupational performance in post-secondary education. The PEOP model can guide the 
transition from high school to post-secondary education by taking a holistic approach and ensuring optimal occupational performance.

There are programs developed to assist students with the transition from high school to post-secondary education including the McDaniel Step Ahead program (Lawson et al, 2016) and the STEPS Program: Stepped Transition in Education Program for Students with ASD (White et al., 2017). The McDaniel Step Ahead transition program is intended to provide tools for navigating college life, including self-advocacy skills and how to properly utilize supports within disability services (Lawson et al., 2016). The STEPS Program was developed to promote successful transition into postsecondary education, improve the post-secondary school experience for students already enrolled, and to promote self-determination and self-regulation skills (White et al., 2017). Although there are programs already developed to assist with the transition from high school to post-secondary education, there is little to no OT involvement and minimal implications on inclusion of these programs into the high school curriculum.

\section{Statement of the Problem}

There are transition programs developed to promote not only a successful transition from high school to post-secondary education, but also to promote success throughout post-secondary education. There are also laws in place to ensure that all secondary students qualified under IDEA obtain a transition plan to help them achieve their post-secondary goals (Spencer et al., 2017). Despite the already developed actions in place to help facilitate a smooth and successful transition for all students with learning differences, there are still barriers students face during this transition. The resources and supports provided by IDEA do not include all students with learning differences, only those who are qualified. The high school to post-secondary education 
transition programs already developed lack an OT foundation and a clear structure on implementation of the programs into the classroom.

Despite the potential for OTs to help students in their transition to post-secondary education, there are currently very few OTs working in this area (Dirette, 2019). Historically, school-based OTs' focus has been on early intervention and underlying skill deficits (Mankey, 2011). School-based OTs tend to provide interventions on foundational skills such as handwriting and organizational skills, and limited intervention on skills to grow independence including self-management and self-advocacy (Seruya \& Ellen, 2015). These skills that assist with the development of independence have a great impact on academic functioning of students in secondary school and should be a critical area of intervention (Seruya \& Ellen, 2015). The OTs working in school settings have not taken on transition planning in general because it was perceived by the OTs that someone else was already working on that with their students (Mankey, 2011). Occupational therapists also have not focused on transition planning because they have felt that they lacked an established role in transition planning within the educational team (Angell et al., 2018; Mankey, 2011). Therefore, OTs are not working with students in the transition from high school to post-secondary education although they have the qualifications and training to support students through this important stage of occupational development.

\section{Purpose Statement}

The purpose of this capstone project is to develop an occupational therapy-based transition program from high school to post-secondary education. The program will reflect the foundations of occupational therapy and include client-centered and occupation-based practices (American Occupational Therapy Association, 2014). The program will focus on social, selfadvocacy, and self-determination skills to help the students transition from high school to post- 
secondary education as smoothly as possible. The goal will be for all students with learning differences in high school to feel prepared for the transition to post-secondary education and feel prepared to be successful in post-secondary education.

\section{Project Rationale}

The unique skills that OT's have would allow them to create a transition program to help students to make the transition from high school to post-secondary education successful. Occupational therapists are able to recognize and address potential barriers to students' occupations, which include education (Shea \& Giles, 2016). The students can collaborate with the OT in order to develop realistic goals regarding their post-secondary education as well as assist in developing a map of their potential pathways towards those goals, giving the students a sense of purpose and motivation (Shea \& Giles, 2016). Occupational therapists can contribute to a positive transition from high school to post-secondary education by creating a program that reduces barriers towards success such as addressing navigation skills in academic programs, managing accommodations and supports through skill development of self-advocacy, developing effective routines and habits, and suggesting assistive technology if needed (Spencer et al., 2017).

\section{Project Significance}

Transition programs help address common concerns that all students feel their first year in post-secondary education, such as feelings of low self-esteem, high anxiety, and intimidation (Lawson et al., 2015). Findings suggest that transition programs help students not only gain knowledge about post-secondary education but also gain leadership skills (Hotez et al., 2018; Shea \& Giles, 2016). They also learn how to build health literacy and self-advocacy skills to receive accommodations and supports necessary to be successful (Rothman et al., 2008). 
Students who participate in transition programs from high school to post-secondary education have positive employment outcomes, such as higher wages and better work hours (Jun et al., 2015).

With the help from an OT, they can assist the students with determining an individualized transition plan to meet those goals (Angell et al., 2018; Spencer et al., 2017). An OT can also address areas of concern which includes self-advocacy and self-determination skills, social interaction skills, and problem-solving skills such as navigating resources on campus (Novakovic \& Ross, 2015; Shea \&Giles, 2016). With the unique skills and capabilities OTs have in promoting self-advocacy and self-determination, they can provide a distinct value in postsecondary transition planning (Angell et al., 2018).

\section{Objectives}

1. Identify and communicate the role of occupational therapy in the transition from high school toward post-secondary goals.

2. Identify measurable outcomes used in transition programs encompassing self-advocacy skills and self-determination skills in order to measure the success of the transition program.

3. Identify methods to teach necessary transition skills through occupation-based role playing and modeling to students in the classroom.

4. Complete a needs assessment focused on assessing the barriers or limitations to selfdetermination skills using information gathered from the students, staff, and administration at Winston School

5. Incorporate self-advocacy skills to enhance the occupation of education into the high school curriculum. 


\section{Assumptions, Limitations, and Delimitations}

\section{Assumptions}

Considering this project is focused on developing an OT based transition program from high school to post-secondary education, it assumes that all students with learning differences will have the intention to attend post-secondary education. Even if a student does not necessarily have the intention to attend post-secondary education and instead intends to go right to work, the skills learned in transition programs can improve overall employment outcomes as well (Jun et al., 2015). If a student is initially unsure regarding their post-secondary plans, then attending a transition program might change their mind about attending post-secondary education (Novakovic \& Ross, 2015). Indicating, that after attending a transition program the students realized that they actually do want to attend college. From transition programs, the students realized the importance of attending post-secondary education as a means to meet his/her future career goals and financial goals (Shea \& Giles, 2016). And lastly, this project also assumes that students with learning differences do not already have the necessary skills to succeed in the transition from high school to post-secondary education.

\section{Limitations}

This project was conducted at a private school called The Winston School consisting of grades $6^{\text {th }}-12^{\text {th }}$ (The Winston School, n.d.). This school is specifically for individuals with learning differences who did not succeed in a traditional school setting (The Winston School, n.d.). Due to the chosen population and setting, this project is difficult to generalize to a typical public school as they may not have the appropriate resources, funding, and supports like Winston. 


\section{Delimitations}

A delimitation of this project is that the population chosen was students with learning differences as that is the population at the chosen site. Students with learning differences can encompass anywhere from a student with a formal diagnosis to a student who just requires extra time on assignments. There is a wide range of individuals with various deficits and severity of deficits when using the population of students with learning differences. Another delimitation is the self-advocacy component of the transition program. A transition program incorporates many different aspects such as financial literacy, independent living, and social skills. However, for this project, the main areas of focus will be on self-advocacy and self-determination.

\section{Definition of Terms}

Learning differences refers to students who learn in different ways or difference paces (The Winston School, n.d.). Students with learning differences could have a variety of formal diagnoses or they could not have any formal diagnosis (The Winston School, n.d.).

Post-secondary education is any education that takes place after high school. It could include a four-year university, community college, trade school, etc. (Top Hat, n.d.).

Self-advocacy has many different definitions (Holzberg et al., 2019). Kay (2019) described selfadvocacy as a "complex set of knowledge and skills with four overarching components: knowledge of self, knowledge of rights, communication, and leadership" (p. 358). In general, self-advocacy is defined as an "individual's ability to effectively recognize and articulate one's needs and rights" (Holzeberg et al., 2019, p. 167).

Self-determination is the skills, knowledge, and beliefs that will assist the individual in participating in goal-directed, self-regulated, autonomous behavior (Collins \& Wolter, 2018). It 
is the process of knowing and valuing oneself in order to make decisions to achieve desired goals (Collins \& Wolter, 2018).

Health literacy is defined as an individual's capacity to obtain, communicate, process, and understand his/her basic health information the services provided to make appropriate health related decisions (Center for Disease Control and Prevention, n.d.).

\section{Chapter 2: Literature Review}

The purpose of this literature review is to gain a better understanding of the current research and literature on an OT-based transition program for high school students transitioning to postsecondary education. In this literature review, the research can be divided into various themes to address necessary components needed for OTs' role in transition planning. These themes are OTs' current role with transition planning, current transition programs, students' experiences during their transition to postsecondary education, and lastly, self-advocacy among students transitioning. After conducting this literature review, there are noted gaps in the literature on OT based transition programs that focus on self-advocacy that can be incorporated directly into the curriculum.

\section{Student Experiences of Transition to Post-Secondary Education}

The transition from high school to postsecondary education is difficult for all students for many reasons. However, there are additional challenges that students with learning differences face throughout this transition such as difficulties with social skills, self-determination, feelings of intimidation, and fears of being stigmatized (Alverson et al., 2019; Anderson et al., 2017; Lawson et al., 2016). These challenges were not only found in high school, but they continued into postsecondary education as well (Alverson et al., 2019). Due to these challenges, students tend to have difficulty with transition planning, requiring extra assistance for establishing 
realistic educational goals and academic preparedness (Shea \& Giles, 2016). Some students are even unaware of the difficulty of post-secondary demands and lacked self-awareness on their own weaknesses (Anderson et al., 2017). There are many factors that can contribute to a poor transition from high school to postsecondary education. The main predictor is said to be the amount and quality of special education services received in high school (Todis et al., 2011). If a student receives a lot of high-quality support in high school, they may expect that same support in college (Lawson et al., 2016; Todis et al., 2011).

\section{The Role of Occupational Therapy in Transition Planning}

Currently, there is a limited number of OTs working in transition planning for postsecondary education and in university disability student services programs (Dirette, 2019). Despite the limited number of OTs helping students transition from high school to postsecondary education, many OTs believe that the profession should provide secondary transition services for students (Mankey, 2011). Occupational therapists can help prepare students for post-secondary education by evaluating the occupation of education, the environment, performance skills, and performance patterns of each student and adapting/modifying each to ensure an optimal transition (Spencer et al., 2017). Occupational therapists can also assist students with career and educational goal planning, while promoting self-advocacy and self-determination skills (Shea \& Giles, 2016).

Self-determination is a critical skill required for successful post-secondary transition planning. This indicates a necessary role for OTs to contribute to students' transition planning as OTs are fully equipped to support the development of self-advocacy and self-determination (Angell et al., 2019; Spencer et al., 2017). Occupational therapists need to secure a role as a crucial member of the transition planning team. This can be done by first describing how transition planning and self-determination skills relates to OT and then demonstrating the ability 
of the OT to promote self-determination skills to improve the transition to postsecondary education (Angell et al., 2019). Occupational therapists can promote this ability by utilizing unique skills of the profession such as a task analysis that breaks down tasks in an individualized way, by teaching self-determination skills through various methods such as role playing, and by helping prepare students to navigate service systems and resources after high school (Angell et al., 2019).

\section{Current Transition Programs}

As evidenced by many articles, a way to improve success for students' transitions from high school to postsecondary education is to provide a transition program. Transition programs not only ensure a successful transition, but it can also improve friendship networks, greater selfsufficiency, and personal growth outside of academics (Wilson et al., 2012). Although there are little to no reported OT-based transition programs, there are many general transition programs that have already been developed. Current transition programs focus on independent living skills, transition skills, navigating college campuses, familiarity of college life and structure, and finding resources for reasonable accommodations (Lawson et al., 2016; Novakovic \& Ross, 2015; Rothman et al., 2008). There are also transition programs that emphasis time management, stress management, social networking, self-advocacy, and health literacy; necessary skills for a successful transition to post-secondary education (Hotez et al., 2018; Lawson et al., 2016; Rogan et al., 2014). There are also transition planning programs from high school directly to employment. These programs include a collaboration with vocational rehabilitation and other community partners to promote positive employment outcomes (Brewer et al., 2011: Jun et al., 2015; Nochajski \& Schweitzer, 2014). These programs are said to improve attendance, self- 
esteem, commitment to a work ethic, knowledge, and self-determination (Sabbatino \& Macrine, 2007).

These established transition programs determined areas that should be emphasized for an effective post-secondary transition plan. These include knowledge of health literacy, knowledge of post- secondary support services; knowledge about disability legislation; and self-advocacy skills (Rothman et al., 2008). A systematic review was done to understand the overall best practices and components of post-secondary transition programs for youth with disabilities (Lindsay et al., 2019). All studies in the review reported improvement in at least one of the following: college enrollment, self-determination, self-confidence, social and vocational selfefficacy, autonomy, social support, career exploration, and transition skills (Lindsay et al., 2019). Some studies found additional improvements in transition planning, self-determination, career exploration, readiness, self-efficacy, knowledge of disabilities, college enrollment, selfconfidence, autonomy, social support, and self-advocacy. (Lindsay et al., 2019).

In general, the current high school transition programs provide an educational overview and promote the skills necessary for post-secondary education. However, students are still facing barriers and complications through this transition (Dirette, 2019). Occupational therapists are an ideal member of the transition planning team due to their professional skills in providing individualized supports and adaptations to ensure a successful transition (Mankey, 2011). A transition program with an OT role can also assist with incorporating the transition program directly into the high school curriculum, as they are skilled in promoting and adapting different roles and routines (American Occupational Therapy Association, 2014). 


\section{Self-Advocacy Framework}

Self-advocacy is consistently reported as being an imperative skill required for successful transition to postsecondary education and general adulthood ("Studies from," 2019; "The value of financial literacy and self-advocacy," 2019). However, there is limited data on teaching selfadvocacy skills directly in the curriculum, despite the obvious need (Spark, 2015). Self-advocacy can be defined many different ways but Kay (2019) describes it as "a complex set of knowledge and skills with four overarching components: knowledge of self, knowledge of rights, communication, and leadership" (p. 358). An assessment tool called the Student Transition Questionnaire is used to determine students' perspectives on transition-related factors (Collier et al., 2015). Within this questionnaire, items related to disability disclosure and self-advocacy were rated the lowest by students, indicating the need for further assistance on teaching these skills (Collier et al., 2015).

There are many developed programs currently in use that teach students self-advocacy skills. However, these programs are not directly incorporated into the high school classrooms nor do they have an OT role. These self-advocacy programs emphasize the importance of student participation in IEP meetings, self- knowledge, confidence and assertiveness to request and negotiate academic accommodations, safety awareness, and problem-solving skills (Cease-Cook et al., 2013; Dryden et al., 2014; Holzberg, 2019; Paraschiv, 2000; Van-Belle et al., 2006). These self-determination and self-advocacy skills are taught through role playing, reviewing target behaviors, and fully immersing students on a university campus for real life practice (Grenwelge \& Zhang, 2012; Holzeberg, 2019; Van-Belle et al., 2006). There are also writing programs used to help improve writing skills while also improving self-advocacy and health literacy skills (Cuenca-Carlino et al., 2019). 
Despite the limited role of OTs in working on self-advocacy skills with students transitioning, there is literature on speech language pathologist addressing self-advocacy in the school setting to promote academic success (Collins \& Wolter, 2018; Waller et al., 2016). A program called Information and Communication Readiness for All Transition Experiences (ICREATE) is used as a framework by speech language pathologists for teaching and shaping social communication behaviors to students in the progression from high school into postsecondary education, the workforce, and independent living (Waller et al., 2016). The authors found that ICREATE demonstrated improvements in social communication behaviors including self-awareness, social reciprocity, and self-advocacy behaviors (Waller et al., 2016).

Although other professionals have taken part in transition planning, in an OT based high school to post-secondary education transition program, the OT can offer the professions specialized expertise that others cannot (Mankey 2011). In addition to self-advocacy and selfdetermination skills, OTs can also address assistive technology, healthy daily living skills, sensory skills, time management, goal setting, and leisure interests (Dirette, 2019; Mankey, 2011).

\section{Literature Review Summary}

There is sufficient evidence to support the need for a transition program to improve the transition planning and process from high school to postsecondary education. There is also sufficient evidence to support the unique skills and qualifications OTs have to contribute to a student's transition team. Despite this supportive evidence, there is little reported evidence on OTs reporting actually contributing to post-secondary transition planning. Self -advocacy and self-determination skills are critical skills required for students, not only to have a successful transition to postsecondary education, but to also be successful in postsecondary education and 
adulthood. Occupational therapists are equipped to address and promote these skills to ensure a successful and smooth transition. There are many transition programs already implemented that address topics such as self-advocacy, independent living, social skills, and navigating new campuses, and more, however, there is limited data on those transition programs being incorporated into the high school curriculum.

\section{Chapter 3: Program Description}

The purpose of this occupation-based transition program is to develop and implement a high school to post-secondary education transition program. Transition programs promote skill development, confidence, and overall personal growth (Wilson et al., 2012). This occupationbased transition program will focus on promoting self-advocacy and self-determination skills as a part of a larger, comprehensive transition program that prepares students for independent living after high school including post-secondary education. The focus of the program will be aligned with occupational therapy values such as client-centered care and occupation-based practices (American Occupational Therapy Association, 2014). While using an OT perspective, the transition program can assist the students in establishing education goals as well as address barriers the students might face towards those goals (Shea \& Giles, 2016). The objectives of this part of the comprehensive transition program are to identify the self-advocacy needs of high school students with learning differences as they transition to post-secondary education and develop and implement a self-advocacy focused-transition program directly into the high school curriculum. 


\section{Setting}

This project took place at The Winston School located in Del Mar, CA. The Winston School currently enrolls around 115 students in grades 6-12 with the student to faculty ratio being around eight to one (The Winston School, n.d.). The Winston School is for students with learning differences that face additional challenges at a typical school and require extra support and flexibility (The Winston School, n.d.). Both academic and personal growth is emphasized at The Winston School (The Winston School, n.d.). Due to the timing of this transition program during a global pandemic, most classes at The Winston School were done virtually. The transition program at The Winston School is embedded directly into the curriculum as an elective class for high school seniors called the College and Career Readiness course. This occupationbased transition program is an additional and vital final component that incorporates selfadvocacy and self-determination skills into the existing curriculum.

\section{Participants}

The participants in this program include the students at The Winston School, particularly the $8^{\text {th }}$ grade and $12^{\text {th }}$ grade students. All the students participating have various types of learning differences. Some of the students have a formal diagnosis such as Autism Spectrum Disorder or ADHD, while others have educational diagnosis of learning disabilities or other health conditions. Staff and faculty at The Winston School also participated in the occupation-based transition program as they were given a survey during the preplanning program phase of the transition program in order to gain another perspective of the students' self-advocacy and selfdetermination skills (See Appendix A).

The transition program took place in the College \& Career Readiness elective course offered at The Winston School, which consisted of only high school seniors. The $12^{\text {th }}$ graders in 
the occupation-based transition program were given a survey on their perceived self-advocacy and self-determination skills as well as a post-survey on their knowledge of self-advocacy and their perceived importance of those skills (See Appendix B and C).

The $8^{\text {th }}$ graders also participated in the occupation-based transition program within their organization class. The $8^{\text {th }}$ graders participated in preparatory activities in order to build foundational skills for the transition program in high school. The $8^{\text {th }}$ graders were also given a survey on their perceived self-advocacy and self-determination skills (See Appendix D). They also participated in a debriefing focus group after the occupation-based transition program.

The Winston School transition team collaborated strategies and methods to smoothly incorporate the transition program interventions into the current curriculum within the College and Career Readiness course. Due to the OT foundation of this transition program, the college and career readiness course aims to advocate for the role of OT in post-secondary transition planning.

\section{Materials}

A survey was given to the 12th grade students who participated in the occupation-based transition program within the college and career readiness course (See Appendix B). The survey was on their perceived self-advocacy and self-determination skills, as well as their perceived readiness for post-secondary education. The survey included questions based on the standardized assessments of the AIR's Self-Determination Scale and Landmark's College Guide to Assessing College Readiness Assessment (Landmark College, 2009; Wolman et al., 1994). The $12^{\text {th }}$ graders received another survey upon completion of the transition program on their understanding of self-advocacy, their perceived comfortability with demonstrating self-advocacy skills, and their satisfaction with the self-advocacy portion of the transition program (See Appendix C). 
Observations in the college and career readiness course were utilized virtually to view the day to day flow of the class. These observations were also used to gain a better understanding of the students' self-advocacy skills first- hand while in the classroom. During this time, the occupational therapist in charge of the college and career readiness course was able to discuss further on the high school seniors' self-advocacy skills and readiness for post-secondary education and/or their future next steps.

The $8^{\text {th }}$ graders who participated in the self-advocacy lesson and activities in their organization class were given a survey similar to the $12^{\text {th }}$ graders as the questions were influenced by the AIR's Self-Determination Scale and Landmark's College Guide to Assessing College Readiness Assessment (Landmark College, 2009; Wolman et al., 1994). The survey was on their perceived self-advocacy and self-determination skills, as well as their perceived readiness for their future (See Appendix D). The $8^{\text {th }}$ grade students also participated in a debriefing focus group after the self-advocacy lesson plans and activities presented in-person during their organization class. In the debriefing focus group, the students were asked openended questions on their perception of self-advocacy and barriers to demonstrating self-advocacy in the classroom. The $8^{\text {th }}$ grade classes were observed both virtually and in-person to gather further information on the students' self-advocacy skills in the classroom while in their natural environment.

\section{Timeline}

The timeline of this project is broken down into the preplanning program, implementation, and program outcome phases. The preplanning program phase was eight weeks long and consisted of identifying the self-advocacy needs of the population, developing the interventions, and observing the students in the classroom. The implementation and program 
outcome phase were overlapped over the last eight weeks. The implementation and program outcome phases included the interventions within the transition program and the methods used to measure the outcomes. The timeline is designed to organize each task into the week it was completed. Figure 1 and 2 is a visual representation of the timeline of this occupation-based transition program for the $12^{\text {th }}$ grade students in the college and career readiness course and the $8^{\text {th }}$ grade students.

\section{Figure 1}

Visual Representation of the Timeline of Objectives for the High School Students

\section{High School Timeline}

\begin{tabular}{|c|c|c|c|c|c|c|c|c|c|c|c|c|c|c|c|c|}
\hline \multirow[t]{3}{*}{ Tasks } & \multicolumn{16}{|c|}{ Weeks } \\
\hline & \multicolumn{8}{|c|}{ Preplanning program Phase } & \multicolumn{8}{|c|}{ Implementation/Program Outcome Phase } \\
\hline & 1 & 2 & 3 & 4 & 5 & 6 & 7 & 8 & 9 & 10 & 11 & 12 & 13 & 14 & 15 & 16 \\
\hline $\begin{array}{l}\text { Create survey } \\
\text { for staff and } \\
\text { student }\end{array}$ & & & & & & & & & & & & & & & & \\
\hline $\begin{array}{l}\text { Create Lesson } \\
\text { Plans }\end{array}$ & & & & & & & & & & & & & & & & \\
\hline $\begin{array}{l}\text { Distribute } \\
\text { surveys to } \\
\text { students and } \\
\text { staff }\end{array}$ & & & & & & & & & & & & & & & & \\
\hline $\begin{array}{l}\text { Classroom } \\
\text { Observation }\end{array}$ & & & & & & & & & & & & & & & & \\
\hline $\begin{array}{l}\text { Develop } \\
\text { Activities }\end{array}$ & & & & & & & & & & & & & & & & \\
\hline Role Playing & & & & & & & & & & & & & & & & \\
\hline Modeling & & & & & & & & & & & & & & & & \\
\hline $\begin{array}{l}\text { Education with } \\
\text { Lesson Plans }\end{array}$ & & & & & & & & & & & & & & & & \\
\hline
\end{tabular}




\section{Figure 2}

Visual Representation of the Timeline of Objectives for the Middle School Students

\section{Middle School Timeline}

\begin{tabular}{|c|c|c|c|c|c|c|c|c|c|c|c|c|c|c|c|c|}
\hline \multirow[t]{3}{*}{ Tasks } & \multicolumn{16}{|c|}{ Weeks } \\
\hline & \multicolumn{8}{|c|}{ Preplanning Program Phase } & \multicolumn{8}{|c|}{ Implementation/Program Outcome Phase } \\
\hline & 1 & 2 & 3 & 4 & 5 & 6 & 7 & 8 & 9 & 1( & 11 & 12 & 13 & 14 & 15 & 16 \\
\hline $\begin{array}{l}\text { Create survey } \\
\text { for staff and } \\
\text { student }\end{array}$ & & & & & & & & & & & & & & & & \\
\hline $\begin{array}{l}\text { Create Lesson } \\
\text { Plans }\end{array}$ & & & & & & & & & & & & & & & & \\
\hline $\begin{array}{l}\text { Distribute } \\
\text { surveys to } \\
\text { students }\end{array}$ & & & & & & & & & & & & & & & & \\
\hline $\begin{array}{l}\text { Classroom } \\
\text { Observation }\end{array}$ & & & & & & & & & & & & & & & & \\
\hline $\begin{array}{l}\text { Develop } \\
\text { Activities }\end{array}$ & & & & & & & & & & & & & & & & \\
\hline Role Playing & & & & & & & & & & & & & & & & \\
\hline $\begin{array}{l}\text { Education witl } \\
\text { Lesson plans }\end{array}$ & & & & & & & & & & & & & & & & \\
\hline $\begin{array}{l}\text { Group guided } \\
\text { learned } \\
\text { discussion }\end{array}$ & & & & & & & & & & & & & & & & \\
\hline
\end{tabular}

High School Program

Preplanning Program. The preplanning program phase for the high schoolers included creating and distributing surveys to the staff at The Winston School and the $12^{\text {th }}$ graders in the college and career readiness course. The surveys were distributed to the staff via a virtual staff meeting on week 8 . The students were given the survey virtually throughout week 7-8. The timing of the delivery of the survey varied during the college and career readiness course for each student due to scheduling difficulties from the virtual environment of the classes. 
The preplanning program phase with the $12^{\text {th }}$ graders involved observing the college and career readiness course virtually. During this time, information was collected on the selfadvocacy needs of this population by viewing the students demonstrating self-advocacy naturally in the virtual classroom. During this phase, the self-advocacy and self-determination lesson plans and activities were created. There were five lesson plans that were presented virtually in the college and career readiness course (See Appendix E). The first was on what self-advocacy and self-determination is, when it is used by providing examples in high school and in postsecondary education, the importance of those skills and the benefits of having self-advocacy and self-determination skills. The second lesson was on how to appropriately communicate when being a self-advocate. The third lesson was on appropriately asking professors/teachers for help in both high school and post-secondary education as well as emphasizing the importance of asking for help. The fourth lesson educated the $12^{\text {th }}$ graders on their rights and responsibilities as a student. This included learning about IDEA, ADA, and section 504 of the rehabilitation act and how those rights and responsibilities differ in post-secondary education. The last lesson provided examples and general instructions on how to request for needed academic accommodations at post-secondary education while utilizing self-advocacy skills.

The lessons plans were created specifically for this college and career readiness course with influence from other transition programs including The Self-Advocacy and Conflict Resolution program (Holzeberg et al., 2019), guidance from research on OTs role with selfdetermination in transition planning (Angell et al., 2019), and from a self-advocacy education handbook (Connecticut Parent Advocacy Center, 2013). The activities created were role playing common high school and post-secondary education scenarios and playing videos of current postsecondary students describing their experiences as well as videos demonstrating how to self- 
advocate as a student. These videos were found through The Self-Advocacy and Conflict Resolution program (Holzeberg et al., 2019) and through the PACER's National Parent Center on Transition and Employment (National Parent Center on Transition and Employment, 2012).

Program Implementation. The implementation phase for the $12^{\text {th }}$ graders was the presentation of the five lesson plans created on self-advocacy and self-determination skills. Role playing and modeling videos were the interventions used to further teach self-advocacy skills through occupation-based practices. The students were asked to demonstrate both good and bad examples of demonstrating self-advocacy in order to note the differences. The role playing and videos was used in repetition to establish an appropriate communication habit when the students are actually attending classes in post-secondary education.

Program Outcomes. The program outcomes were measured with the $12^{\text {th }}$ graders in the college and career readiness course through a virtual survey (See Appendix C). The survey was used to gain an understanding on if the students learned what self-advocacy is, the importance of it, and on their perceived abilities and comfortability of utilizing self-advocacy skills in education. Also, within that survey, the students evaluated their satisfaction of the transition program and the self-advocacy components.

\section{Middle School Program}

Over the course of the preplanning program and implementation phase for the high school students, it became clear that students would need to gain experience in self-advocacy in order to understand its impact and their role in self-determination. So, the preplanning program phase and implementation phase for the $8^{\text {th }}$ graders overlapped in order to provide introductory lessons in self-advocacy to prepare the $8^{\text {th }}$ graders for their participation in the high school transition program called the college and career readiness course. 
Preplanning Program. The preplanning program phase with the $8^{\text {th }}$ graders started with observations in the virtual classes to note the current self-advocacy and self-determination skills in the middle school population. This phase also included distributing a virtual student survey to the $8^{\text {th }}$ graders in their organization class. Similar to the high school timeline, the students were given the survey virtually throughout week 7-8, depending on scheduling due to the virtual environment.

Two lesson plans were created for the $8^{\text {th }}$ graders during the preplanning program phase (See Appendix F). The lesson plans were on what self-advocacy and self-determination is, when it is used by providing examples in middle school and high school, the importance of those skills and the benefits of having self-advocacy and self-determination skills. The second lesson was on how to appropriately communicate when being a self-advocate. These lessons were similar to the lessons used for the high school students in the transition program, but they needed to be graded down to meet the cognitive levels of the middle schoolers. The role-playing scenarios were also created for the $8^{\text {th }}$ graders to practice common middle school and high school scenarios.

Program Implementation. The implementation phase for the $8^{\text {th }}$ grade students took place starting week 12 and was delivered in-person for the students who were on campus. The $8^{\text {th }}$ graders also participated in role playing with scenarios common to middle school and high school students demonstrating both good and bad examples. The role playing was a guided occupation-based activity used in repetition for the students to build appropriate communication habits when advocating.

Program Outcomes. The program outcome for the $8^{\text {th }}$ graders was measured by a debriefing session after each self-advocacy lesson. The students were able to discuss openly what they thought about the self-advocacy lessons as well as providing a time for the students to 
openly share what they were thinking. They were also asked open-ended questions that were discussed together as a group. The questions asked were whether or not the students believed self-advocacy and self-determination was an important skill to learn and why. They were also asked to discuss what barriers they came across when trying to self-advocate.

\section{Program Description Conclusion}

This OT-based high school to post-secondary education transition program took place at The Winston School located in Del Mar, CA for students with learning differences. Although the participants of the transition program in the college and career readiness course were high school seniors, there were other individuals involved in this project such as middle school students and staff at the Winston School. The preplanning program phase was used for identifying needs, developing the intervention activities, and preparing for the implementation. The implementation phase involved executing the self-advocacy and self-determination component of the transition program. The program outcome phase was evaluating the program's success. The purpose of this transition program was to improve self-advocacy skills for adulthood, confidence levels, and success during the transition from high school to each students' individualized post-secondary education goals.

\section{Staff Results}

\section{Chapter 4: Results}

The staff surveys given prior to the start of the occupation-based transition program had eight responses (See Appendix G). Looking at figure 3, when asked if students know what selfadvocacy is, only $25 \%$ of the responses reported yes. Indicating that even if the students hear the term self-advocacy in their classes, the staff at The Winston School still report most students may or may not actually understand what it means. 


\section{Figure 3}

Teachers Responses to Question: Do the Students Know What Self-Advocacy is?

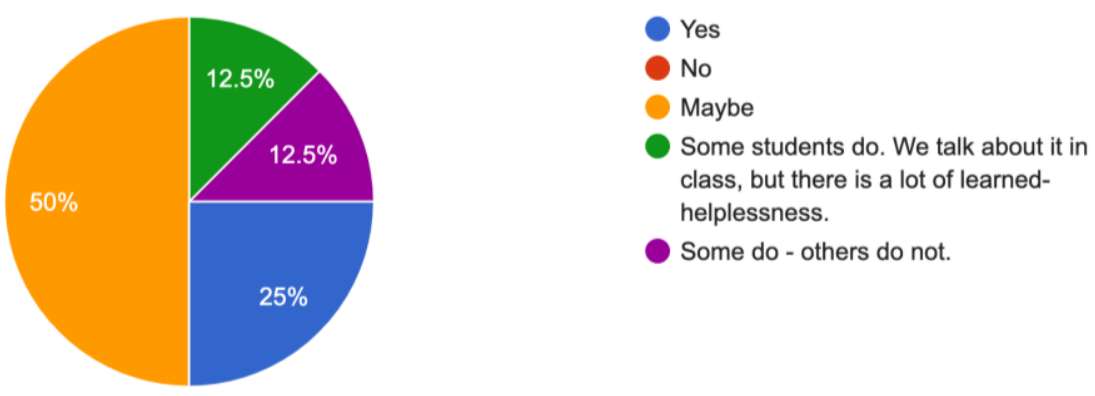

Most of the teachers stated that the students demonstrate self-advocacy and self-determination skills at an average level (three out of five rating) shown by figure 4. Although, in figure 5, greater than $85 \%$ of the staff reported self-advocacy as a skill that still needs to be taught to all students prior to the transition to post-secondary education.

\section{Figure 4}

Teachers Responses to Question: How Would You Rate the Students' Overall Self-Advocacy and Self-Determination Skills?

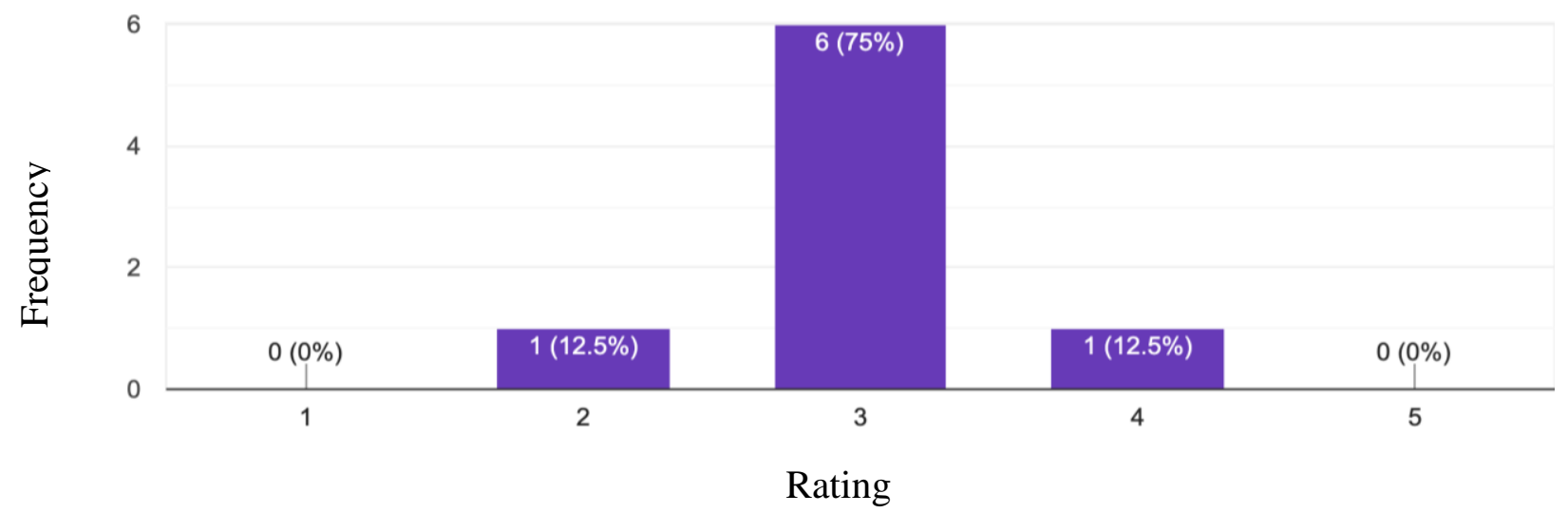




\section{Figure 5}

Teachers Responses to Question: What are Some Areas Students Need to Work on Prior to the Transition to Post-Secondary Education?

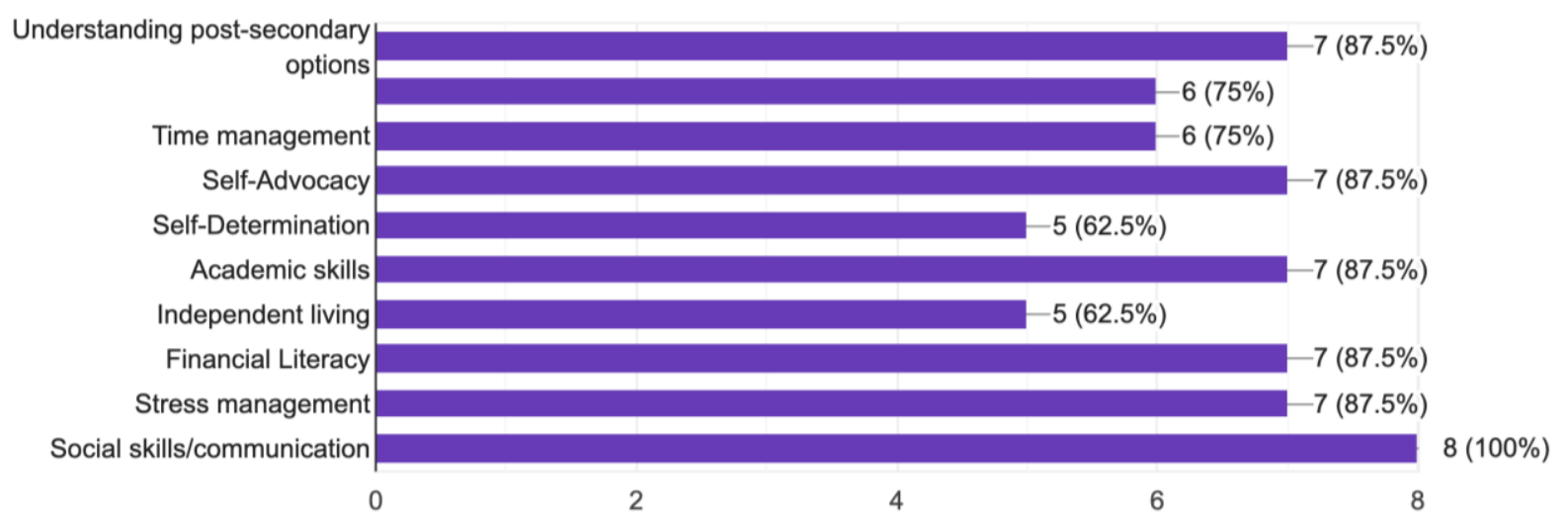

\section{Figure 6}

Teachers Responses to Question: Do Students Ask for Help When Needed on Assignments and

Projects?
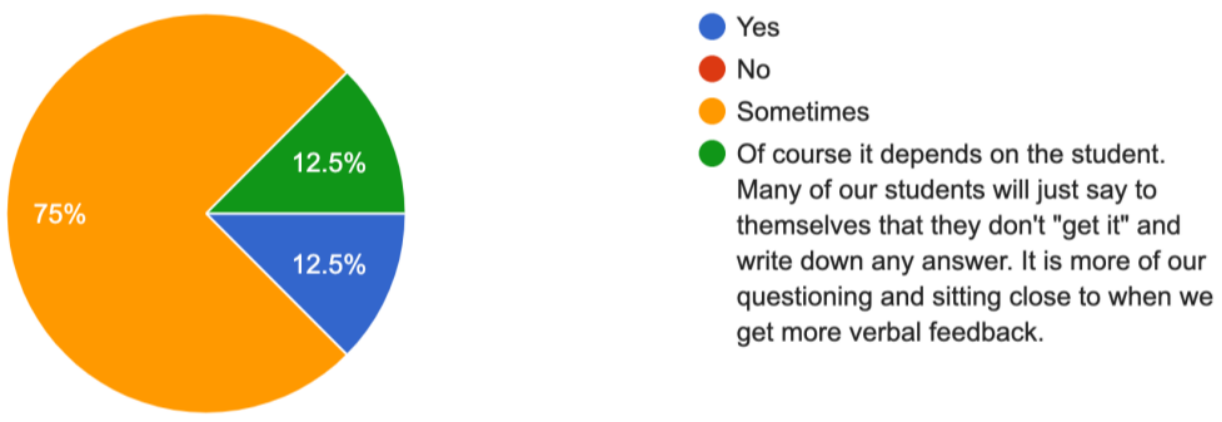
Many of our students will just say to themselves that they don't "get it" and write down any answer. It is more of our questioning and sitting close to when we get more verbal feedback. 


\section{Figure 7}

Teachers Responses to Question: When the Students Ask for Help, is it Done Appropriately?
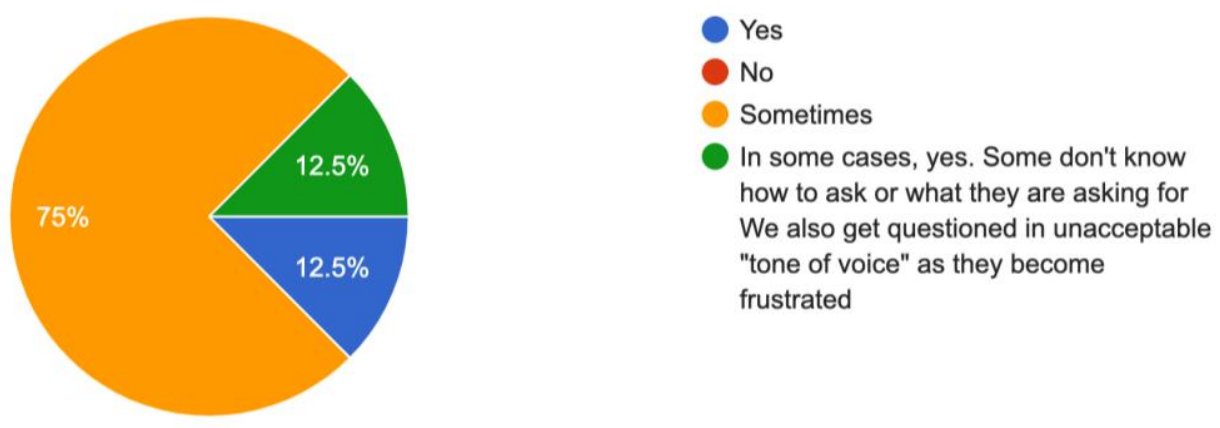

In figure 6 and 7, the question asks specifically on how the students demonstrate self-advocacy skills in the classroom by asking if they ask for help if needed and if so, is it done appropriately. Most of the teachers reported that only sometimes the students ask for help and if they do it is only sometimes done appropriately. This signifies an inconsistency in the students' selfadvocacy communication habits.

In the last question of the staff survey, looking at figure 8, it displays that the students are not learning about their rights as a student and the laws protecting them or that the staff are just unsure if anyone is teaching this to the students. It is critical knowledge for the students to understand their rights as a student and the laws such as ADA or IDEA as there is a difference between these rights and laws in high school and in post-secondary education (Collier et al., 2015). If the students do not understand the differences then they do not know they need the selfadvocacy skills to receive needed academic accommodations in order to succeed in postsecondary education (Collier et al., 2015) 


\section{Figure 8}

Teachers Responses to Question: Are the Students Taught About Their Rights as a Student and Laws Such as ADA and IDEA?
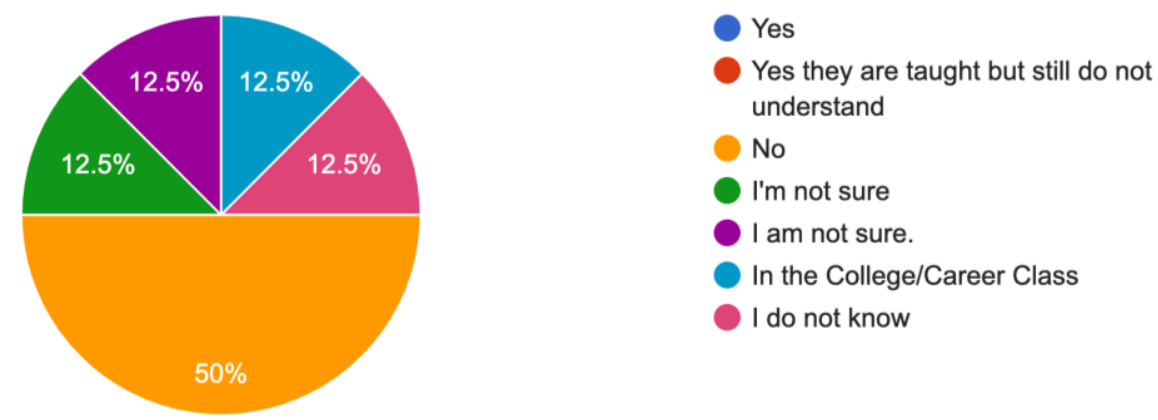

\section{High School Results}

Observations were utilized to gather data on students' self-advocacy and selfdetermination skills naturally in their classes virtually. In the college and career readiness course with $12^{\text {th }}$ graders, it was observed that most of the $12^{\text {th }}$ graders were able to ask for help when needed. If there was something they did not understand or if they needed clarification, instead of pretending they understood, they were able to ask the OT for help or assistance. When asking for assistance, most of the time, the $12^{\text {th }}$ graders would ask appropriately with an occasional student asking for help in the middle of someone else speaking. The $12^{\text {th }}$ graders were also able to express their own interests and needs with minimal prompting required. The $12^{\text {th }}$ graders, however, did need to be educated on their rights as a student, laws protecting them, how to request for needed accommodations, and how self-advocacy plays a role in all of that. There was a lack of knowledge on the idea that students are more independent in post-secondary education which is why self-advocacy is so important.

A survey was given to the high school students prior to the start of the occupation-based transition program, the responses are as follows (See Appendix H). Figure 9 and 10 illustrate the 
responses to the questions regarding the students' self-awareness which is correlated to their selfadvocacy skills. Most of the high school students reported having average or above average selfawareness.

\section{Figure 9}

High School Students Responses to Question: How Well do you Know Your Academic Strengths?

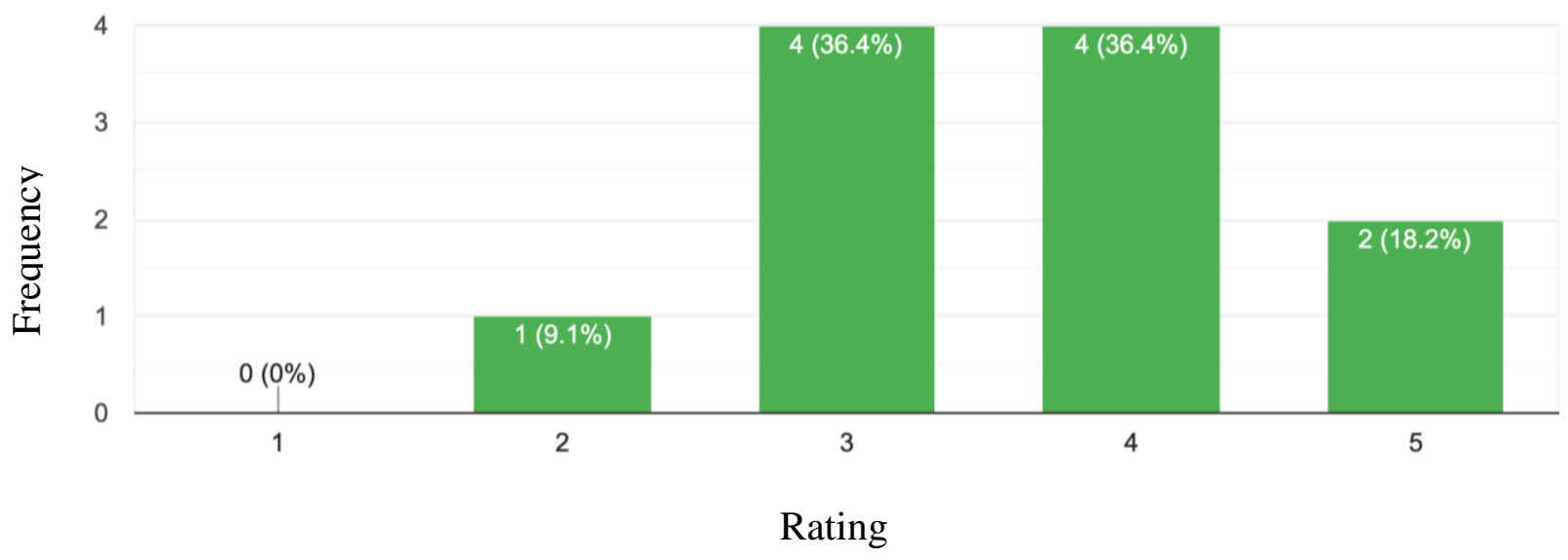

\section{Figure 10}

High School Students Responses to Question: How Well do you Know Which Academic Tasks Give you the Most Difficulty?

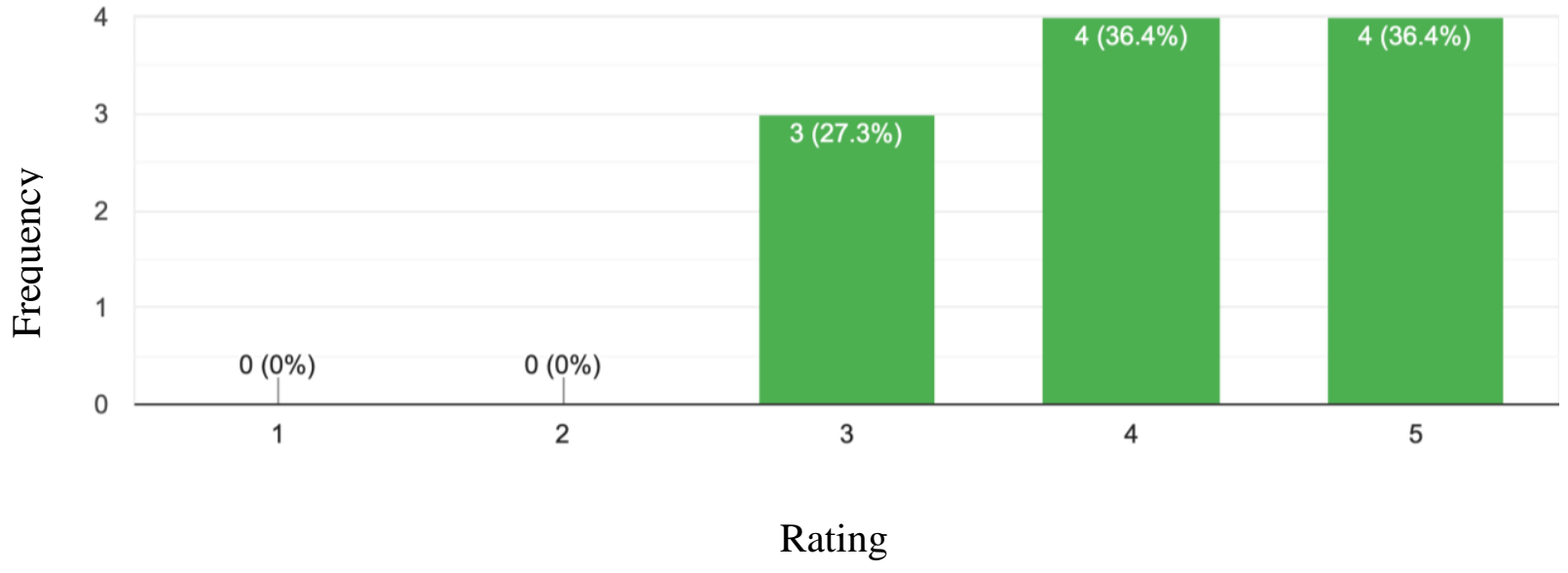


When asked if the high school students ask for help when needed in figure 11, greater than $60 \%$ reported that they do sometimes or more. The other students were able to honestly report that they do not always ask for help when needed. This indicates that most of the high school students demonstrate self-advocacy when needed in the classroom and the others are aware and honest about the lack of their self-advocacy skills.

\section{Figure 11}

High School Students Responses to Question: How Often do you Ask for Help When you Run into Difficulty?

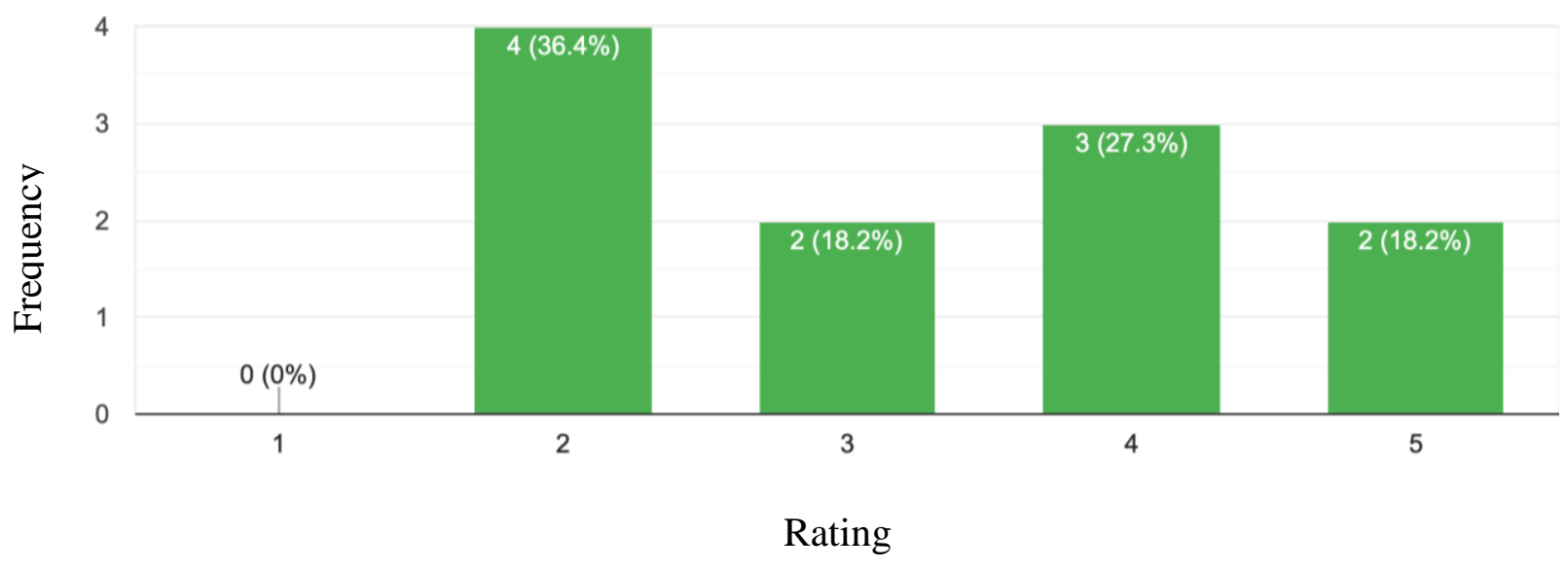




\section{Figure 12}

High School Students Responses to Question: How Would you Rate Your System of Keeping Organized?

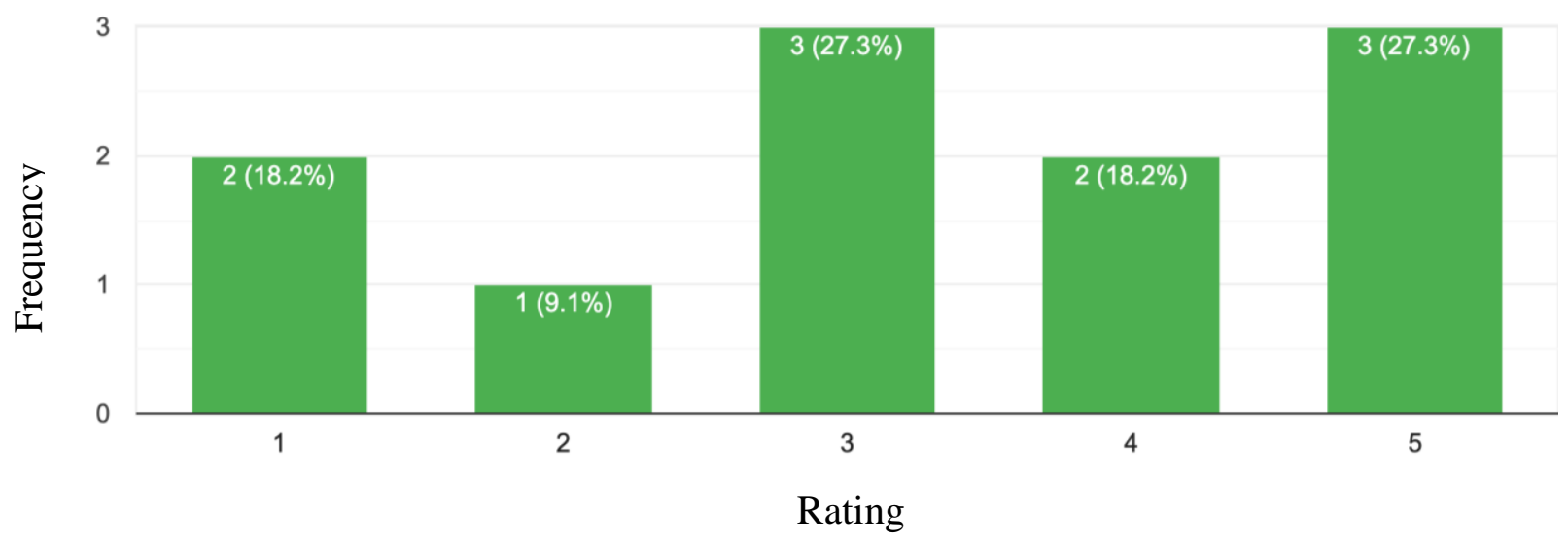

\section{Figure 13}

High School Students Responses to Question: How Would you Rate Your Perceived Ability to Succeed?

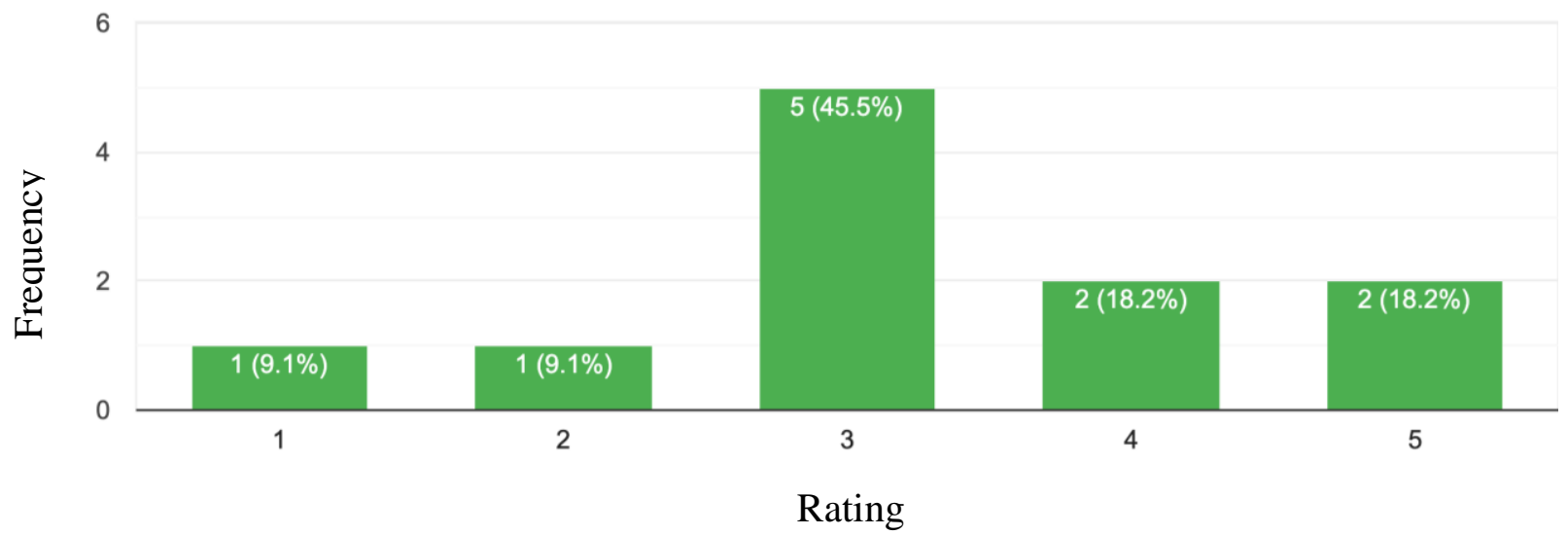

Figure 12 and 13 show questions on the students perceived self-determination skills. Based on the results, most of the high school students perceive their self-determination skills as average or above. 


\section{Figure 14}

High School Students Responses to Question: How Often do you Make Your Own Snacks and Meals?

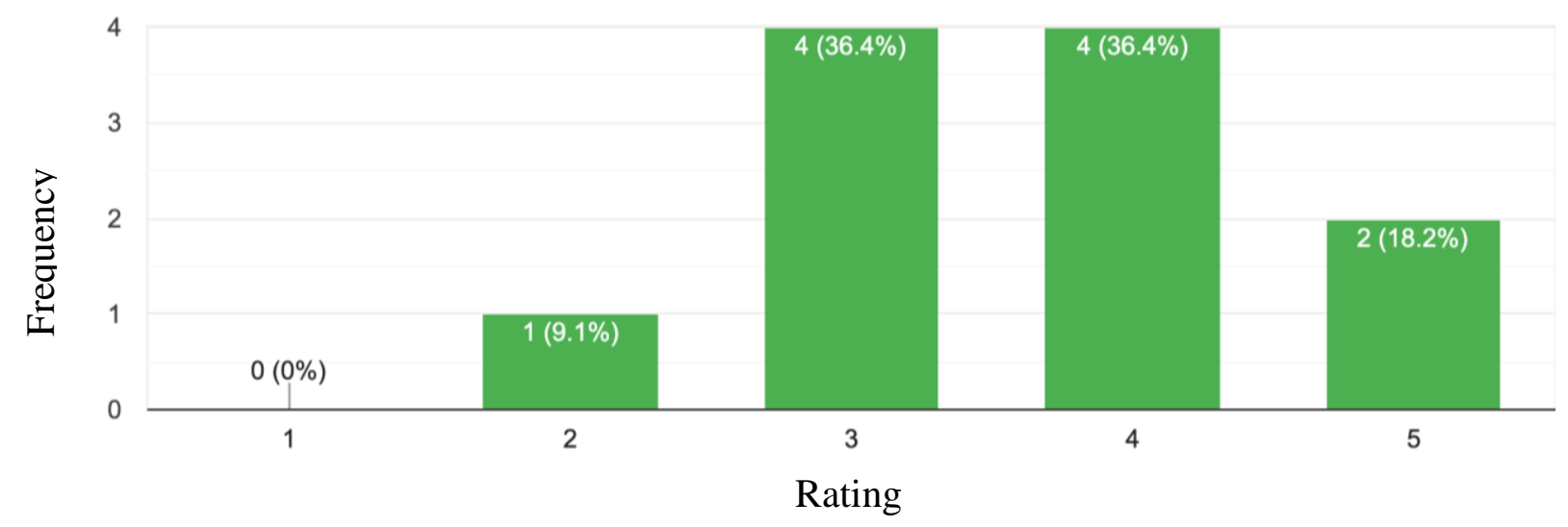

\section{Figure 15}

High School Students Responses to Question: How Often do you Choose Your Own Hair and Clothing Style?

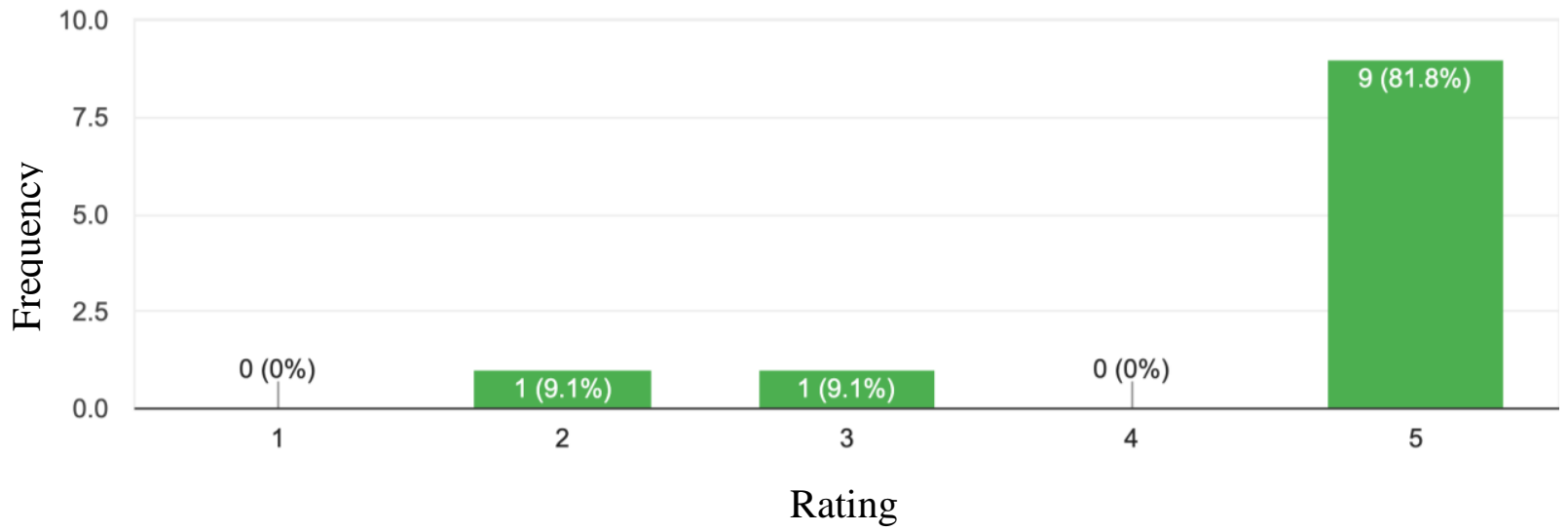

When looking at self-advocacy and self-determination skills, it is important to gain an understanding of the students' perceptions of their skills utilized outside of the classroom. Figure 14 and 15 demonstrate the responses to the self-advocacy and self-determination skills questions 
on their skills outside of the classroom. It shows that the majority of the high school students demonstrate self-advocacy frequently outside of the classroom.

A post-survey was given to only the high school students who are enrolled in the transition program, also called the college and career readiness course at The Winston School. The survey was given after the occupation-based transition program and the results are as followed (See Appendix I). The $12^{\text {th }}$ graders were able to provide an accurate definition of what self-advocacy is. In figures 16,17 , and 18, it shows that after the self-advocacy lessons and activities all five of the students in the college and career readiness course recognized selfadvocacy as an important skill to learn. They also not only found it helpful to learn about selfadvocacy and self-determination, but they also enjoyed learning about those skills. These results that after a transition program the students can identify self-advocacy as an important skill towards their success is similar to previous research found on other transition programs (Rothman et al., 2008)

\section{Figure 16}

High School Students Responses to Question: How Important is it to learn Self-Advocacy Skills?

6

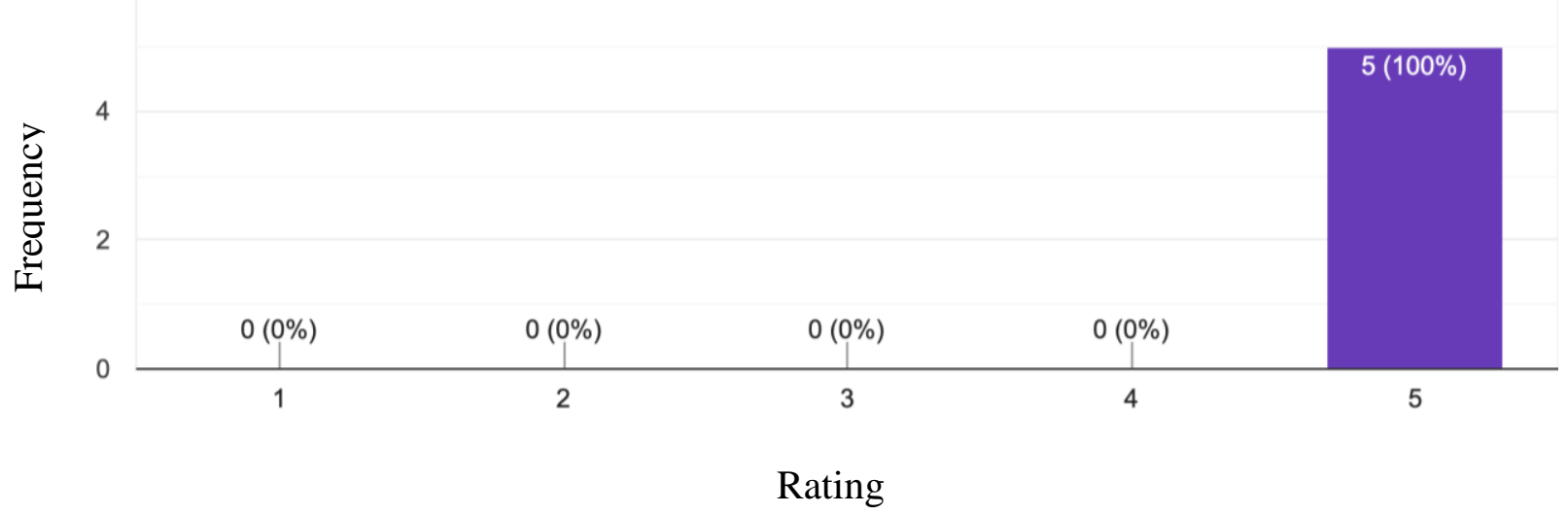




\section{Figure 17}

High School Students Responses to Question: Did you Find it Helpful to Learn About SelfAdvocacy and Self-Determination?

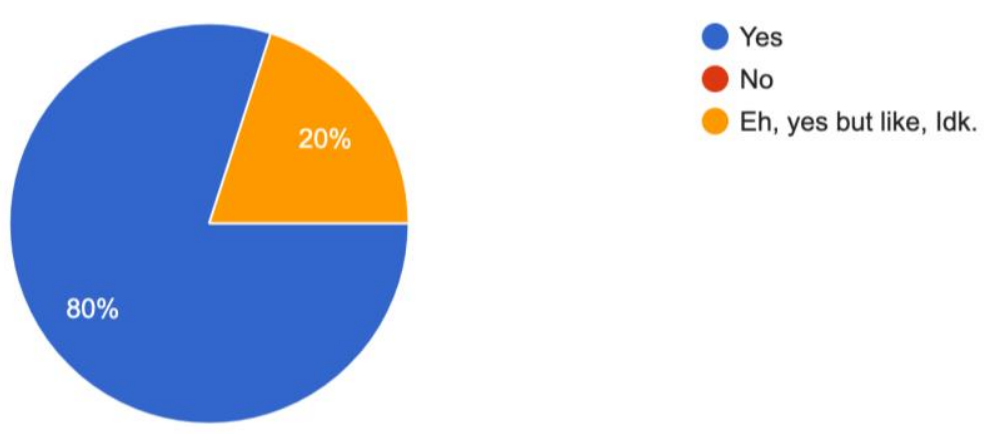

\section{Figure 18}

High School Students Responses to Question: Did you Enjoy Learning Self-Advocacy and SelfDetermination Skills?

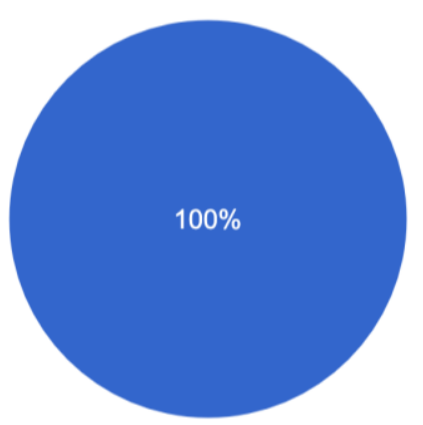

Yes

No

The $12^{\text {th }}$ graders were asked when they believe the best time to learn about self-advocacy and self-determination is. The results shown in figure 19 , show that $60 \%$ reported that they should be introduced freshman year or sooner. 


\section{Figure 19}

High School Students Responses to Question: When Would be the Best Time to Learn About SelfAdvocacy?

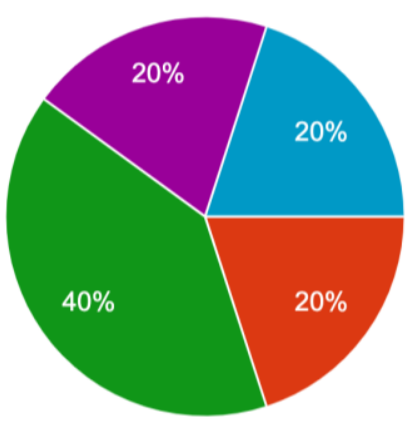

Senior year of high school

Junior year of high school

Sophomore year of high school

Freshman year of high school

Middle school

It does not need to be taught at all

\section{Figure 20}

High School Students Responses to Question: How Comfortable do you Feel Asking Your Teacher/Professor for Help?

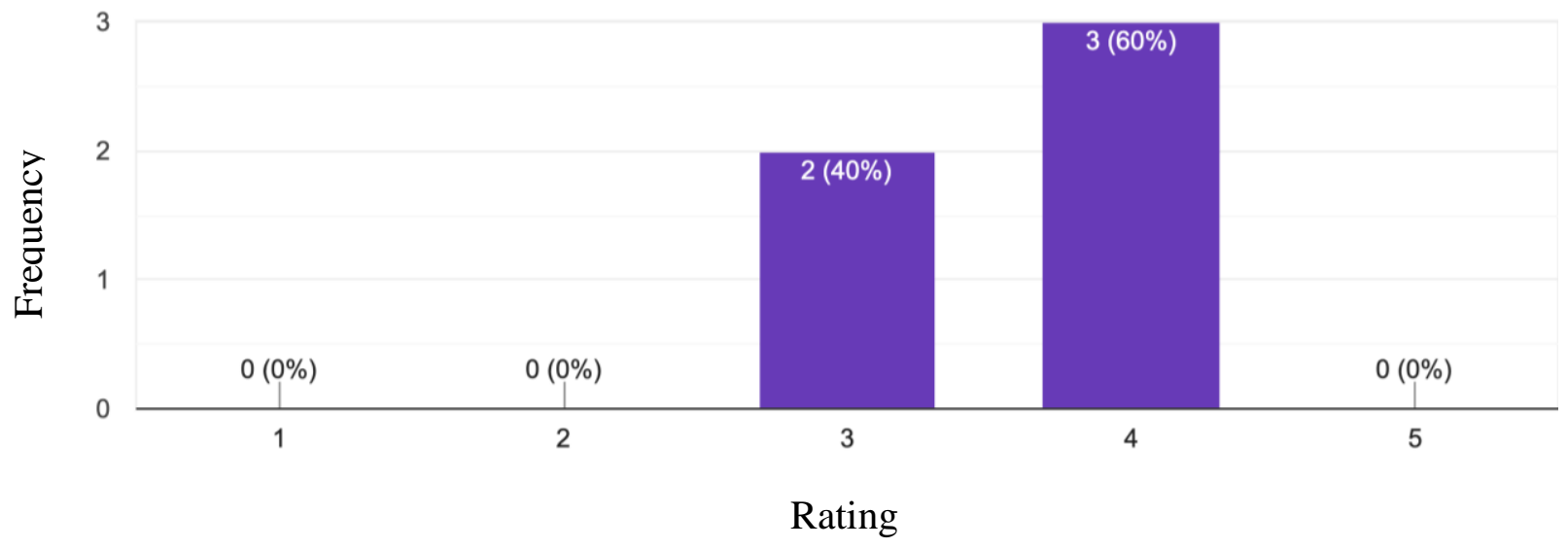




\section{Figure 21}

High School Students Responses to Question: How Comfortable do you Feel Requesting for Accommodations in Post-Secondary Education?

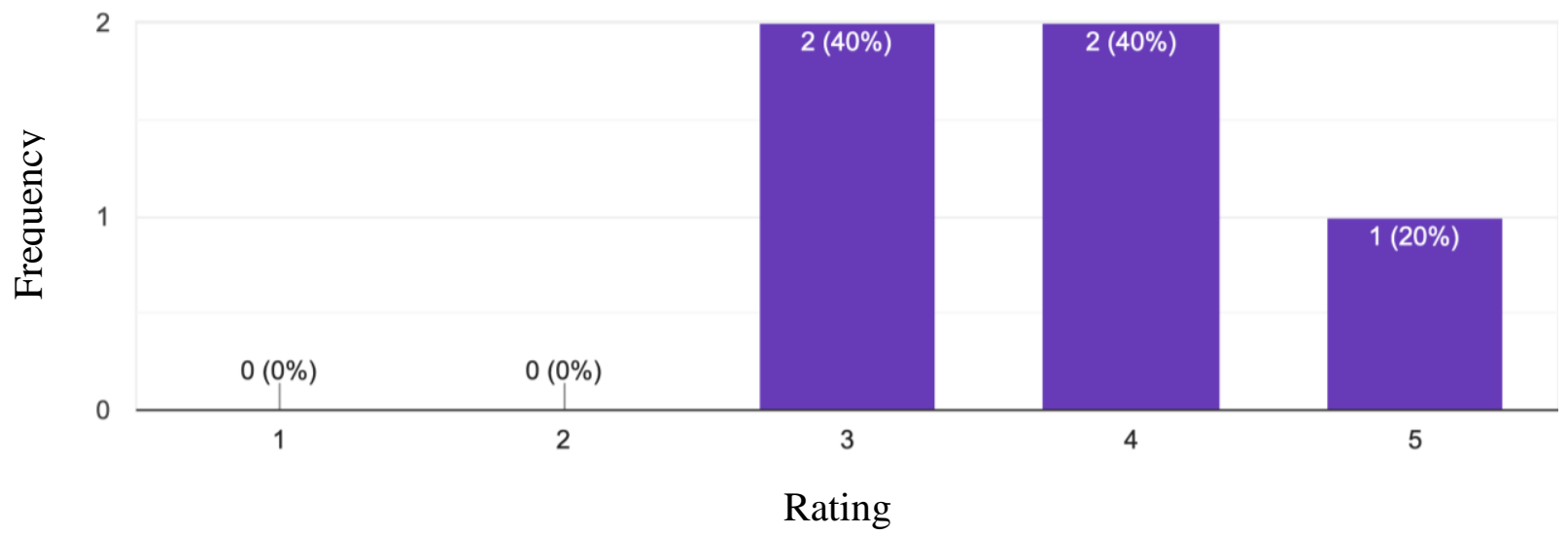

\section{Figure 22}

High School Students Responses to Question: How Comfortable do you Feel Disclosing Your Disability to Receive Academic Accommodations?

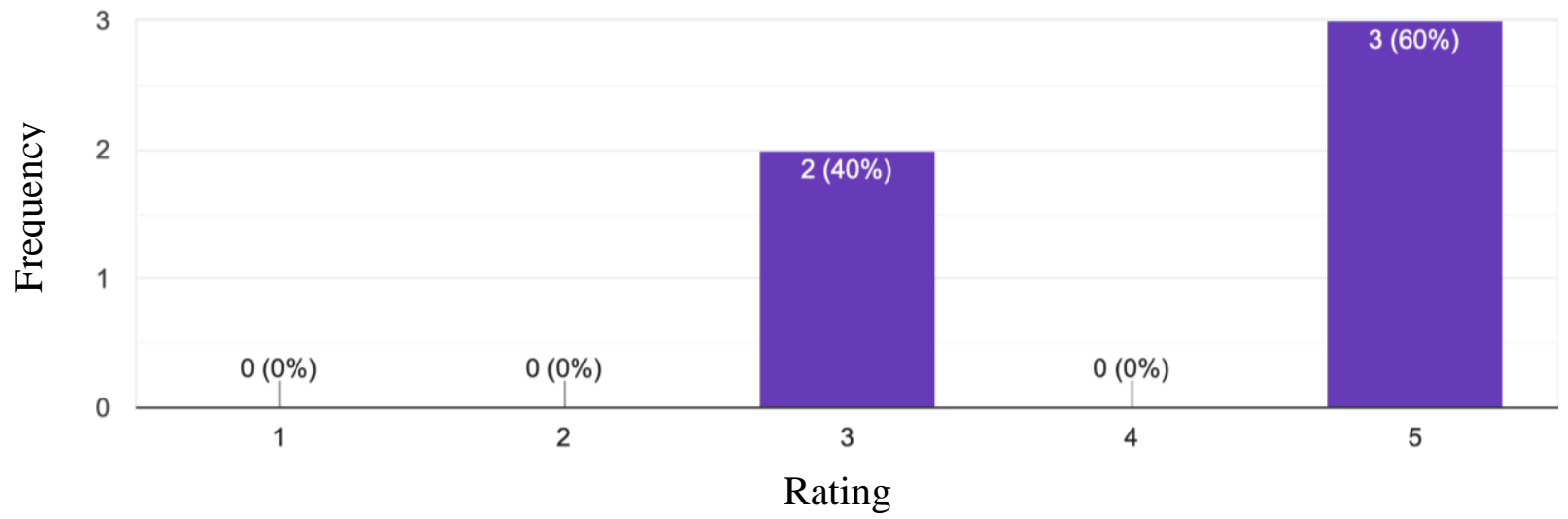

In the self-advocacy lessons presented in the college and career readiness course, also known as the occupation-based transition program, the students were educated and instructed on the general process to receive academic accommodations in post-secondary education. This process emphasizes the importance of utilizing self-advocacy skills as the students will need to disclose of their disability, request accommodations, and ask for help when needed. In figures 20,21 , and 
22 , it shows that the $12^{\text {th }}$ graders now feel comfortable advocating for themselves in order to receive those academic accommodations in post-secondary education. The increased comfortability with requesting accommodations in post-secondary education after a transition program reflects in previous research on other transition programs as well (Lawson et al., 2015). Although the $12^{\text {th }}$ graders were also educated on their rights as a student, including the laws that protect them, the responses shown in figure 23 demonstrate the students vary in comfortability when knowing these rights and laws.

\section{Figure 23}

High School Students Responses to Question: How Well do you Know Your Student Rights and Laws?

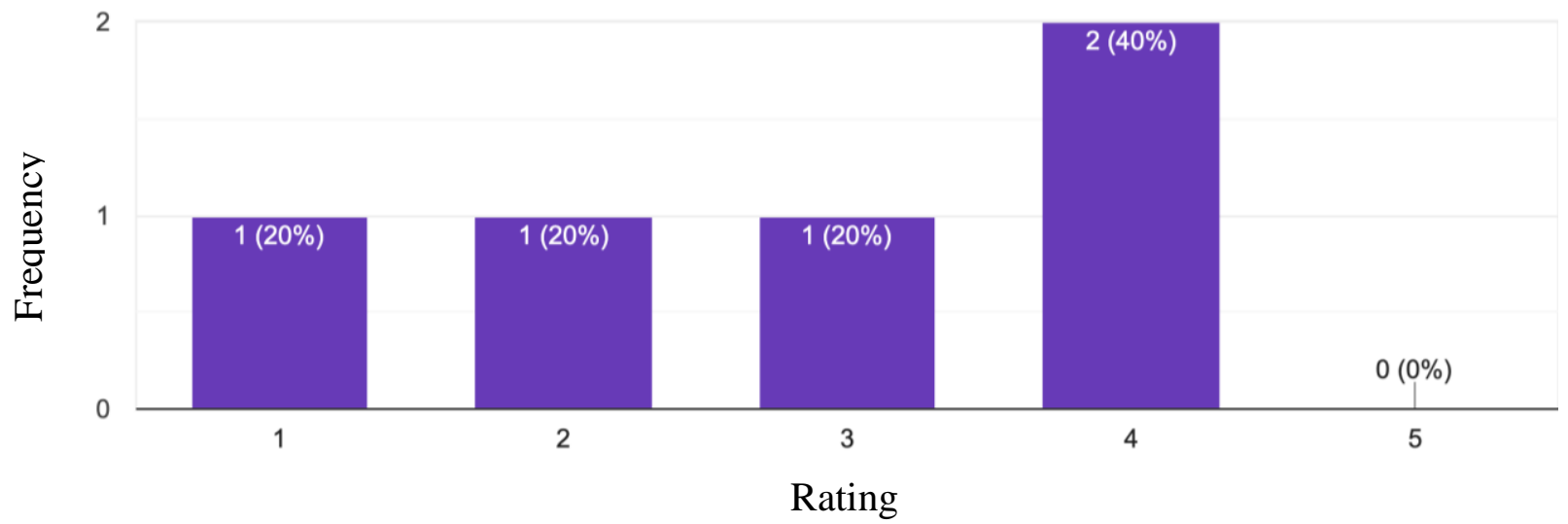

\section{Middle School Results}

Based on the observations in the middle school classes, it was noted that students hear the term self-advocacy from their teachers, as the teachers encourage the students to ask for help or express their needs and wants. It was observed that when the middle schoolers were working on assignments in class and required cueing or assistance, instead of asking for help, they would just wait until a teacher approached them first. If a teacher did not ask if they needed help, they 
would not ask themselves. If the middle schoolers did ask for help, it would not always be at the proper time or they would not use appropriate communication skills. In some occasions, the students would demonstrate difficulties with emotional regulation causing them to become too frustrated to ask for help. The middle schoolers were very aware of their strengths as students but had trouble identifying areas of improvement.

The middle school students received a similar survey to the high schoolers prior to the occupation-based transition program. There were three middle schoolers who completed the survey (See Appendix J). Two of three reported that they demonstrate average or above selfawareness skills shown from the questions in figures 24 and 25.

\section{Figure 24}

Middle School Students Responses to Question: How Well do you Know Your Academic Strengths?

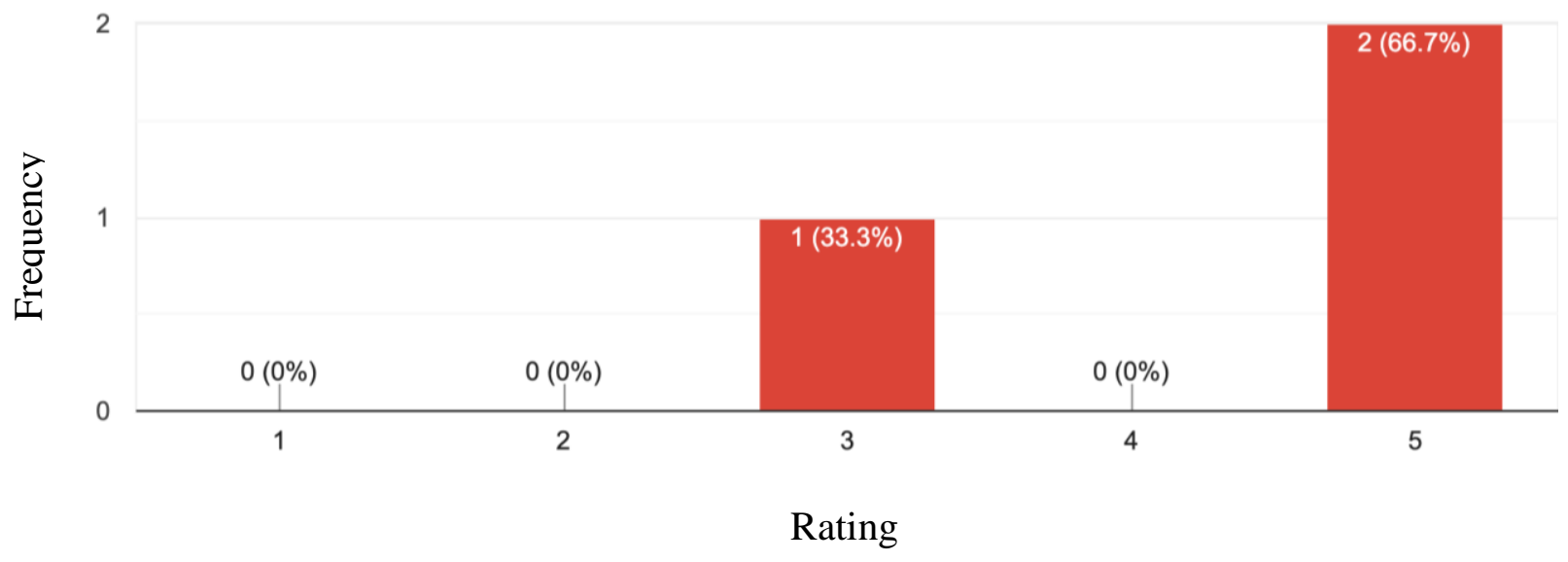




\section{Figure 25}

Middle School Students Responses to Question: How Well do you Know Which Academic Tasks Give you the Most Difficulty?

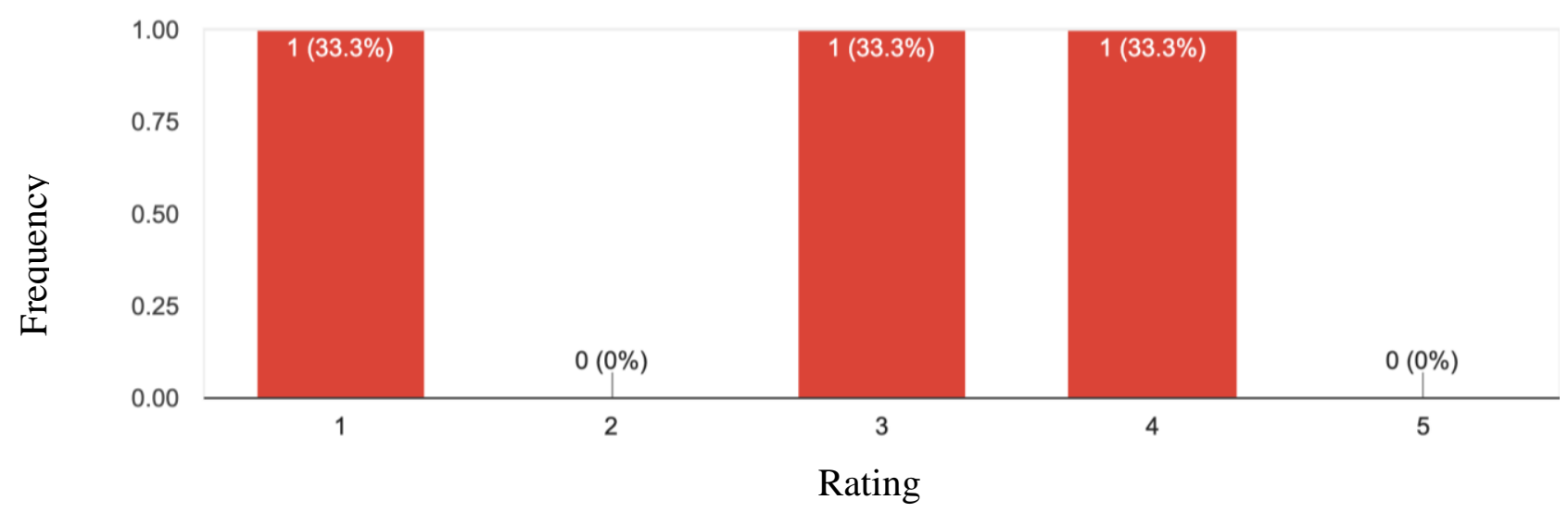

In figure 26, the students are asked if they are aware of their rights as a student, all three stated they knew their rights very well. As noted previously in the staff survey results, the staff at The Winston School do not recall anyone teaching their students about their rights as a student or the staff is unsure if anyone does. This indicates a discrepancy between the staff response and $8^{\text {th }}$ graders responses. 


\section{Figure 26}

Middle School Students Responses to Question: How Well do you Know Your Legal Rights as. Student?

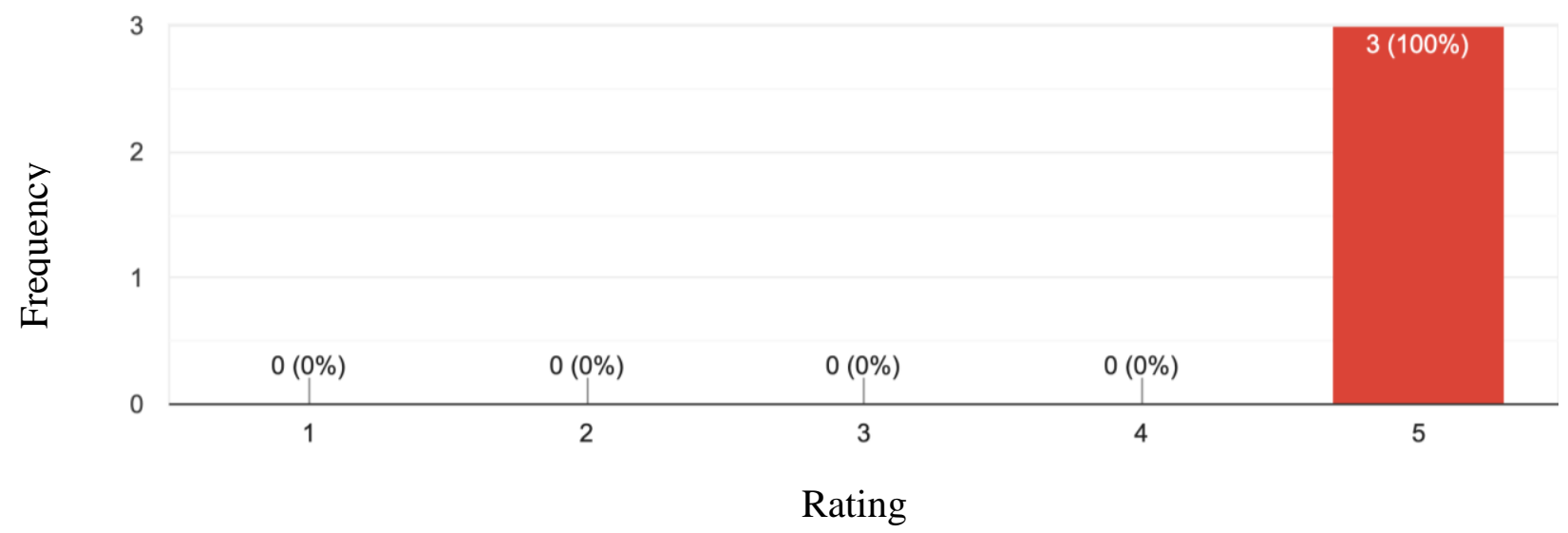

Asking for help is a form of demonstrating self-advocacy in the classroom, the middle schoolers stated that they all sometimes or more ask for help when needed as illustrated in figure 27. Figure 28 shows the middle school students' perceived self-determination skills. Based on those results, it shows that the students believe that they demonstrate average or above in selfdetermination. This indicates that all three middle schoolers believe they have good selfadvocacy and self-determination skills. Similar to the high school survey, in the middle school survey it was important to gain an understanding of the students' perceived self-advocacy outside of the classroom. Based on the results in figure 29, it shows that the middle schoolers also believe they have good self-advocacy skills outside of the classroom as well. 


\section{Figure 27}

Middle School Students Responses to Question: How Often do you Ask for Help When you Run into Difficulty?

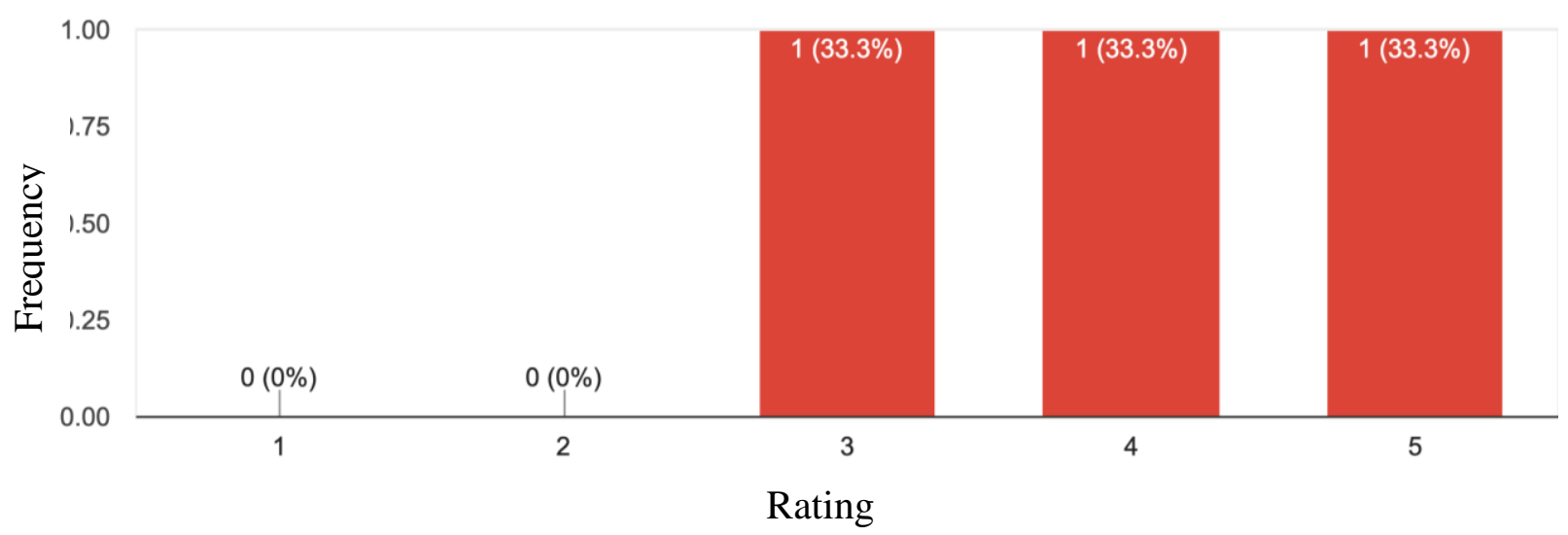

Figure 28

Middle School Students Responses to Question: How Would you Rate Your System of Keeping Organized?

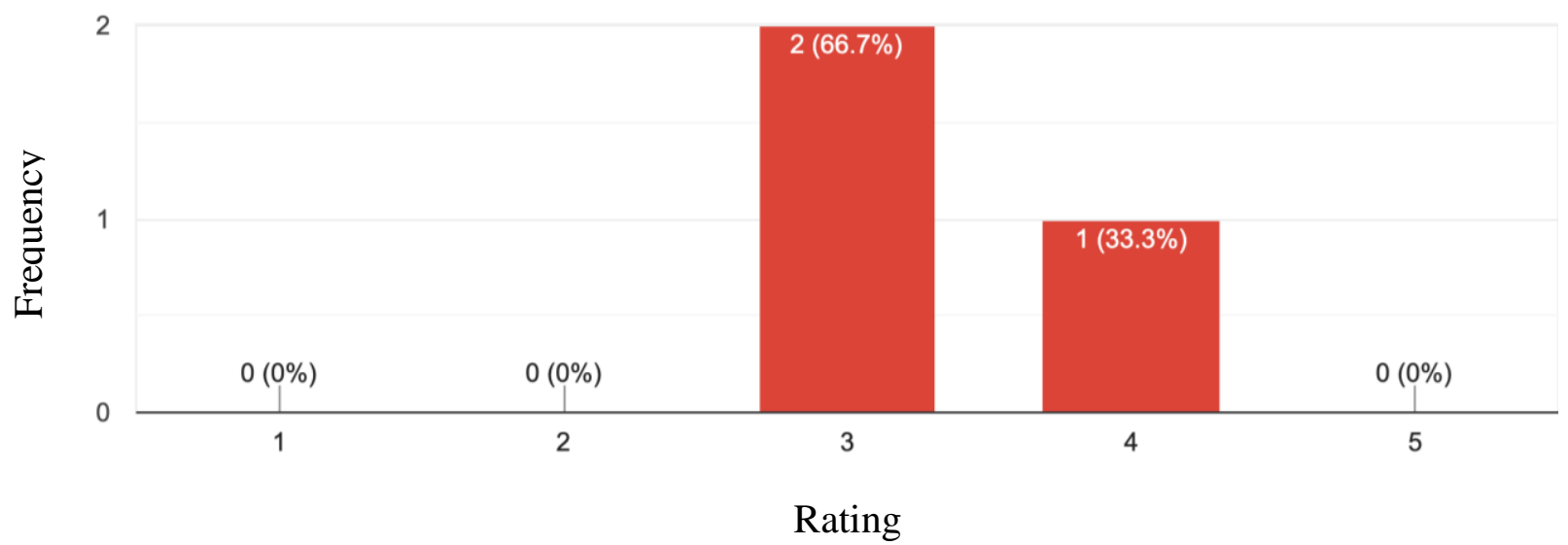




\section{Figure 29}

Middle School Students Responses to Question: How Often do you Choose Your Own Hair and Clothing Style?

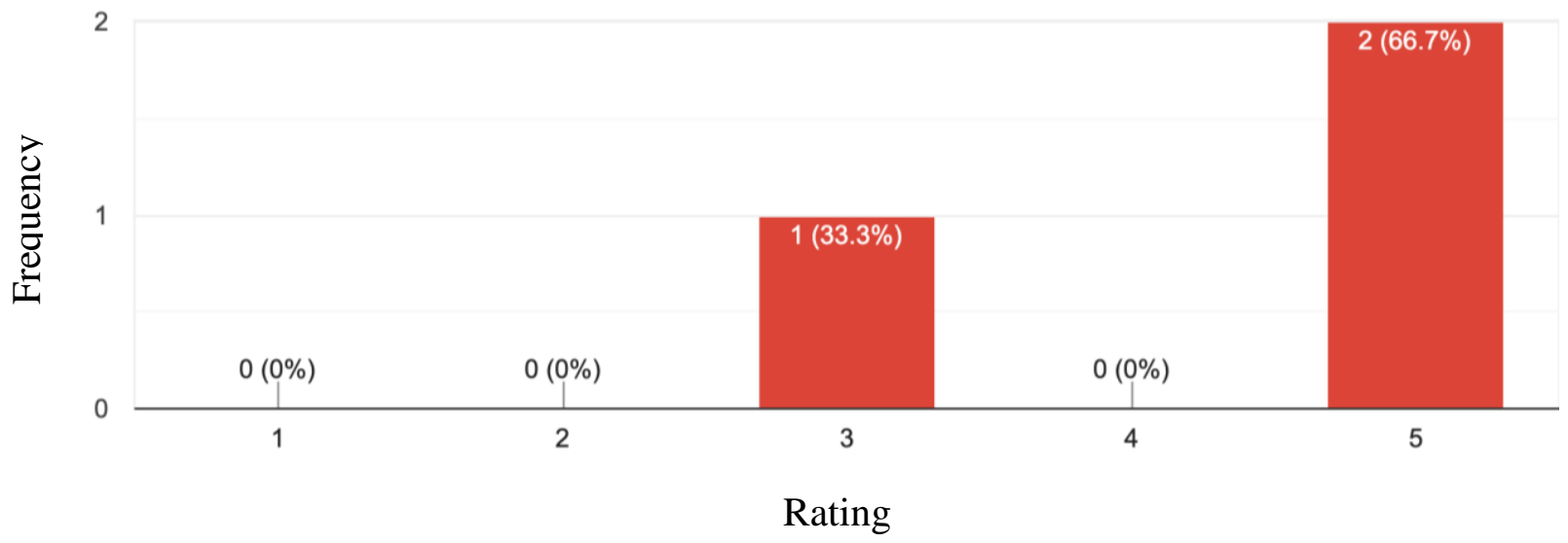

The program outcome results for the $8^{\text {th }}$ grade students were the results from the debriefing session where they were asked questions regarding self-advocacy and selfdetermination. After the self-advocacy lessons, five out of seven students reported self-advocacy as an important skill to learn. When asked why, one student stated that they believe "it is important to take control of one's own life otherwise someone else will take control for you and who knows what will happen then". Another student stated that self-advocacy is important because "you need it in order to get what you want". It is clear that the $8^{\text {th }}$ graders were able to identify asking for help as an example of self-advocacy but that was the only definition or example of self-advocacy they could provide. There were three common themes found when the students were asked about barriers to demonstrating self-advocacy in the classroom. The three themes were:

1. Being too afraid to get into trouble 
The students are aware of when to demonstrate self-advocacy skills but are unsure of what is considered appropriate. They do not want to self-advocate incorrectly causing them to get into trouble for it.

2. Feeling ashamed of looking less than

This refers to the students asking for help. The students feel ashamed when they ask for help because it makes them feel like they are less than.

3. Assuming someone else would do it for them.

This indicates that the students believe that they do not need to advocate for themselves because there will always be someone to do it for them.

\section{Chapter 5: Discussion}

Throughout this occupation-based transition program, there were multiple challenges that were presented as this program took place during the global pandemic of COVID-19. The Winston School taught classes virtually through Zoom for most of the days during this school year, which lead to changes to the students' environment, tasks, and overall occupational performance in school. In week 12 of this transition program, the students were given the option to return to school for only two days a week, altering their typical school routines. Due to COVID-19 with the virtual classes, it led to difficulties with the timeline of this transition program as there were many scheduling conflicts. The scheduling conflicts were the difficulties faced when finding the time to present the self-advocacy lessons and activities to the high school and middle school students. Class times were also reduced to only 30 minutes through the virtual service delivery. The reduced class times contributed to the scheduling difficulties as less class time was available to add the self-advocacy components within the curriculum. The reduced 
class times also altered the students' educational tasks and occupational performance in the classroom.

The AIR's Self-Determination Scale and Landmark's College Guide to Assessing College Readiness Assessment are standardized assessments that were planned to be utilized for this occupation-based transition program (Landmark College, 2009; Wolman et al., 1994). The assessments were to be used prior to the start of the program in order to provide a baseline of the student's self-determination/self-advocacy skills as well as the baseline for their perceived readiness for post-secondary education. Student and staff interviews were planned to gain additional information on the needs of the self-advocacy skills of those students transitioning to post-secondary education. Neither standardized assessments nor interviews were utilized due to the global pandemic. Standardized assessments could not be administered to the students virtually, nor was there time to sit down with each student to administer the assessments. The interviews were not conducted due to the scheduling difficulties as well as the fact that the students and staff were experiencing significant transitions and personal challenges going through this global pandemic. Instead, observations in the virtual classes and in-person classes starting week 12 were utilized to gather information for the assessment of the self-advocacy needs of this population.

The results from the post-transition program survey that was given to the high school seniors, found that the students learned and understood what self-advocacy is and the importance of it. The high school students in the college and career readiness course also reported the selfadvocacy lessons and activities being useful towards their skill development and growth towards overall adulthood. Based on the observations in the virtual high school classes including the college and career readiness course, it was observed that the students were able to demonstrate 
good self-advocacy skills in the classroom. This was aligned with the results from the staff survey and the high school survey given prior to the occupation-based transition program as well. It was observed that most of the students were able to appropriately ask for help when needed and were able to express their interests and needs for their own futures. Similarly, to what the research stated, the high school students did need to be educated on their rights and responsibilities as a student and on the process of requesting needed academic accommodations for post-secondary education, as those topics are beneficial to the success of the student in postsecondary education (Holzberg et al., 2019; Rothman et al., 2008). The $12^{\text {th }}$ graders also needed to be educated on the differences of their student rights and responsibilities between high school and post-secondary education. All of which, was addressed in the self-advocacy lessons and activities in the occupation-based transition program.

Majority of the high school students believed that these lessons should be taught sooner such as freshman year of high school or middle school. Self-advocacy and self-determination are different than other transition skills needed for post-secondary education. Self-advocacy and selfdetermination are skills that need to be taught and built over time. Teaching self-advocacy and self-determination skills requires a higher level of abstract thinking compared to teaching students how to cook/clean or teaching them how to balance a checkbook. When teaching selfadvocacy and self-determination, the students need to practice, get comfortable, and build selfconfidence over time. Due to the extra time needed to learn these skills, it was found that selfadvocacy and self-determination skills need to be addressed and taught in middle school.

When the self-advocacy surveys were given to the middle school students prior to the occupation-based transition program, the $8^{\text {th }}$ graders reported that they all knew their rights as a student very well. But based on the results from the staff survey and on observations in the 
classroom, it was notable that the $8^{\text {th }}$ graders taking the survey may not have been as self-aware or honest. Furthermore, in the survey, around $60 \%$ of the students reported that they demonstrated average or above average self-advocacy skills in the classroom and outside the classroom. Based on observations of the virtual and in-person middle school classes, they demonstrated an apparent need for self-advocacy in the middle school population. The observations showed only some of the students asking for help but when they did it was not done appropriately. They would interrupt the class or someone else speaking when they needed help, they would ask for help without attempting to solve themselves, or they would ask for help in an inappropriate way. From the observations, it was apparent that the students hear the term selfadvocacy from their teachers and staff at The Winston School, however, it is unclear if they really understand the full meaning of it and its importance. They were able to understand that asking for help demonstrates self-advocacy skills but that isn't all of what self-advocacy encompasses. It also includes knowledge of themselves, their strengths, weaknesses, and their learning difference. It also includes knowledge of their rights as a student and the ability to advocate for society and others. The conclusion found that self-advocacy needs be addressed in middle school is aligned with the ideas of Jean Piaget and his theory of cognitive development (DeWolfe, 2019). In the ages 11 and up, a student is still developing abstract thinking, such as the concept of self-advocacy (DeWolfe, 2019). This further indicates an imperative stage of development to introduce abstract skills needed for post-secondary education like self-advocacy and self-determination.

In the in-person self-advocacy lessons and activities, the $8^{\text {th }}$ grade students were taught what exactly self-advocacy means and what it encompasses as well as why and when they use it. Even after the lessons, most of the students were still only able to identify asking for help as an 
example of self-advocacy. That is a great start to learning self-advocacy skills, however, they need to understand all it encompasses prior to their transition to post-secondary education.

In the debriefing session, three themes emerged on barriers to why the students do not demonstrate self-advocacy skills. The three themes were 1. Being too afraid to get into trouble, 2. Feeling ashamed of looking less than, and 3. Assuming someone else would do it for them. Based on theme one, whether the students are afraid of asking for help or afraid of expressing their feelings, the teachers need to emphasize the importance of self-advocacy skills and encourage the use of it in practical situations. If teachers discuss classroom norms of demonstrating self-advocacy skills appropriately with the students at the beginning of each semester, and repeat these norms regularly, the students will know what is right and wrong and will no longer be afraid.

Theme two of feeling ashamed of looking less than, indicates that the students need to build confidence and self-esteem with practice. The more the students practice self-advocacy skills the more comfortable they will become with using them. It also needs to be emphasized that asking for help or expressing different opinions/feelings/interests doesn't mean you are less than, it means they are self-aware. This goes back to the need of addressing self-advocacy in middle school, so they have the time to develop this skill and build the confidence. The last theme stated that the students assumed someone would advocate for them. This is a fair assumption as the students in middle school tend to get used to the fact that adults will help them with everything. Whether it is their parents, their teachers, or the school itself, there is always an adult there to guide the students, especially at The Winston School. At the Winston School, the students have extra support and smaller class sizes resulting in more individual assistance. As 
helpful as this is to the middle school students, it is important for the students to gain exposure to advocating for themselves in order to build their independence for the future.

\section{Transition Plan and OT}

Occupational therapists working the school setting need a more established role on the transition planning team. As OTs are able to address skills such as self-advocacy and selfdetermination to prepare the students as they transition to post-secondary education and general adulthood (Shea \& Giles, 2016; Spencer et al., 2017). Most research recommends post-secondary transition programs for high school students (Lawson et al, 2016; Rothman et al., 2008), selfadvocacy and self-determination skills require more time and practice in order for the students to be more confident. Transition programs need to either start earlier in middle school or OT's need to start addressing self-advocacy and self-determination in services for the middle school students. This occupation-based transition program within the college and career readiness course was ran and taught by an occupational therapist. It was developed by an occupational therapist and occupational therapy students. This transition program utilized occupation-based interventions as well as use an OT focus to look at the students, the students' education tasks, the students' environment at the school and how all those components impact the students' occupational performance.

\section{Future of Occupation-Based Transition Program}

The future of this occupation-based transition program includes the further development of this transition program by adding additional components necessary for the transition to postsecondary education. This can include mentorship program, interview training, coping strategies, and self-regulation. In the future, another outcome measure of this occupation-based transition program is to measure the success of each high school student as they transition to post- 
secondary education. This outcome measure can be assessed by measuring the retention rate of the high school students at The Winston School who participated in the transition program at their first semester of post-secondary school and at the second-year mark. The success of each high school student while in post-secondary education can also be assessed in the long term by number of degrees obtained by those students who participated in the transition program.

These self-advocacy lessons can be incorporated into the high school curriculum through the transition program within the college \& career readiness course. However, there was a need to introduce self-advocacy lessons to the middle school students so they can develop this skill overtime. This may include creating a life skills elective course in middle school curriculum or starting the transition program earlier. Occupational therapist's need to establish a role on the transition planning team to assist in the development of self-advocacy at multiple levels of the school system in order to promote success in post-secondary education. 


\section{References}

American Occupational Therapy Association. (2014). Occupational therapy practice framework: Domain and process. American Journal of Occupational Therapy, 68(1), S1-S48. https://doi.org/10.5014/ajot.2014.682006

Alverson, C. Y., Lindstrom, L. E., \& Hirano, K. A. (2019). High school to college: Transition experiences of young adults with autism. Focus on Autism and Other Developmental Disabilities, 34(1), 52-64. https://doi.org/10.1177/1088357615611880

Anderson, A. H., Stephenson, J., \& Carter, M. (2017). A systematic literature review of the experiences and supports of students with autism spectrum disorder in post-secondary education. Research in Autism Spectrum Disorders, 39, 33-53. https://doi.org/10.1016/j.rasd.2017.04.002

Angell, A. M., Carroll, T. C., Bagatell, N., Chen, C., Kramer, J. M., Schwartz, A., Tallon, M. B., \& Hammel, J. (2019). Understanding self-determination as a crucial component in promoting the distinct value of occupational therapy in post-secondary transition planning. Journal of Occupational Therapy, Schools, \& Early Intervention, 12(1), 129143. https://doi.org/10.1080/19411243.2018.1496870

Baum, C. M., Christiansen, C. H., \& Bass, J. D. (Eds). (2015). The Person-EnvironmentOccupation- Performance (PEOP) model. In C. H. Christiansen, C. M. Baum, \& J. D. Bass (Eds.), Occupational therapy: Performance, participation, and well-being (4 ${ }^{\text {th }}$ ed., 49-56). SLACK Incorporated.

Brewer, D., Karpur, A., Pi, S., Erickson, W., Unger, D., \& Malzer, V. (2011). Evaluation of a multi-site transition to adulthood program for youth with disabilities. Journal of Rehabilitation, 77(3), 3-13. 
Cease-Cook, J., Test, D. W., \& Scroggins, L. S. (2013). Effects of the CD-ROM version of the self-advocacy strategy on quality of contributions in IEP meetings of high school students with intellectual disability. Education and Training in Autism and Developmental Disabilities, 48(2), 258-268.

Centers for Disease Control and Prevention. (n.d.). What is health literacy? https://www.cdc.gov/healthliteracy/learn/index.html

Chandroo, R., Strnadova, I., \& Cumming, T. M. (2018). A systematic review of the involvement of students with autism spectrum disorder in the transition planning process: Need for voice and empowerment. Research in Developmental Disabilities, 83, 8-17. https://doi.org/10.1016/j.ridd.2018.07.011

Collier, M., Griffin, M. M., \& Wei, Y. (2015). Learning from students about transition needs: Identifying gaps in knowledge and experience. Journal of Vocational Rehabilitation, 46, 1-10. https://doi.org/10.3233/JVR-160837

Collins, G., \& Wolter, J. A. (2018). Facilitating postsecondary transition and promoting academic success through language/literacy- based self-determination strategies. Language, Speech, and Hearing Services in Schools, 49, 176-188. https://doi.org/10.1044/2017_LSHSS-17-0061

Connecticut Parent Advocacy Center. (2013). Stepping forward: A self-advocacy guide for middle and high school students. Bloomfield Public Schools. http://www.bloomfieldschools.org/UserFiles/Servers/Server_86794/File/SteppingForward.pdf

Cuenca-Carlino, Y., Mustian, A. L., Allen, R. D., \& Whitley, S. F. (2019). Writing for my future: Transition-focused self-advocacy of secondary students with emotional/behavioral 
disorders. Remedial and Special Education, 40(2), 83-96.

https://doi.org/10.1177/0741932517751212

DeWolfe, T. E. (2019). Jean Piaget's theory of cognitive development. Salem Press Encyclopedia of Health.

Dirette, D. P. (2019). Disability services for students in post-secondary education: Opportunities for occupational therapy. The Open Journal of Occupational Therapy, 7(2), 1-5. https://doi.org/10.15453/2168-6408.1609

Dryden, E. M., Desmarais, J., \& Arsenault, L. (2014). Effectiveness of the IMPACT: Ability program to improve safety and self-advocacy skills in high school students with disabilities. Journal of School Health, 84(12), 793-801. https://doi.org/10.1111/josh.12211

Grenwelge, C., \& Zhang, D. (2012). The effects of the Texas Youth Leadership Forum summer training on the self-advocacy abilities of high school students with disabilities. Journal of Disability Policy Studies, 24(3), 158-169. https://doi.org/10.1177/1044207312457415

Hotez, E., Shane-Simpson, C., Obeid, R., DeNigris, D., Siller, M., Costikas, C., Pickens, J., Massa, A., Giannola, M., D’Onofrio, J., \& Gillespie-Lynch, K. (2018). Designing a summer transition program for incoming and current college students on the autism spectrum: A participatory approach. Frontiers in Psychology, 9(46), 1-16. https://doi.org/10.3389/fpsyg.2018.00046

Holzberg, D. G., Test, D. W., \& Rusher, D. E. (2019). Self-advocacy instruction to teach high school seniors with mild disabilities to access accommodations in college. Remedial and Special Education, 40(3), 166-176. https://doi.org/10.1177/0741932517752059 
Jun, S., Osmanir, K., Kortering, L., \& Zhang, D. (2015). Vocational rehabilitation transition outcomes: A look at one state's evidence. Journal of Rehabilitation, 81(2), 47-53.

Kay, D. (2019). On the participation of children with medical conditions in risk assessment: A case for development of self-advocacy. Educational Psychology in Practice, 35(4), 357367. https://doi.org/10.1080/02667363.2019.1609424

Kielhofner, G., \& Burke, J. P. (1980). A model of human occupation, part 1. Conceptual framework and content. American Journal of Occupational Therapy, 34(9), 572-581. https://doi.org/10.5014/ajot.34.9.572

Landmark College. (2009). A guide to assessing college readiness. College Changes Everything. https://www.collegechangeseverything.org/events/2018-media/Session-1I-College$\underline{\text { Readiness-Guide.pdf }}$

Lawson, D. L., Gould, S. A., \& Conley, M. L. (2016). McDaniel Step Ahead: A summer transitional program for first year college students with disabilities. Journal of Postsecondary Education and Disability, 29(3), 229-302.

Lindsay, S., Lamptey, D., Cagliostro, E., Srikanthan, D., Mortaji, N., \& Karon, L. (2019). A systematic review of post-secondary transition interventions for youth with disabilities. Disability and Rehabilitation, 41(21), 2492-2505. https://doi.org/10.1080/09638288.2018.1470260

Mankey, T. M. (2011). Occupational therapists' beliefs and involvement with secondary transition planning. Physical \& Occupational Therapy in Pediatrics, 31(4), 345-358. https://doi.org/10.3109/01942638.2011.572582

National Center for Learning Disabilities. (n.d.). Learn the law: IDEA. https://www.ncld.org/get$\underline{\text { involved/learn-the-law/idea }}$ 
National Parent Center on Transition and Employment. (2012). Disability resources: A student perspective. [Video]. https://www.pacer.org/transition/video/player.asp?video=159

Nochajski, M. S., \& Schweitzer, A. J. (2014). Promoting school to work transition for students with emotional/behavioral disorders. Work, 48(3), 413-422. https://doi.org/10.3233/WOR-131790

Novakovic, A., \& Ross, D. E. (2015). College student for a day: A transition program for high school students with disabilities. Journal of Postsecondary Education and Disability, $28(2), 229-234$.

Paraschiv, I. (2000, June 1). Development of a high school curriculum that promotes selfdetermination and independence skills [Paper presentation]. Annual Meeting of the American Association on Mental Retardation, Washington, DC, United States.

Rogan, P., Updike, J., Chesterfield, G., \& Savage, S. (2014). The SITE program at IUPUI: A post-secondary program for individuals with intellectual disabilities. Journal of Vocational Rehabilitation, 40,109-116. https://doi.org/10.3233/JVR-140673

Rothman, T., Maldonado, J. M., \& Rothman, H. (2008). Building self-confidence and future career success through a pre-college transition program for individuals with disabilities. Journal of Vocational Rehabilitation, 28(2), 73-83.

Sabbatino, E. D., \& Macrine, S. L. (2007). Start on success: A model transition program for high school students with disabilities. Preventing School Failure: Alternative Education for Children and Youth, 52(1), 33-39. https://doi.org/10.3200/PSFL.52.1.33-40

Seruya, F. M., \& Ellen, K. M. (2015). Role of the middle school occupational therapist: An initial exploration. Early Interventions \& School, 22(2), 1-4. 
Shea, C. K., \& Giles, G. M. (2016). Goals and expectations of continuation high school students transitioning to postsecondary education. Open Journal of Occupational Therapy (OJOT), 4(4), 1-13. https://doi.org/10.15453/2168-6408.1237

Sparks, S. D. (2015). For students with disabilities, transition from high school requires selfadvocacy. Education Week, 34(33), 8. http://www.edweek.org/ew/index.html

Spencer, B., Sherman, L., Nielsen, S., \& Thormodson, K. (2017). Effectiveness of occupational therapy interventions for students with mental illness transitioning to higher education: A systematic review. Occupational Therapy in Mental Health, 34(2), 151-164. https://doi.org/10.1080/0164212X.2017.1380559

Studies from University of North Carolina describe new findings in remedial and special education (self-advocacy instruction to teach high school seniors with mild disabilities to access accommodations in college). (2019). Education Letter, 483. http://www.verticalnews.com/newsletters/Education-Letter.html

The value of financial literacy and self-advocacy. (2019). US Official News. https://link.gale.com/apps/doc/A584448957/STND?u=lirn55718\&sid=STND\&xid=a590 $\underline{164 c}$

The Winston School. (n.d.). About us: Mission \& values. https://www.thewinstonschool.org/about-us/mission-values/

Todis, B., Glang, A., Bullis, M., Ettel, D., \& Hood, D. (2011). Longitudinal investigation of the post-high school transition experiences of adolescents with traumatic brain injury. Journal of Head Trauma and Rehabilitation, 26(2), 138-149. https://doi.org/10.1097/HTR.0b013e3181e5a87a 
Top Hat. (n.d.). Postsecondary Education. In tophat.com/glossary. Retrieved May 29, 2020, from https://tophat.com/glossary/p/postsecondary-education/

Van-Belle, J., Marks, S., Martin, R., \& Chun, M. (2006). Voicing one’s dreams: High school students with developmental disabilities learn about self-advocacy. Teaching Exceptional Children, 38(4), 40-46.

Waller, J., Sanford, M., Caswell, T., \& Bainbridge, C. (2016). Comprehensive social communication support for improving transitions for adolescents with autism spectrum disorder (ASD). Perspectives of the ASHA Special Interest Groups, 1(3), 63-77. https://doi.org/10.1044/persp1.SIG16.63

White, S. W., Elias, R., Capriola-Hall, N. N., Smith, I. C., Conner, C. M., Asselin, S. B., Howlin, P., Getzel, E. E., \& Mazefsky, C. A. (2017). Development of a college transition and support program for students with autism spectrum disorder. Journal of Autism and Developmental Disorders, 47(10), 3072-3078. https://doi.org/10.1007/s10803-017-3236$\underline{8}$

Wilson, H., Bialk, P., Freeze, T. B., Freeze, R., \& Lutfiyya, Z. M. (2012). Heidi’s and Philip's stories: Transitions to post-secondary education. British Journal of Learning Disabilities, 40(2), 87-93. https://doi.org/10.1111/j.1468-3156.2012.00746.x

Wolman, J. M., Campeau, P. L., DuBois, P. A., Mithaug, D. E., \& Stolarski, V. S. (1994). AIR Self-Determination Scale and user guide. Zarrow Center for Learning Enrichment: The University of Oklahoma. https://www.ou.edu/content/dam/Education/documents/miscellaneous/air-selfdetermination-user-guide.pdf 


\section{Appendix A}

\section{Staff Survey}

This is just to gain a better understanding of the self-advocacy skills of the students who are currently enrolled at The Winston School. This is just for general purposes so guesses are okay.

1. What grade level do you teach?

2. 2. What are some areas students need to work on prior to the transition to postsecondary education? Click all that apply

Check all that apply.

Understanding post-secondary options

Application process

Time management

Self-Advocacy

Self-Determination

Academic skills

Independent living

Financial Literacy

Stress management

Social skills/communication

Other:

3. 3. Do the students know what self-advocacy is?

Mark only one oval.
Yes
No
Maybe
Other: 
4. 4. In general, how would you rate the students' overall self-advocacy and selfdetermination skills?

Mark only one oval.

$\begin{array}{lllll}1 & 2 & 3 & 4 & 5 \\ \text { Very poor } \square & \square & \square & \\ & \square & \square \text { Very good }\end{array}$

5. 5. Do students ask for help when needed on assignments and projects?

Mark only one oval.

$\bigcirc$ Yes

$\bigcirc$ No

Sometimes

$\longrightarrow$ Other:

6. 6. When the students ask for help, is it done appropriately?

Mark only one oval.

$\bigcirc$ Yes

$\bigcirc$ No

Sometimes

$\longrightarrow$ Other:

7. 7. If no, what do they do that is inappropriate when asking for help? (Is it too often, not at the right time, not asking politely, etc) 
8. 8. Do the students ask for clarification or feedback when they do not understand why they received the grade they did?

Mark only one oval.

$\bigcirc$ Too often

$\bigcirc$ Yes, an appropriate amount

No

$\bigcirc$ Sometimes

Other:

9. 9. Do the students have an opportunity to disclose of their disability on their own and in their own words?

Mark only one oval.

Yes

No

Other:

10. 10. Are the students aware of their disability, their strengths, and weaknesses? Mark only one oval.

Yes

No

Sometimes

other: 
11. 11. Are the students taught about their rights as a student and laws such as ADA and IDEA?

Mark only one oval.

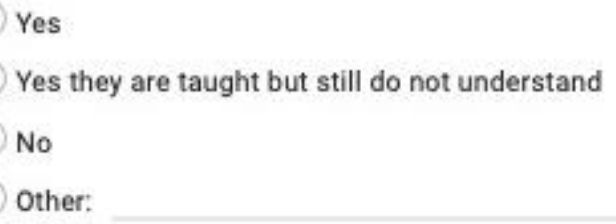




\section{Appendix B}

\section{Self Advocacy Survey}

High School Students

1. Name

2. 1. What grade are you in?

3. 2. How well do you know your academic strengths?

Mark only one oval.

I DO NOT know my academic strengths

4. 3. How well do you know which academic tasks give you the most difficulty

Mark only one oval.

I DO NOT KNOW which academic tasks give me the most difficulty

5. 4. How well can you identify the academic supports you need to be successful

Mark only one oval.

I CAN NOT identify any academic supports

6. 5. How well do you know your legal rights as a student

Mark only one oval.

I DO NOT KNOW my legal rights as a student

7. 6. How often do you ask for help when you run into difficulty

Mark only one oval.

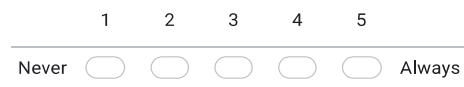


8. 7. How often do you schedule your own appointments with doctors, advisors, and counselors

Mark only one oval.

\begin{tabular}{llllll}
1 & 2 & 3 & 4 & 5 \\
Never $\square$ & $\square$ & \\
\hline Always
\end{tabular}

9. 8. If a school or college refused to provide you with an appropriate accommodation, how likely are you to dispute the decision

Mark only one oval.

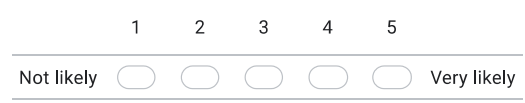

10. 9. How would you rate your system of keeping organized?(Example: keeping track of projects, books, and papers)

Mark only one oval.

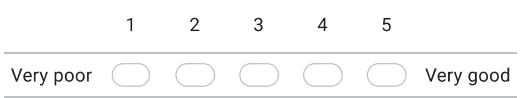

11. 10. How well are you at ignoring distractions and focusing on the task at hand Mark only one oval.

I am VERY POOR at ignoring distractions $\square \bigcirc$ I am VERY GOOD at ignoring distractions

12. 11. How well are you able to complete all steps of a project in a timely manner

Mark only one oval.

I am VERY POOR at completing all steps of a project in a timely manner

13. 12. How would you rate your ability to complete tasks that you find boring

Mark only one oval.

I am VERY POOR at completing tasks that I find boring


14. 13. How would you rate your perceived ability to succeed?

Mark only one oval.

I DO NOT think I have the ability to succeed

15. 14. When you think about what you have to do in college are you excited?

Mark only one oval.

$\bigcirc$ Yes

$\bigcirc$ No

Not sure yet

$\bigcirc$ other:

16. 15. Can you imagine your life in 10 years?

Mark only one oval.

$\bigcirc$ Yes

$\longrightarrow$ No

Not sure yet

Other:

17. 16. How often do you make your own snacks and meals?

Mark only one oval

$\begin{array}{llllll}1 & 2 & 3 & 4 & 5 \\ \text { Never } & \square & & \end{array}$

18

17. How often do you make friends with other kids your age

Mark only one oval.

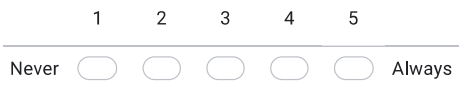

19. 18. How often do you plan weekend activities that you like to do

Mark only one oval

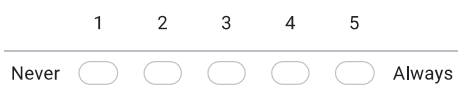


20

19. How often do you choose your own hair and clothing style
Mark only ane oval
Never

21. 20. Do you make lang term career plans?

Mark oníy one oval

Yes

No

Other:

22. 21. Do you have an acaderric subject that you find interesting? If so what is it?

23. 22 . Is there anything else you would like to say or share with me? 


\section{Appendix C}

\section{Self-Advocacy Post-Survey}

High School Students

1. 1. Name

2. 2. In your own words, what is Self-Advocacy?

3. 3. In your opinion, how important is it to learn self-advocacy skills?

Mark only one oval.

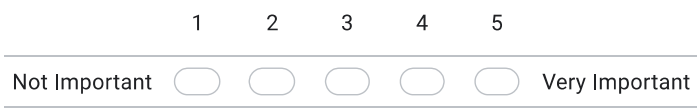

4. 4. Did you find it helpful to learn about self-advocacy and self-determination? Mark only one oval.

$\square$ Yes
No
Other:


5. 5. In your opinion, when would be the best time to learn about self-advocacy?

Mark only one oval.

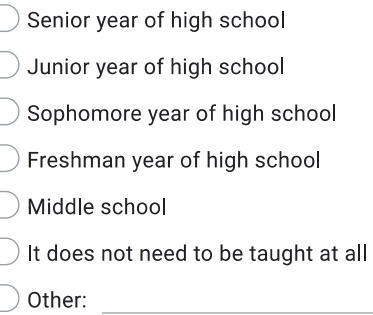

6. 6. What was most beneficial to your learning of self-advocacy and selfdetermination skills?

Check all that apply.

$\square$ Lessons

$\square$ Role playing activities

$\square$ Videos

$\square$ Class discussions

None of it was beneficial

Other:

7. 7. Did you enjoy learning self-advocacy and self-determination skills?

Mark only one oval.

$\bigcirc$ Yes

No

Other:

8. 8 . Did you enjoy the role playing activities?

Mark only one oval.

$\square_{\text {Nos }}$
Other:


9. 9. How comfortable do you feel asking your teacher/professor for help?

Mark only one oval.

\begin{tabular}{lllllll} 
& 1 & 2 & 3 & 4 & 5 & \\
\hline Not Comfortable & $\square$ & $\bigcirc$ & $\square$ & $\square$
\end{tabular}

10. 10. How comfortable do you feel requesting for accommodations in postsecondary education?

Mark only one oval.

$\begin{array}{lllllll}1 & 2 & 3 & 4 & 5 & \\ \text { Not Comfortable } \square & \square & \square & \square & \square \\ & \square & & \square\end{array}$

11. 11. If you have a disability, how comfortable do you feel disclosing your disability to receive academic accommodations?

Mark only one oval.

\begin{tabular}{lllllll}
1 & 2 & 3 & 4 & 5 & \\
\hline Not Comfortable & $\square$ & $\square$ & $\square$ & $\square$ \\
\hline
\end{tabular}

12. 12. Do you know the process of how to request for accommodations in postsecondary education?

Mark only one oval.

$\square_{\text {No }}$ Yes

13. 13. How well do you know your student rights and laws?

Mark only one oval

I still don't know my student rights and laws


14. 14. What are some differences between high school and post-secondary education?

15. 15. Would you recommend the self-advocacy lessons to other students?

Mark only one oval.

$\square$ Yes
No
Other:

16. 16. What was one thing you liked about the self-advocacy and self-determination lessons/activities?

17. 17. What is one thing you would change about the self-advocacy and selfdetermination lessons/activities? 


\section{Appendix D}

\section{College Readiness Survey}

Middle School Students

1. What grade are you in?

2. 2. How well do you know your academic strengths?

Mark only one oval.

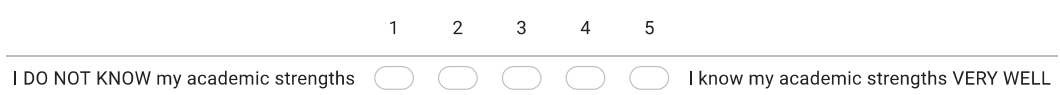

3. 3. How well do you know which academic tasks give you the most difficulty

Mark only one oval.

I DO NOT KNOW which academic tasks give me the most difficulty

4. 4. How well can you identify the academic supports you need to be successful

Mark only one oval.

I CAN NOT identify any academic supports

5. 5. How well do you know your legal rights as a student

Mark only one oval.

I DO NOT KNOW my legal rights as a student

6. 6. How often do you ask for help when you run into difficulty

Mark only one oval.

$\begin{array}{llllll}1 & 2 & 3 & 4 & 5 \\ \text { Never } \square & \square & \square\end{array}$


7. 7. How would you rate your system of keeping organized (Example: Keeping track of projects, books, and papers)

Mark only one oval.

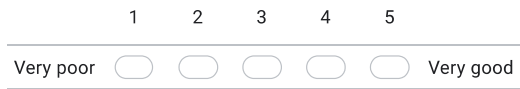

8. 8. How well are you at ignoring distractions and focusing on the task at hand

Mark only one oval.

$\begin{array}{llllll}1 & 2 & 3 & 4 & 5 \\ \text { I am VERY POOR at ignoring distractions } & & \end{array}$

9. 9. How well are you able to complete all steps of a project in a timely manner

Mark only one oval.

I am VERY POOR at completing all steps of a project in a timely manner

10. 10. How would you rate your ability to complete tasks that you find boring

Mark only one oval

I am VERY POOR at completing tasks that I find boring

11. 11. How would you rate your perceived ability to succeed?

Mark only one oval.

$\begin{array}{lllll}1 & 2 & 3 & 4 & 5\end{array}$

I DO NOT think I have the ability to succeed $\square$ I think I have the ability to be VERY SUCCESSFUL

12. 12. When you think about what you have to do in college are you excited?

Mark only one oval.
Yes
$\longrightarrow$ No
Not sure yet
Other: 
13. 13. Can you imagine your life in 10 years?

Mark only one oval.

$\bigcirc$ Yes

$\bigcirc$ No

Not sure yet

$\bigcirc$ other:

14. 14. How often do you make your own snacks and meals?

Mark only one oval

$\begin{array}{llllll}1 & 2 & 3 & 4 & 5 \\ \text { Never } & \bigcirc & \bigcirc & \square & \end{array}$

15.

15. How often do you make friends with other kids your age

Mark only one oval.

$\begin{array}{llllll}1 & 2 & 3 & 4 & 5 \\ \text { Never } & \bigcirc & \bigcirc & \bigcirc & \square \text { Always }\end{array}$

16. 16. How often do you plan weekend activities that you like to do

Mark only one oval.

$\begin{array}{lllll}1 & 2 & 3 & 4 & 5 \\ \text { Never } & \square & \square & \square \text { Always }\end{array}$

17. 17. How often do you choose your own hair and clothing style

Mark only one oval.

$\begin{array}{llllll}1 & 2 & 3 & 4 & 5 \\ \text { Never } & \square & \square & \square\end{array}$

18. Do you have an academic subject that you find interesting? If so what is it? 
19. Is there amything else you would to say or share with me? 


\section{Appendix E}

Lesson Plans in College and Career Readiness Course

Self-Advocacy and Self-Determination

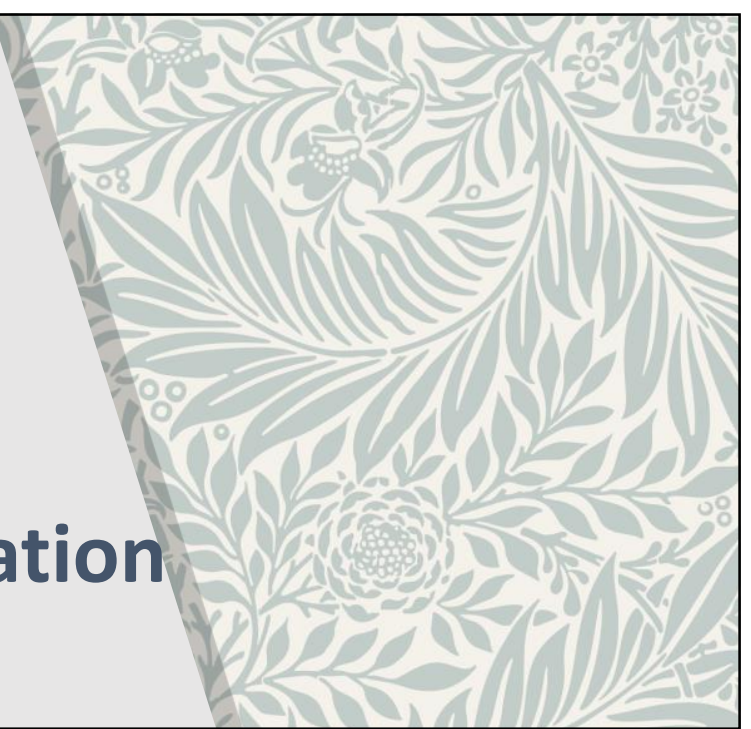

1

\section{What is self- determination?}

Self-determination is described as the extent to which a person assumes responsibility for his or her own goals, accomplishments, and setbacks (Ward, 1988) 


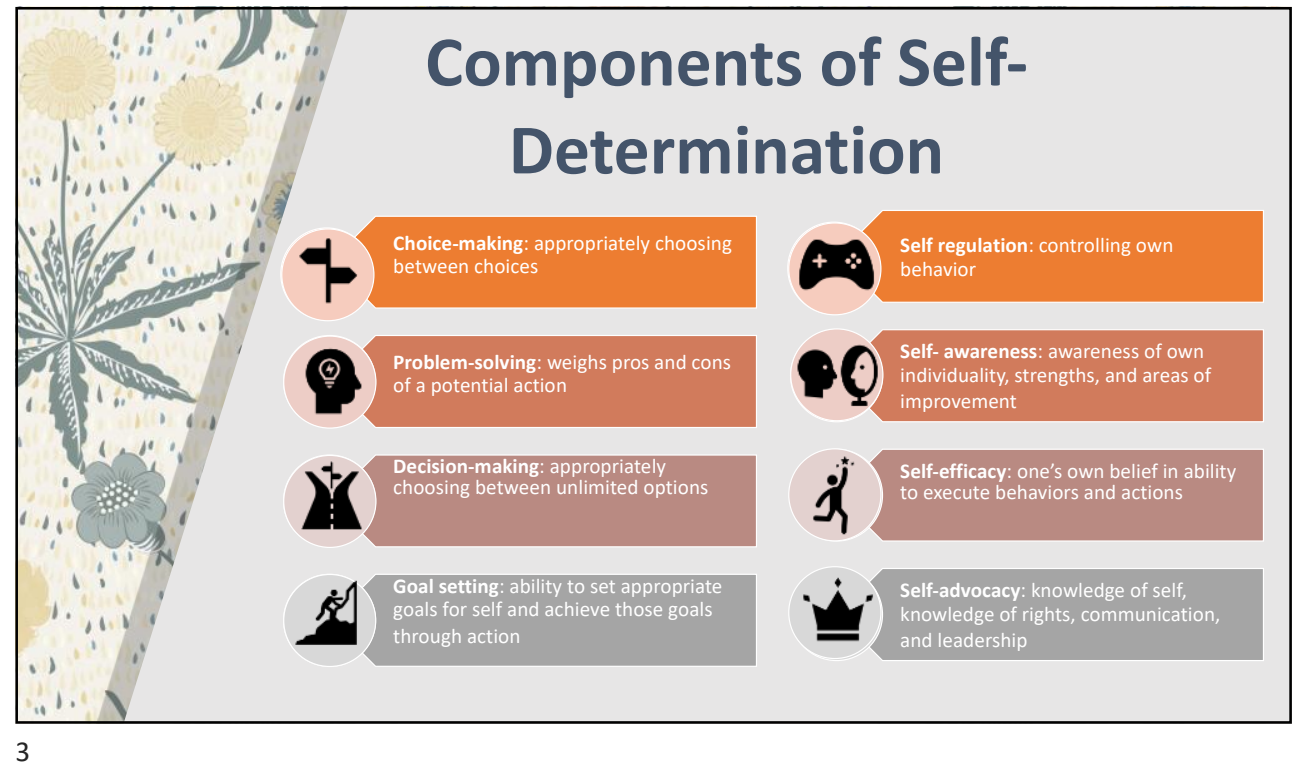

3

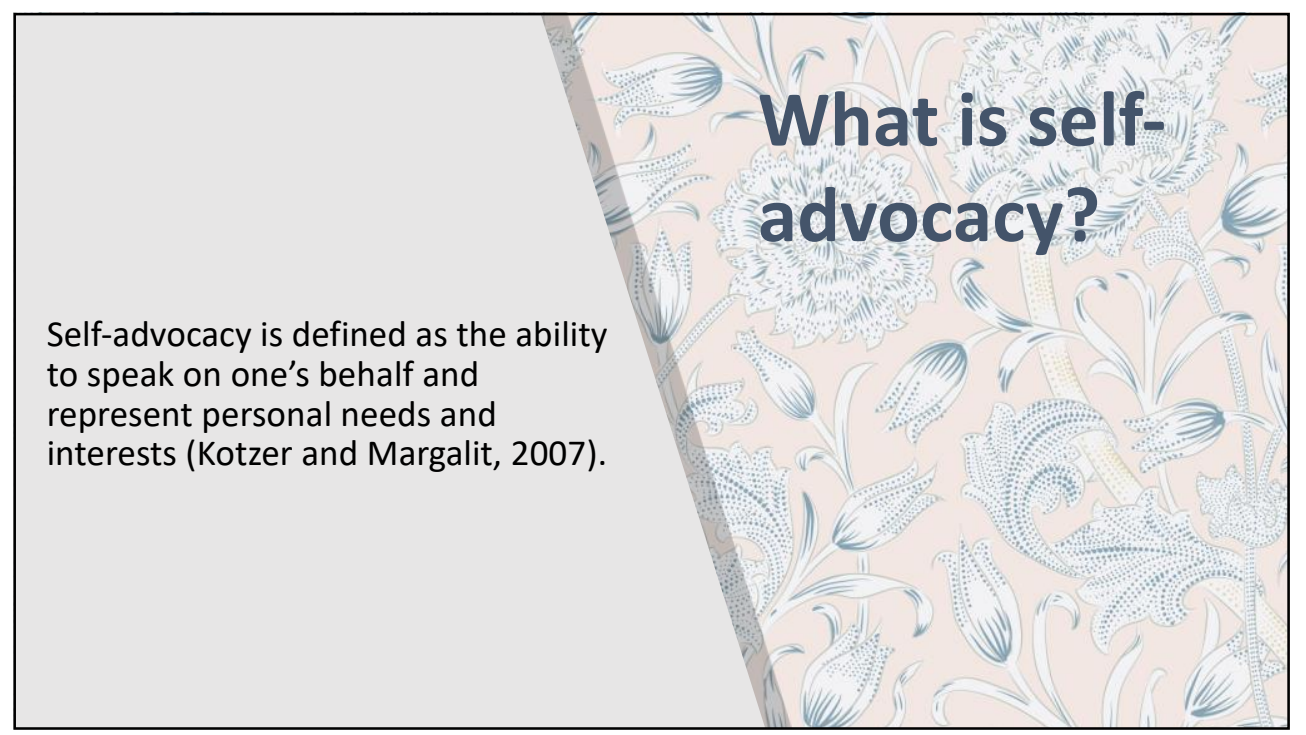




\section{Components of Self-Advocacy}

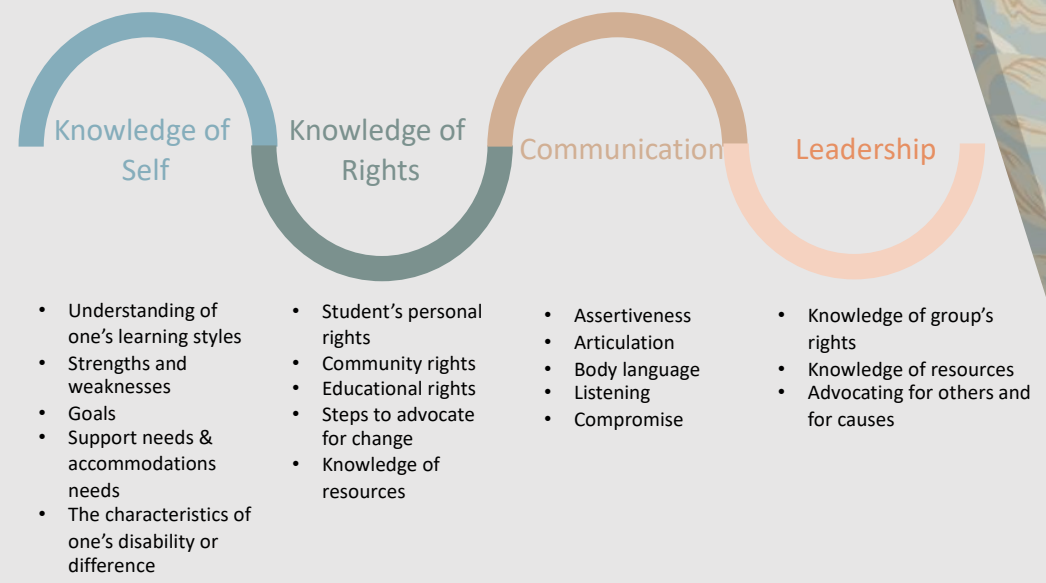

\section{Benefits of Self-Advocacy and Self-Determination Skills}

\section{Increase problem solving skills}

Improve self-confidence

Feeling of control over choices and life

Increase independence

Self-empowerment

Health \& Wellness 


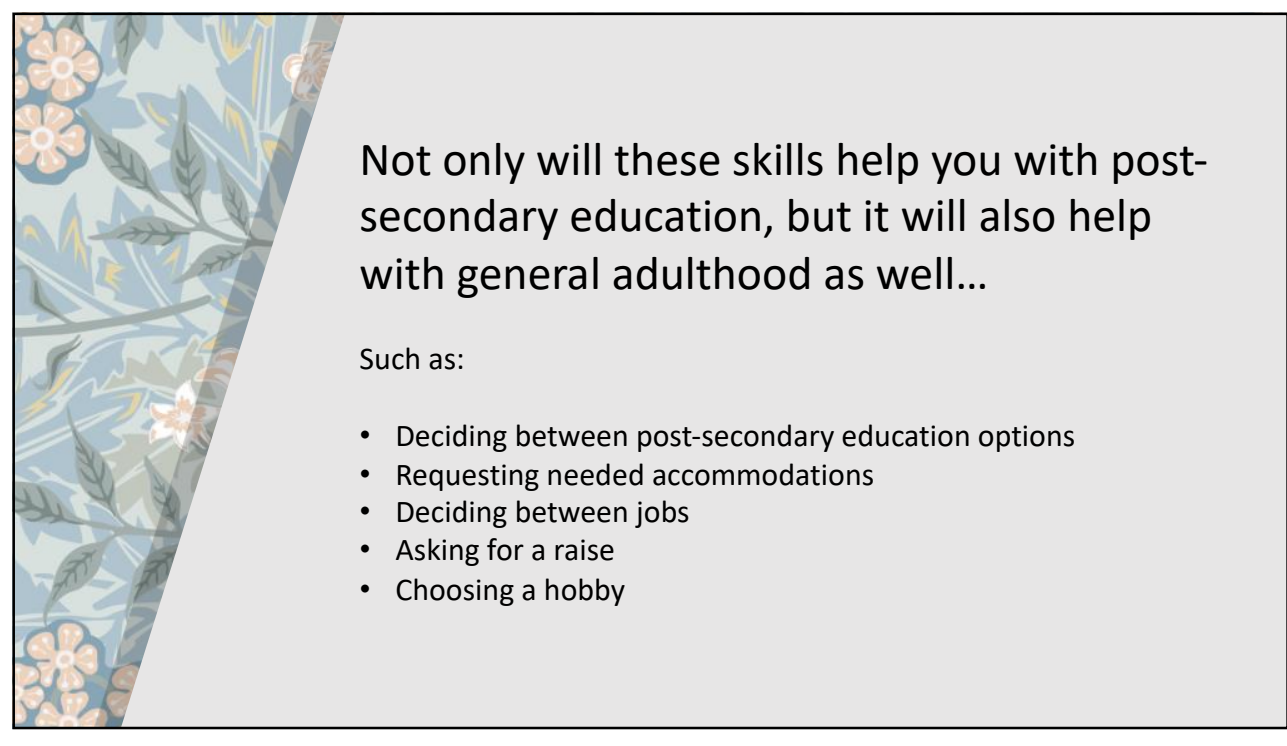

7

Examples

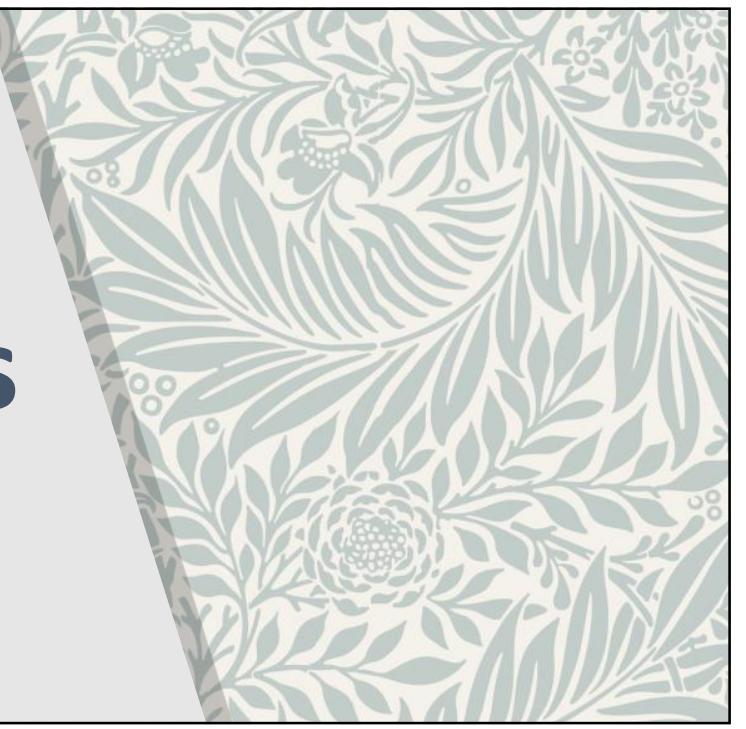




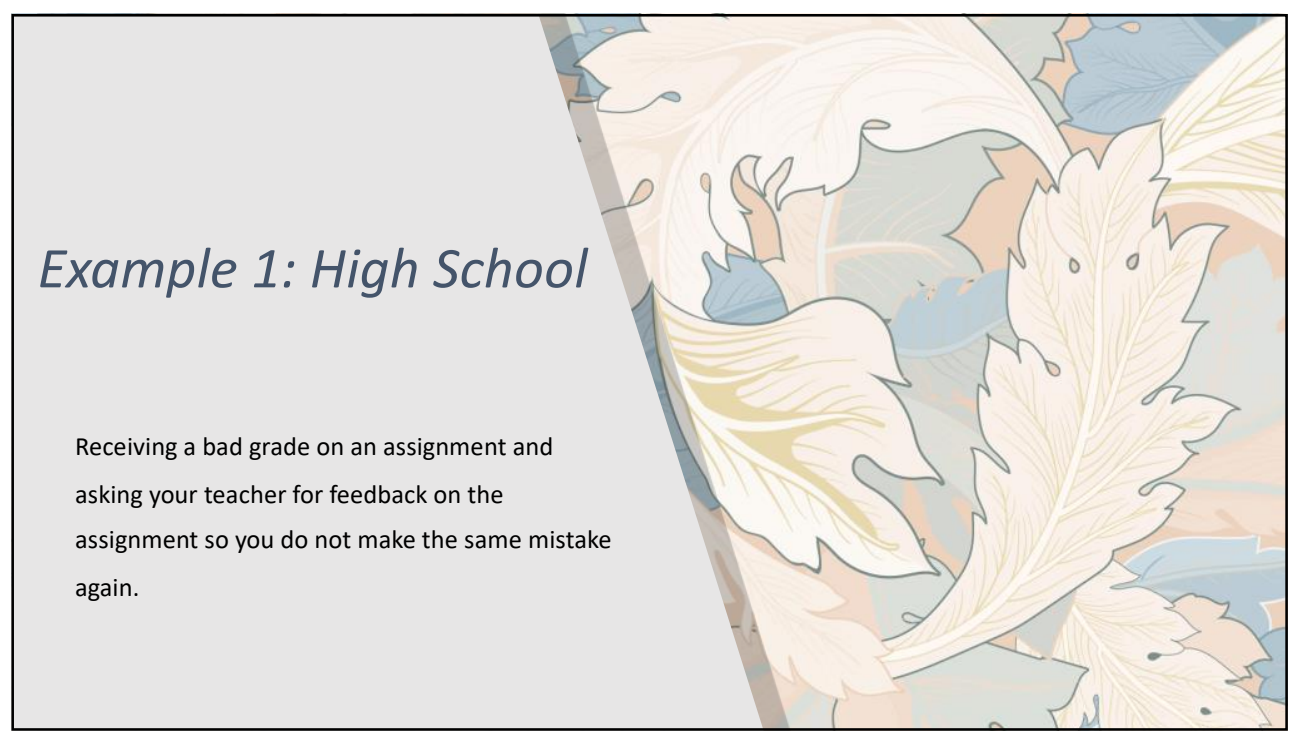

9

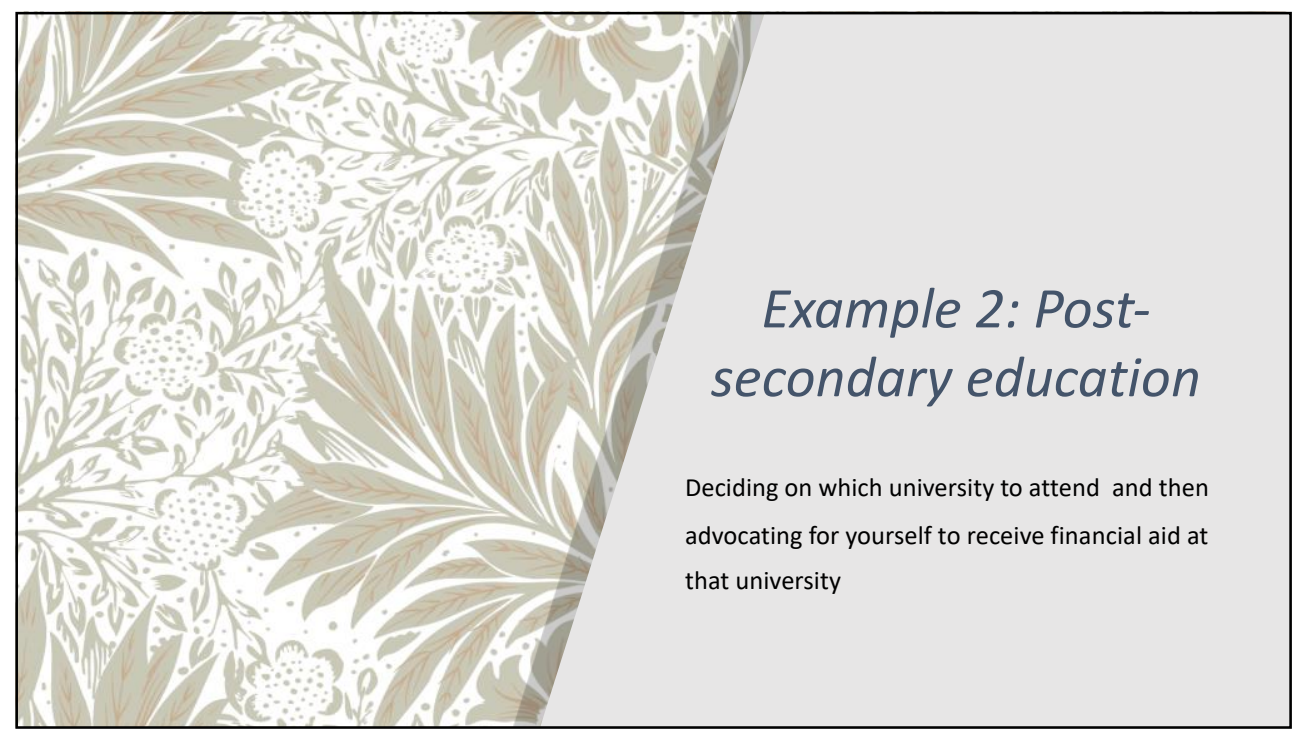




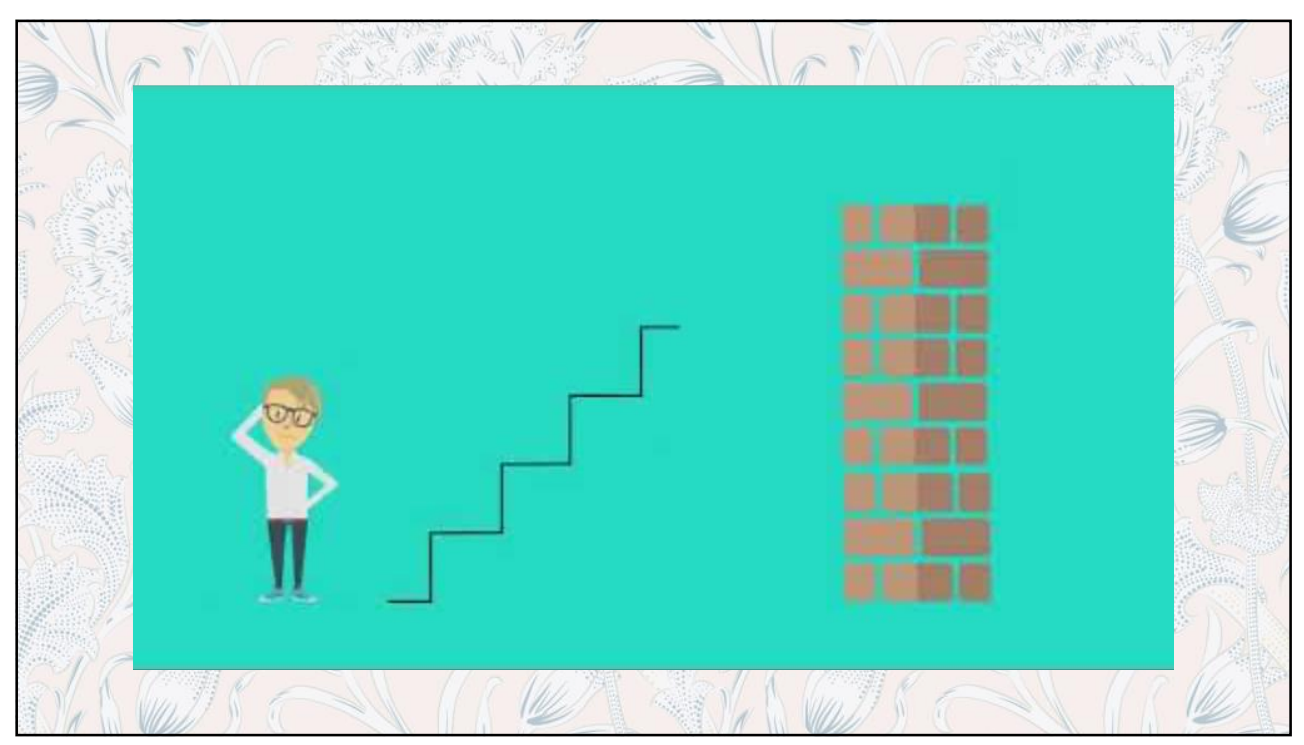




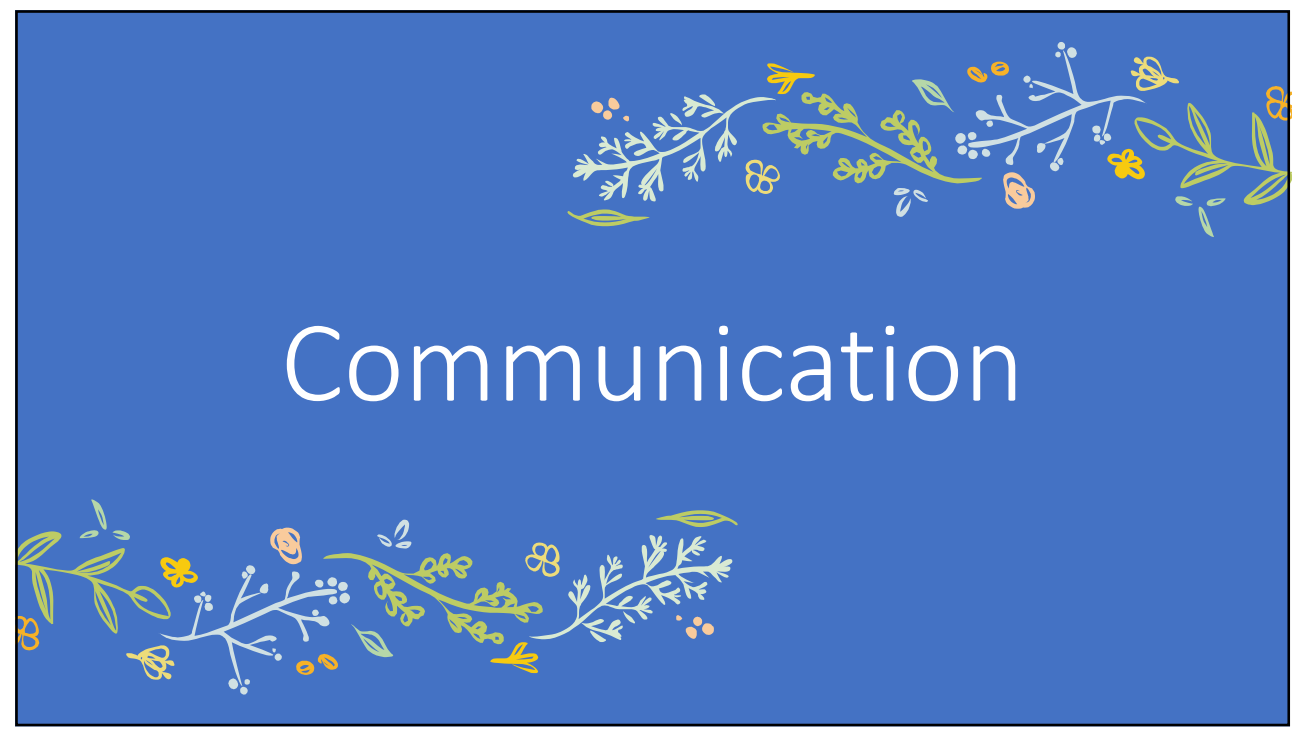

1

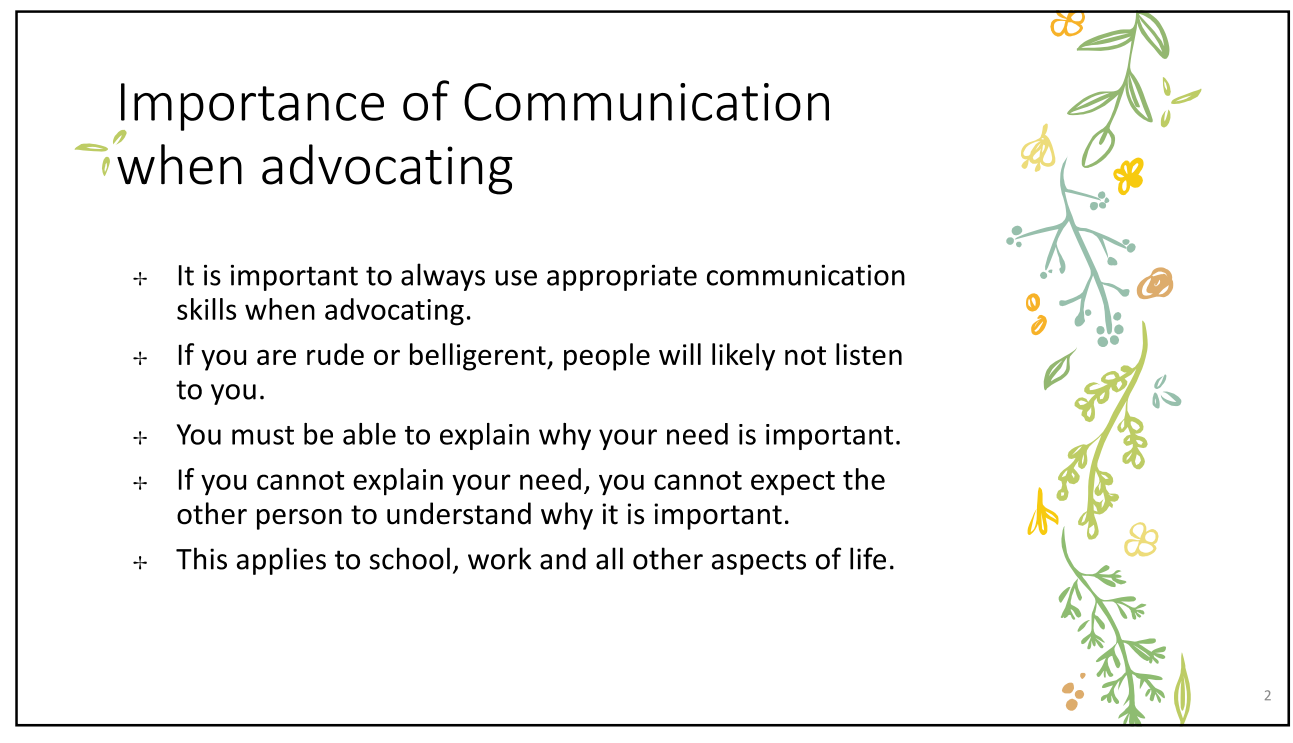

2 


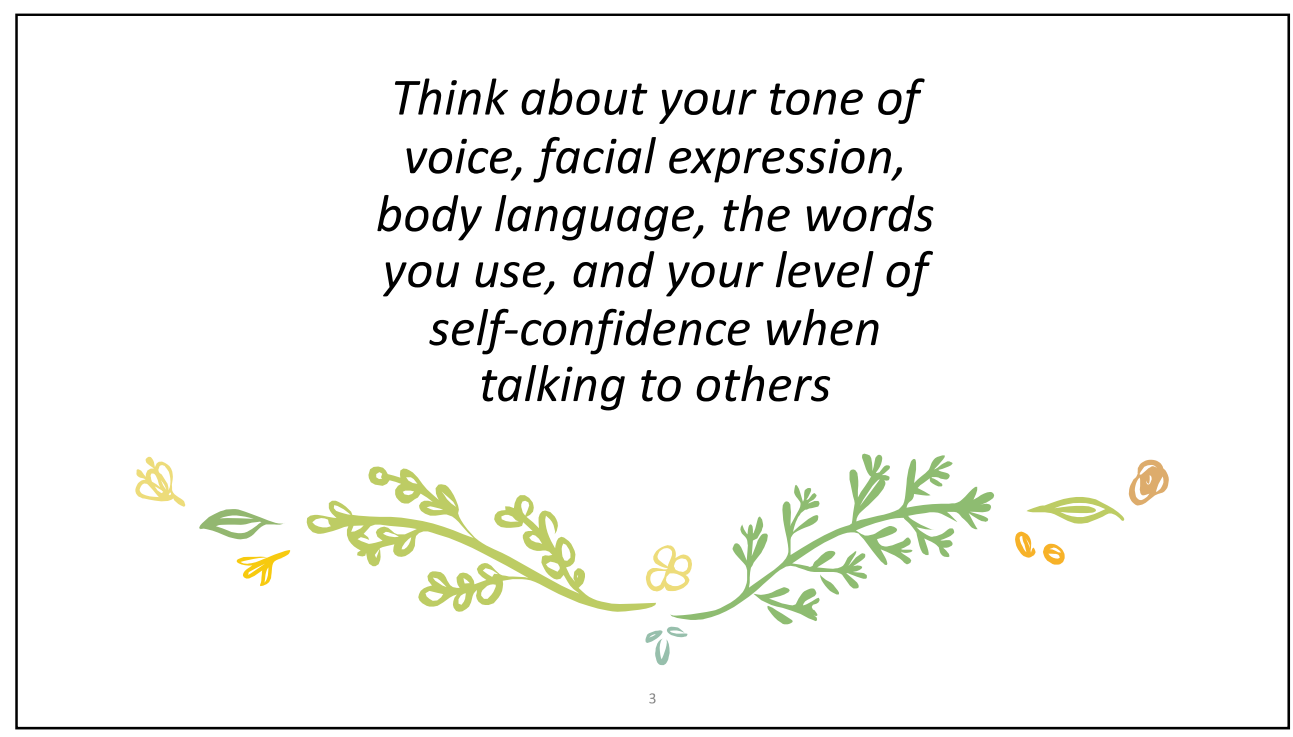

3

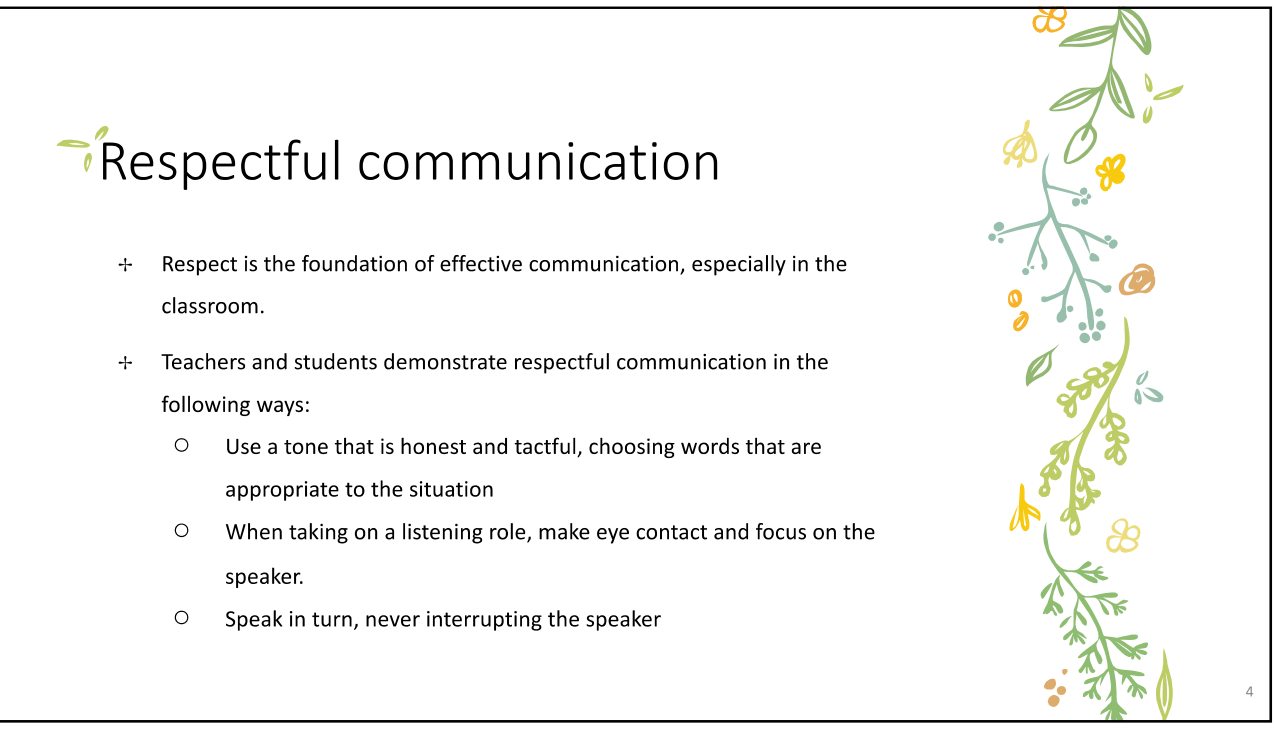

4 

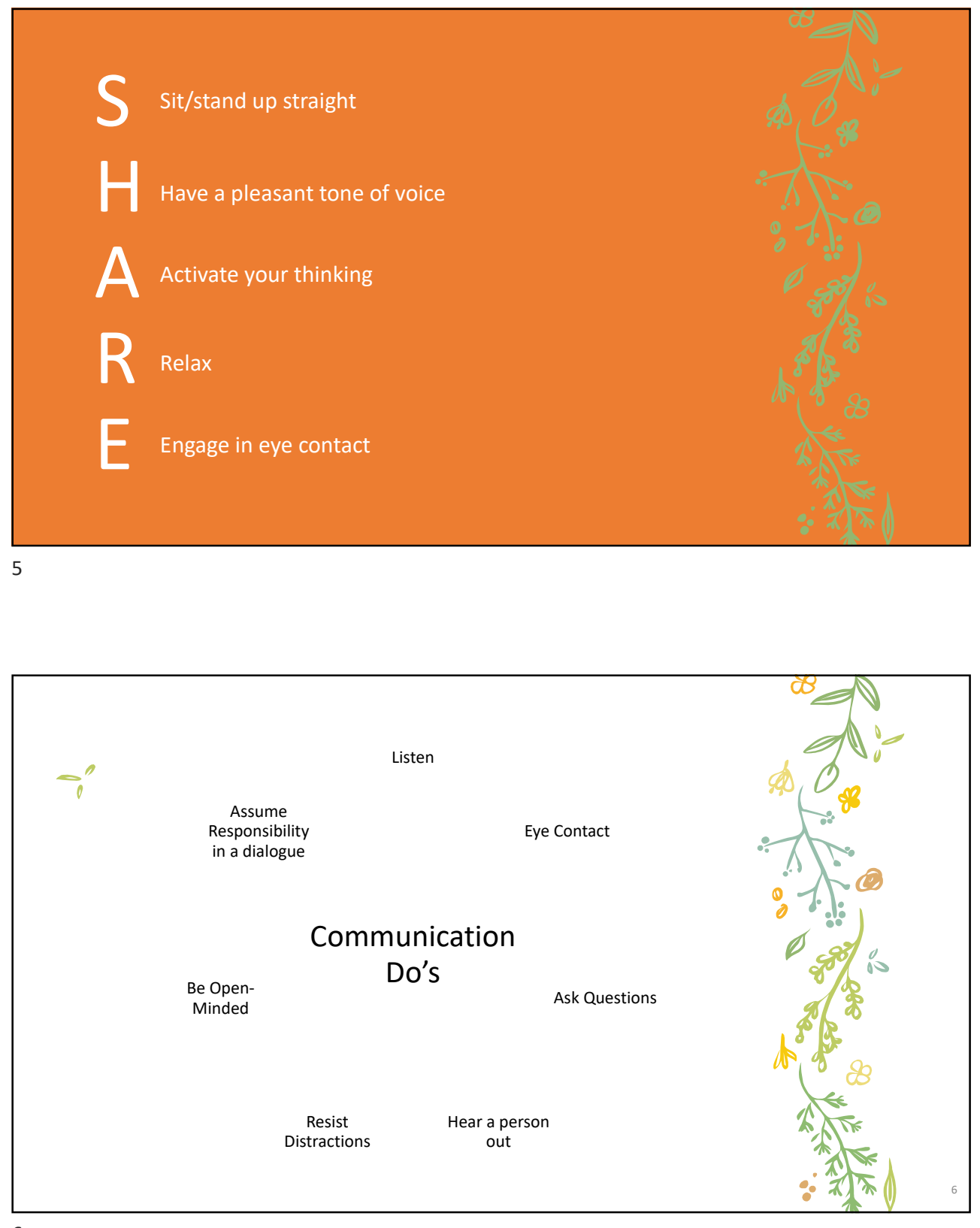

6 


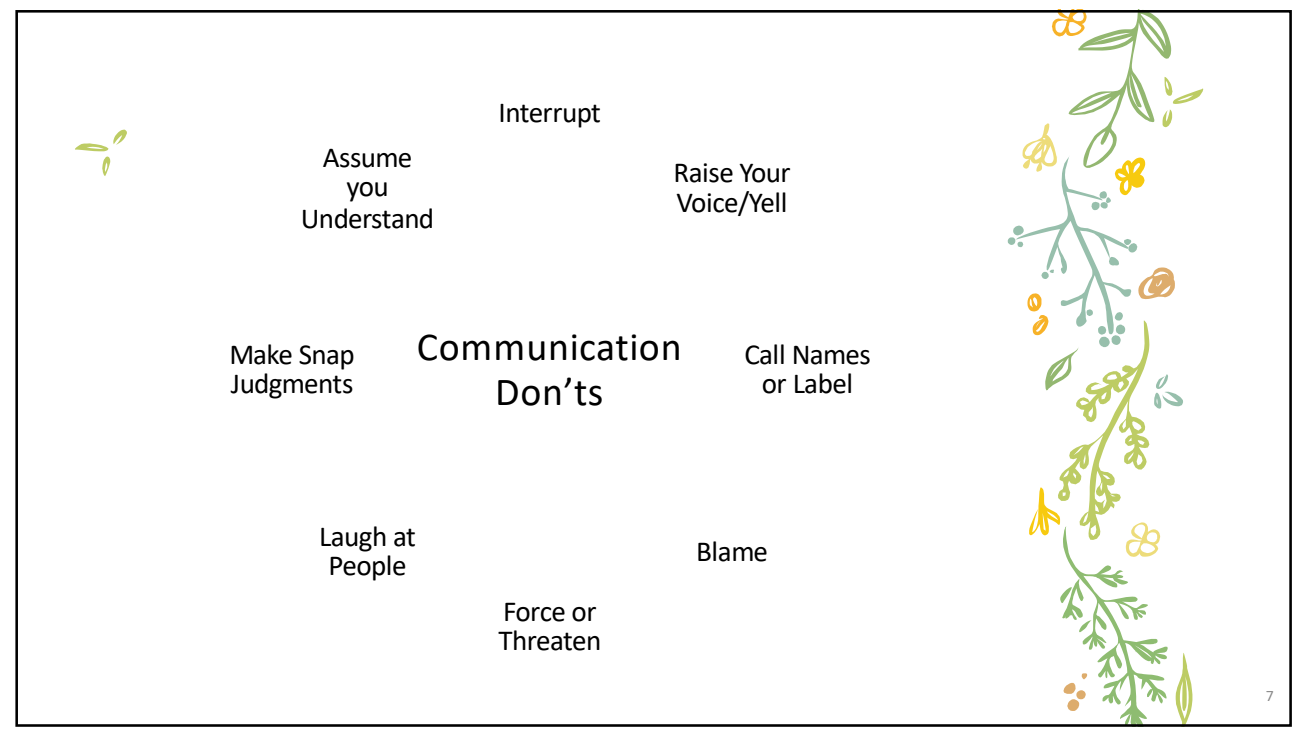

7

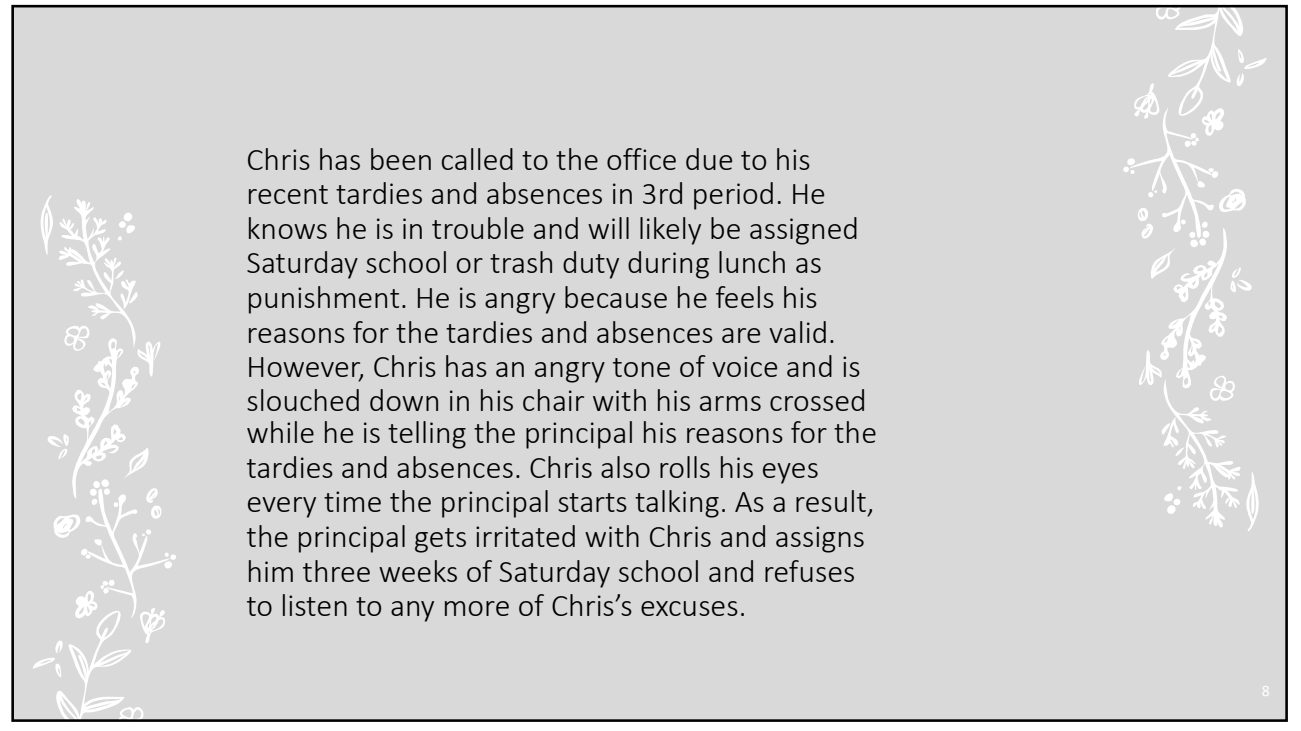




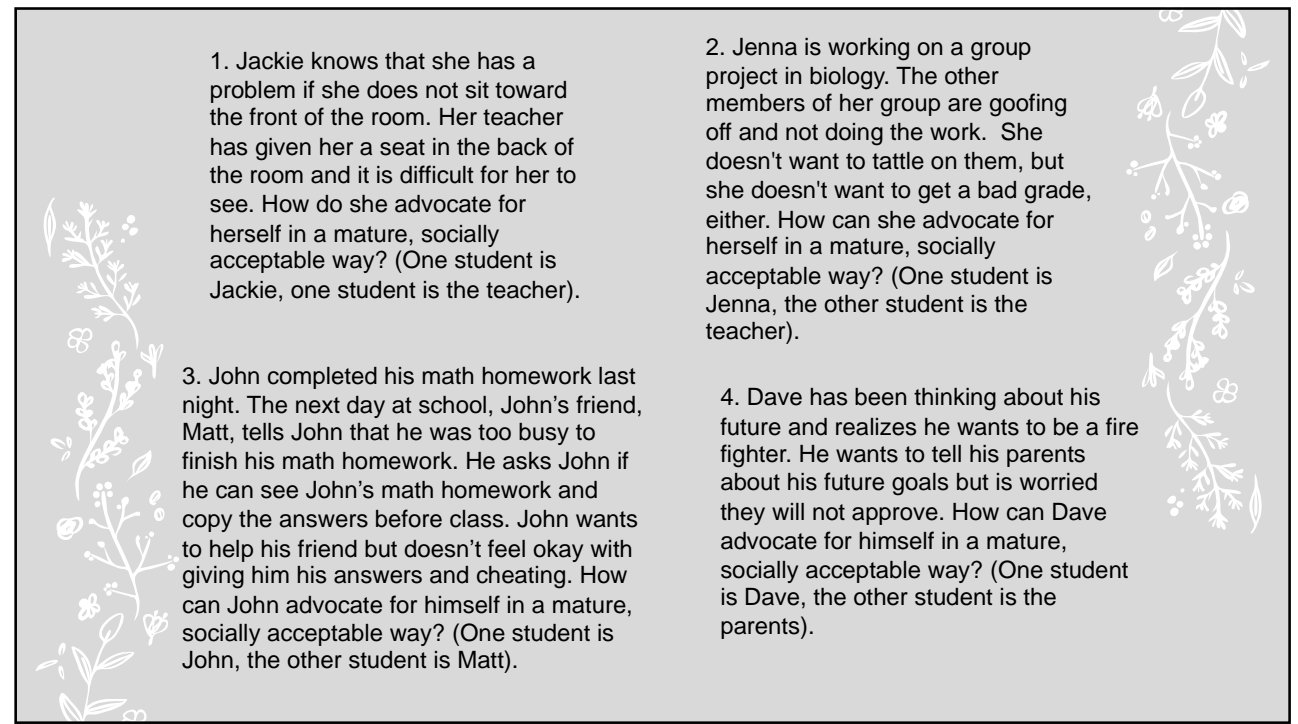

9 


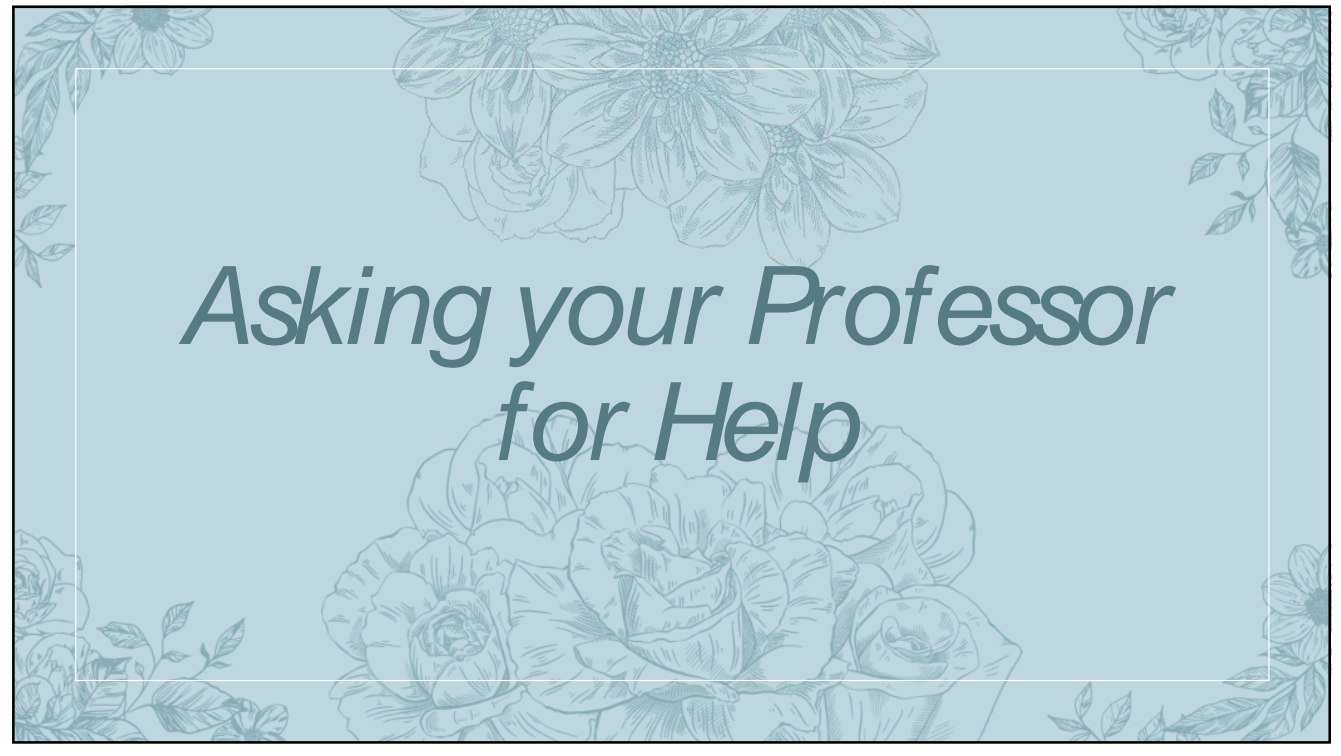

1

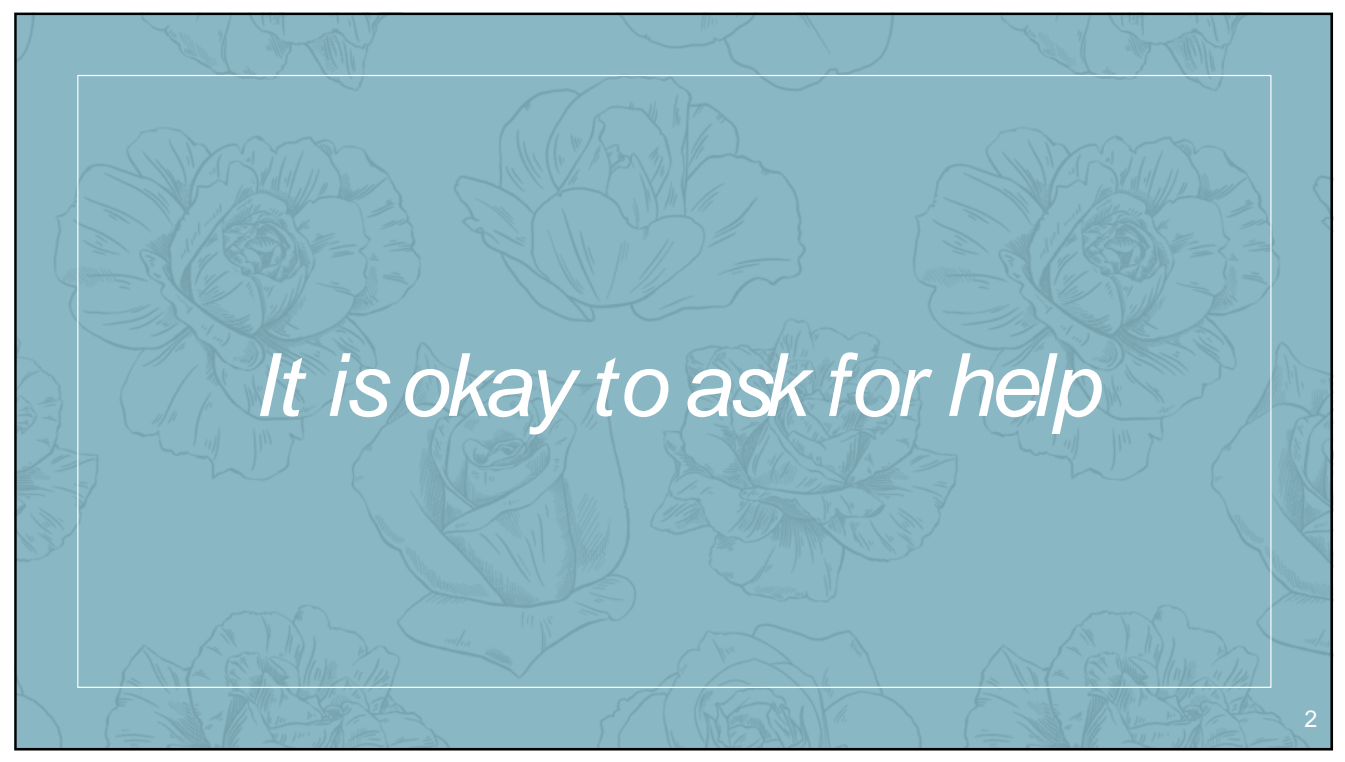




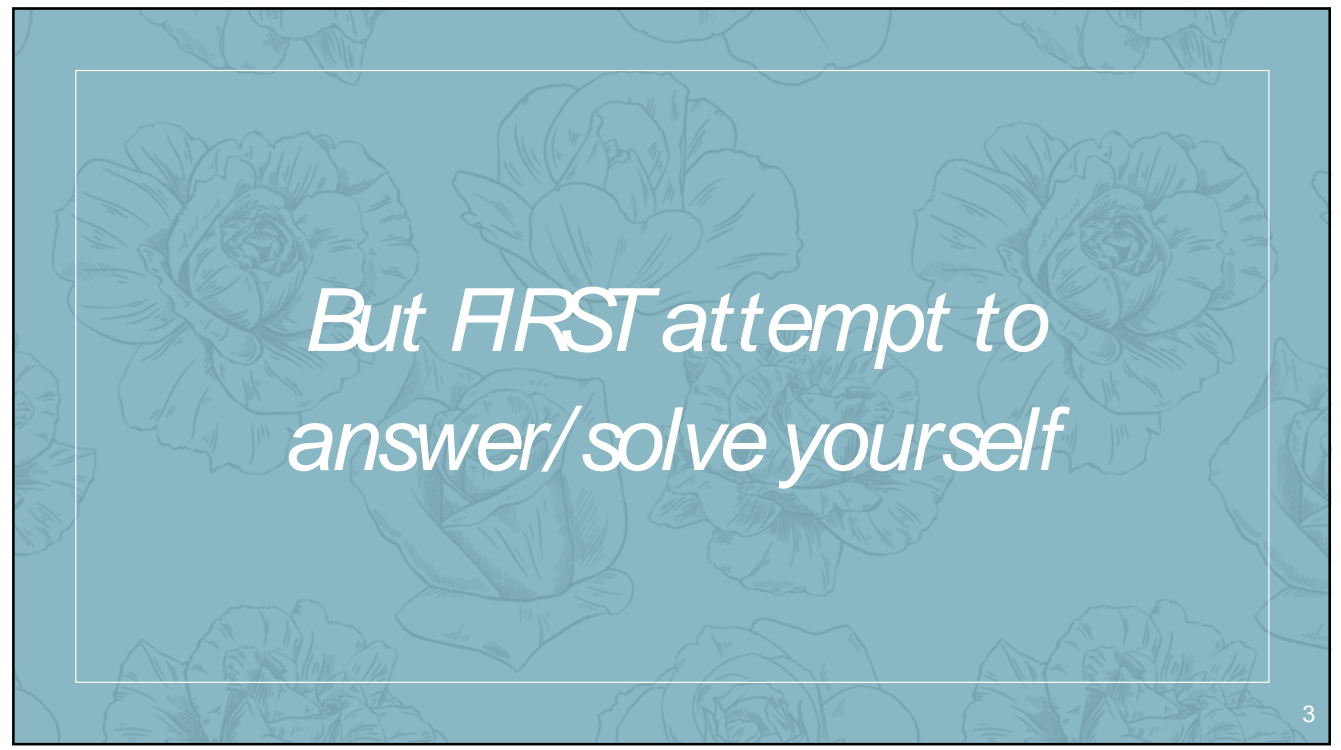

3

\section{Steps to take when you do not know the answer to a question}

1. Pelax

Take a deep breath and relax. Everything will be okay

4. Pe-read resources

Once you understand all parts of the question and have removed the extra "fluff" in the question, re-read the

resources now that you know exactly what the question is asking
2. Find resources and review

Find the correct resources required to answer the question (book, article, examples, lecture slides

5. Ask peer

If you still do not know the answer, then ask a peer for assistance. DO NOT UST ASKFORTHEANSWER Ask a peer to help you understand
3. Pe-read question

Some questions have "fluff" added or may contain words you do not know. This can make it difficult to understand what the question is really asking. So ignore the extra fluff and look up any words/phrases you do not understand.

6. Ask for help

If no one is able to understand the question and find the answer, then ask the professor for assistance in an appropriate way. 


\section{How to ask for help}

- Be considerate

- Ask specific questions

- Do not just ask for the answer

- Listen, do not interrupt

- Ask follow up questions if you still do not understand

- Respect the answer

\section{When to ask for help}

- Do not interrupt the class

- Raise your hand

- Approach the teacher/professor appropriately and politely

- Make an appointment if needed 


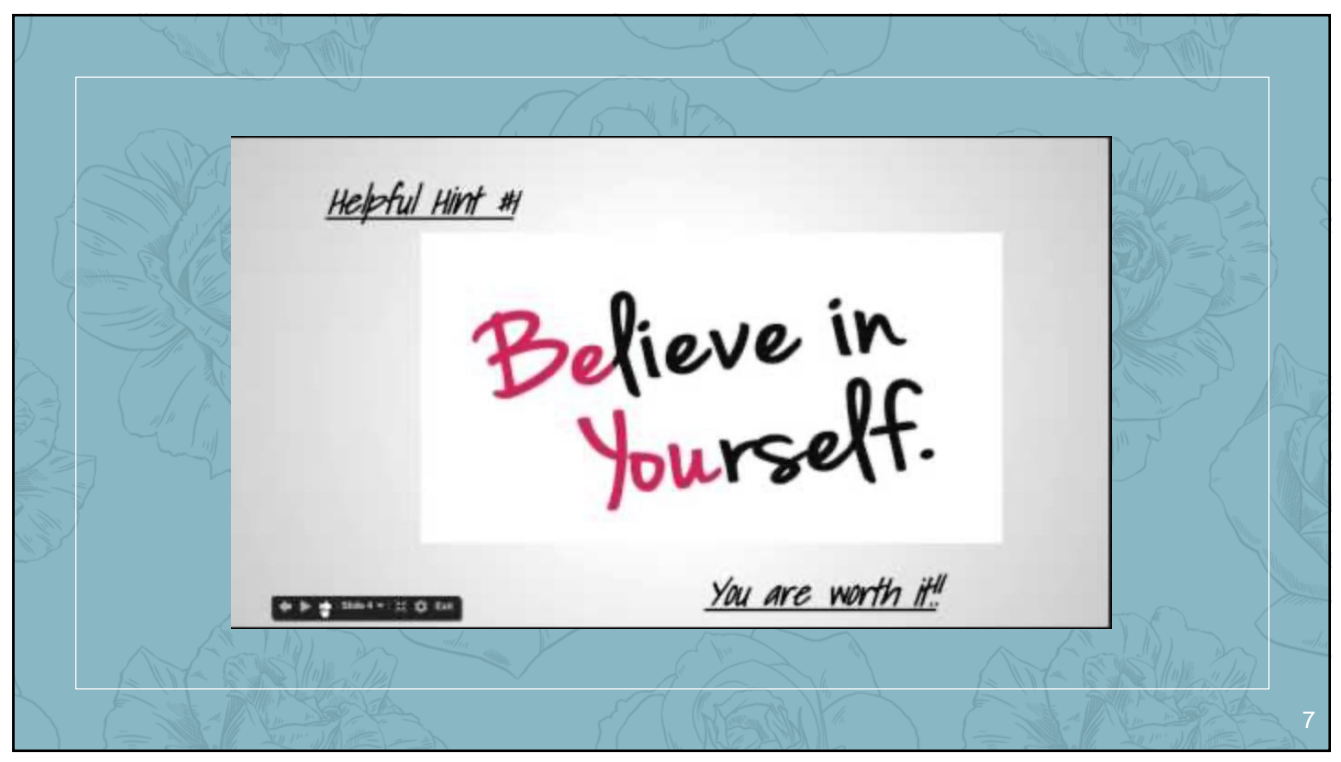

7

Cody is working on a history assignment in the library after class but is having a hard time completing question 4 . He is unsure what the question is asking and does not know how to approach the question to get the answer. Cody wants to ask the professor for help. His next history class isn't for 2 more days and the assignment is due in 4 days. How can Cody advocate for himself in a mature, socially acceptable way? (One student is Cody, the other student is professor). 


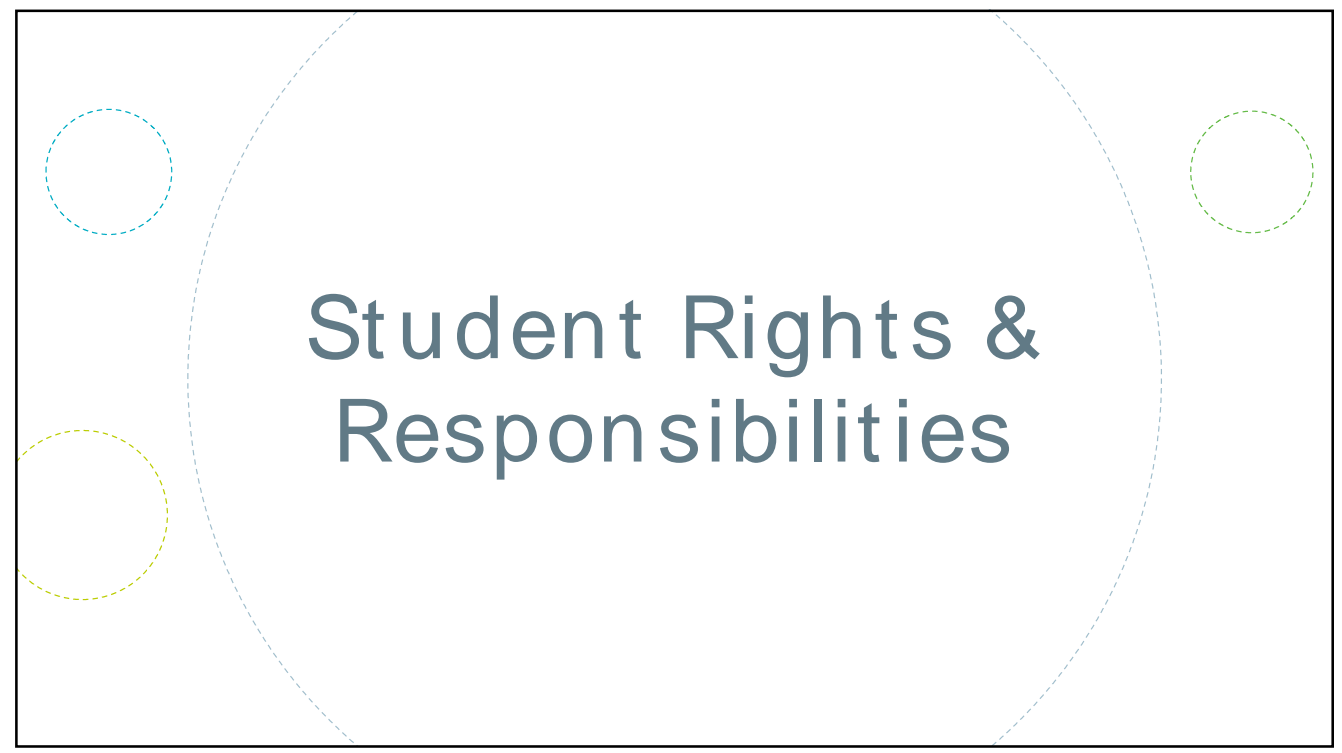

1

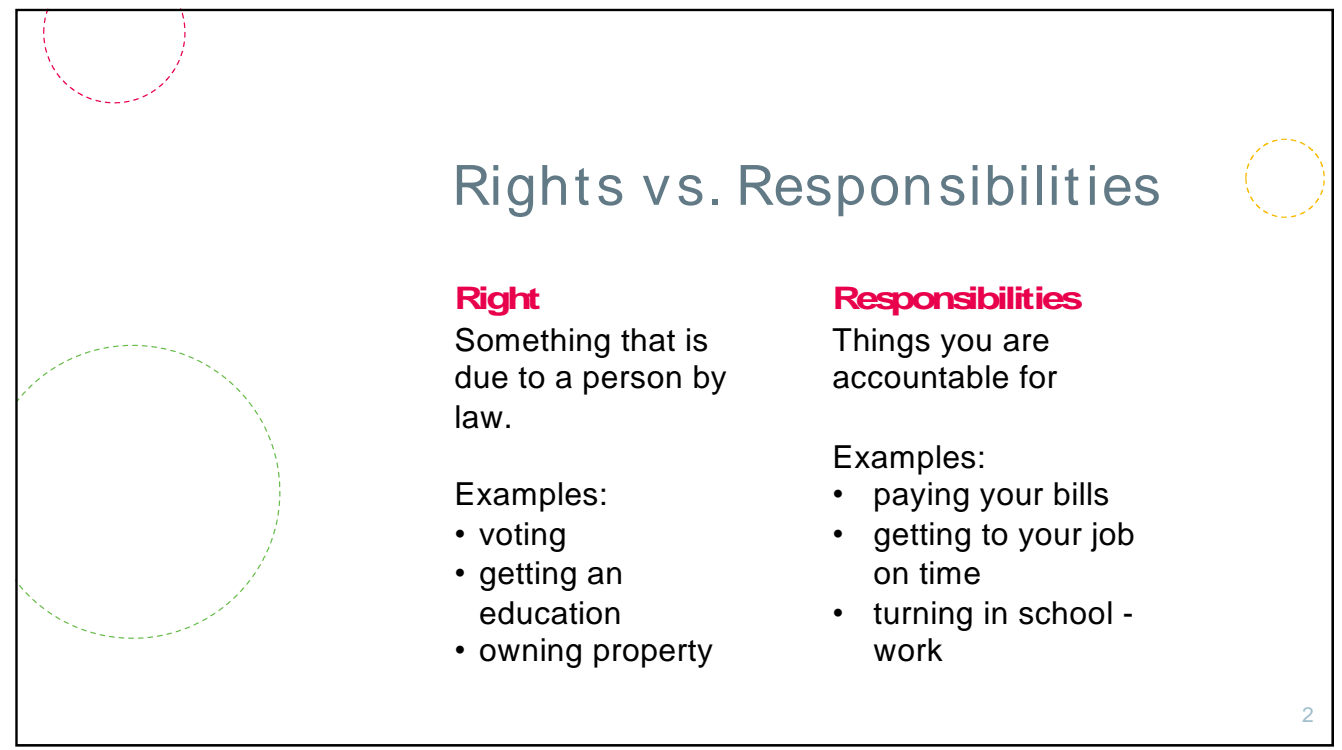

2 


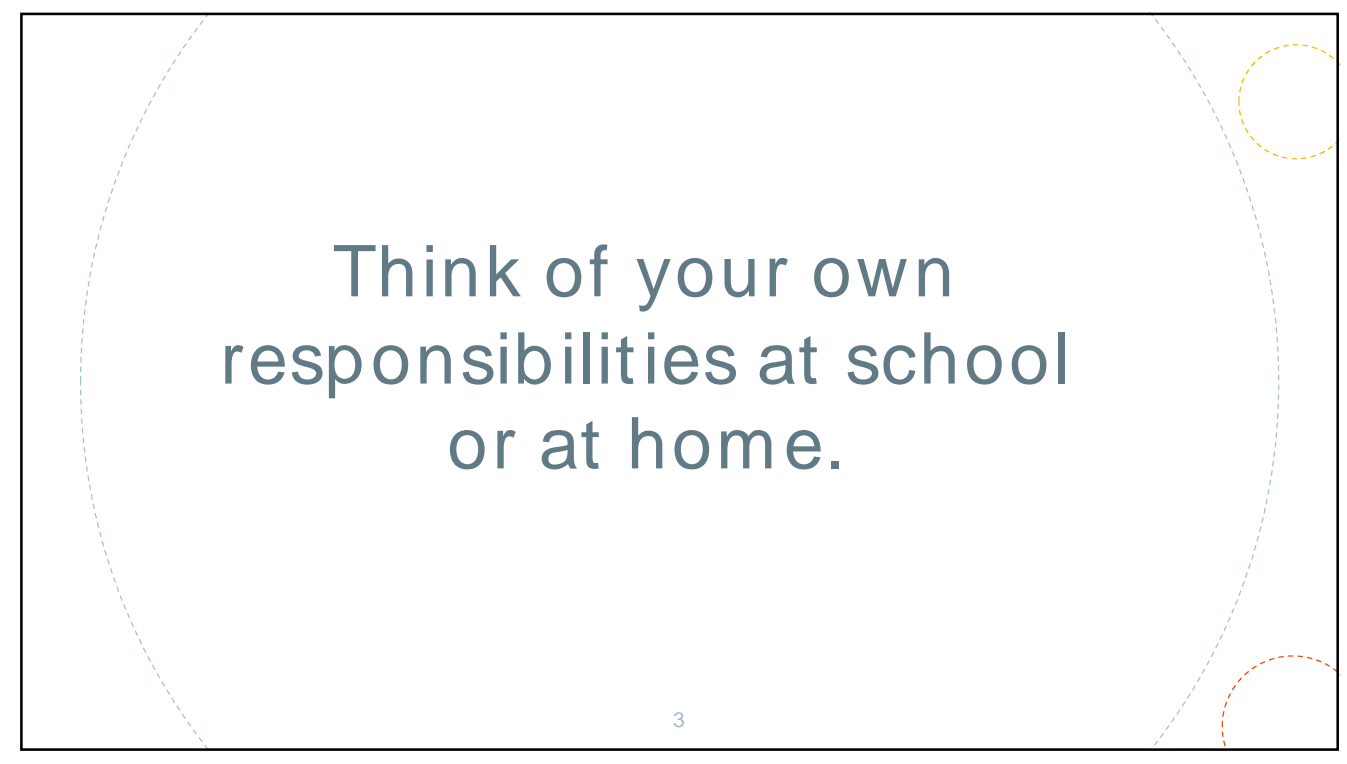

3

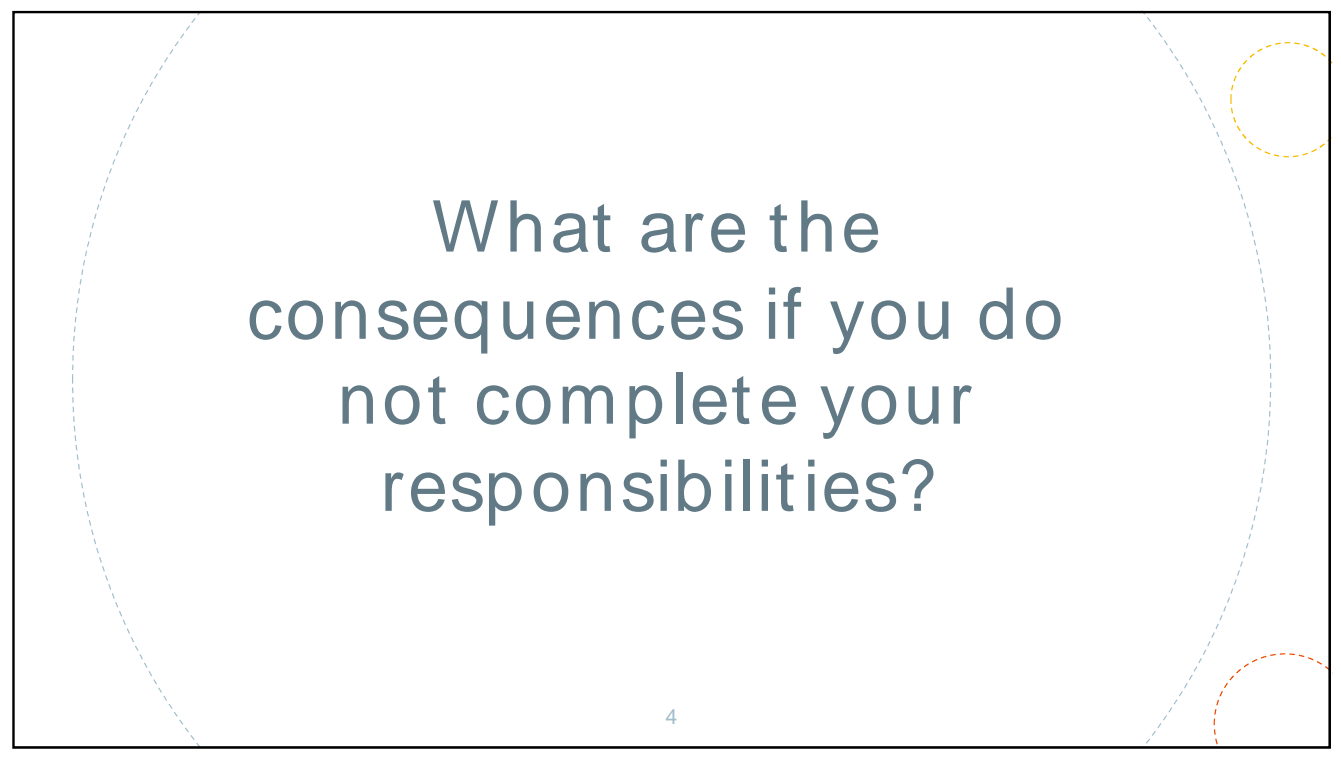

4 


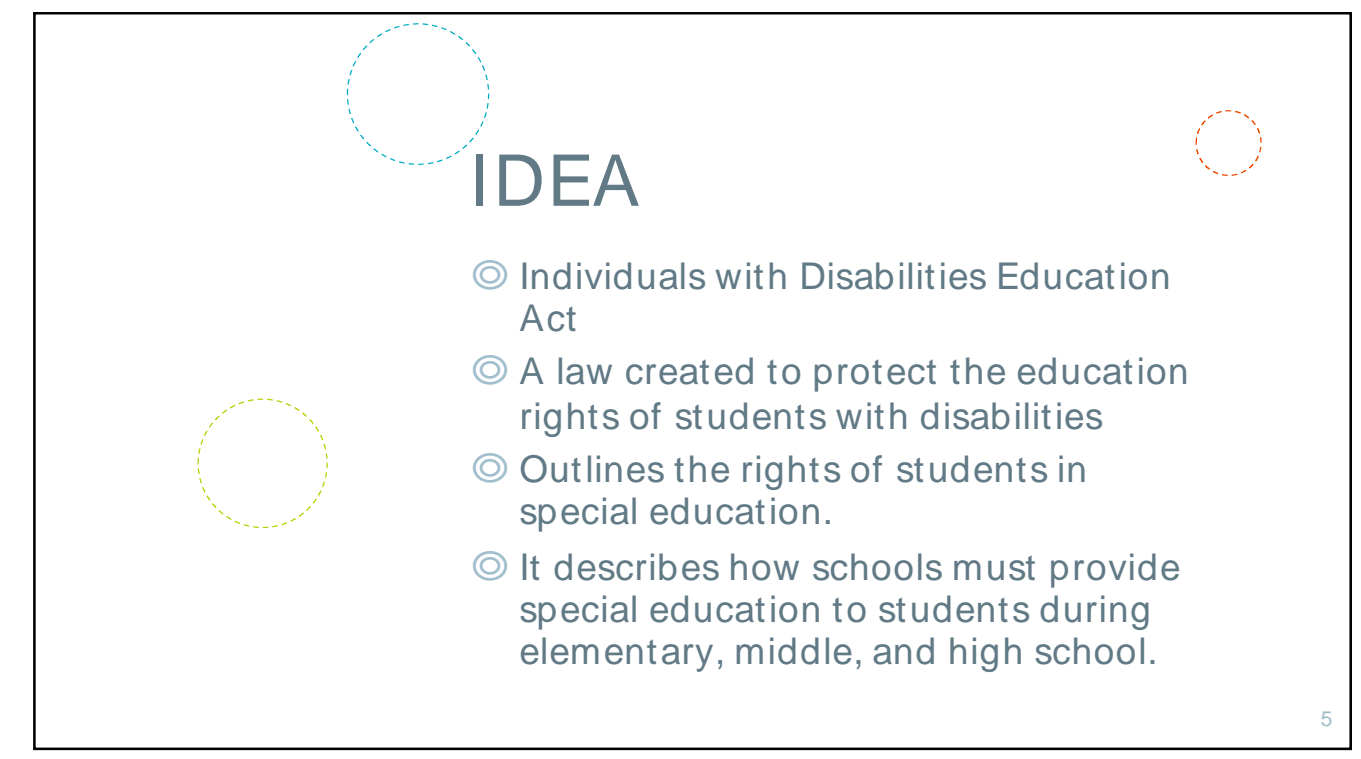

5

\section{IDEA}

(a) There are four things in the IDEA that are especially important for you to understand while you are in high school.

() Those things include

O FAPE

Child Find

O Accommodations

() Modifications. 

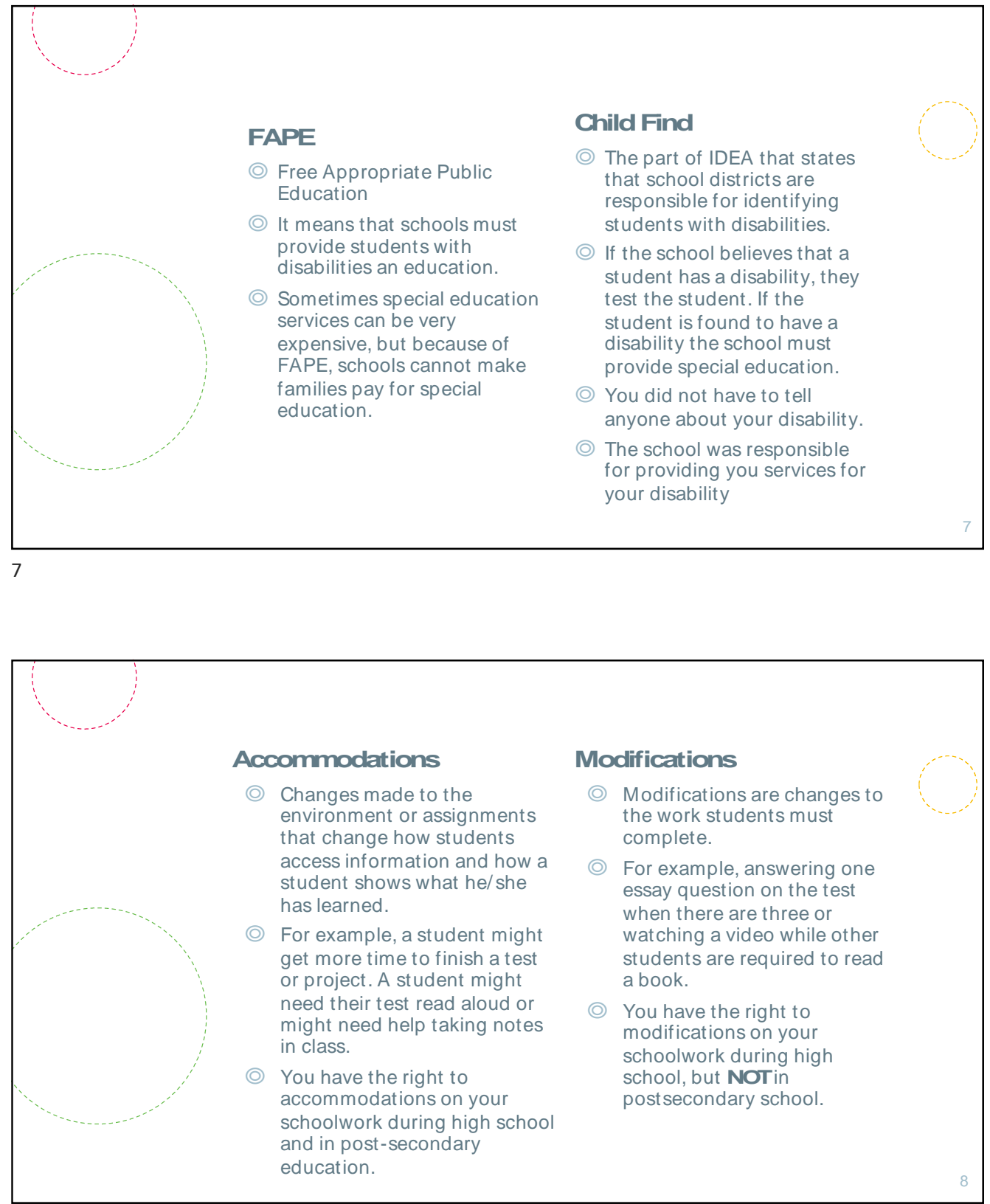


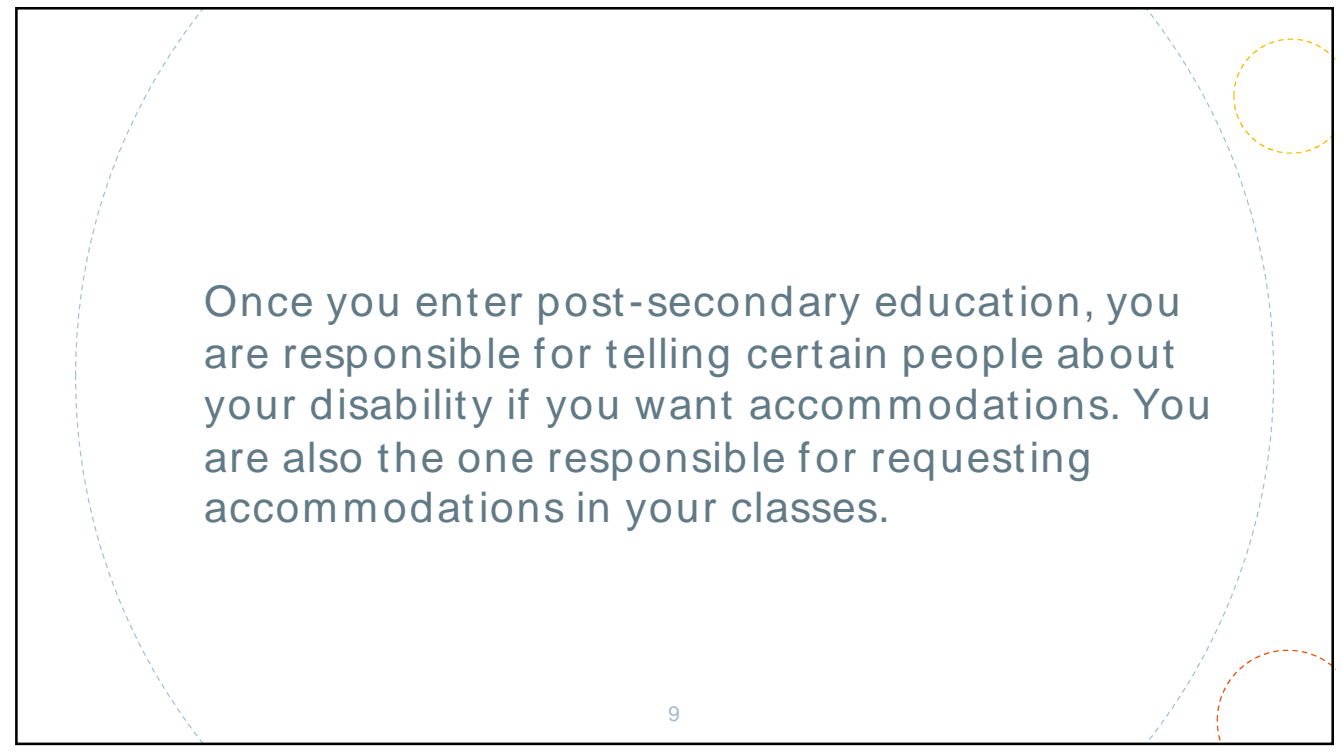

9

\section{Section 504}

(a) In Rehabilitation Act of 1973

(2) Anti-discrimination law

(a) That means that schools cannot discriminate against students for having a disability.

(a) Schools must provide students with disabilities access to education.

(2) Access can mean things such as ramps by the doors so a student using a wheelchair can get into the building or it can mean access to assignments.

Access $=$ Accommodations 


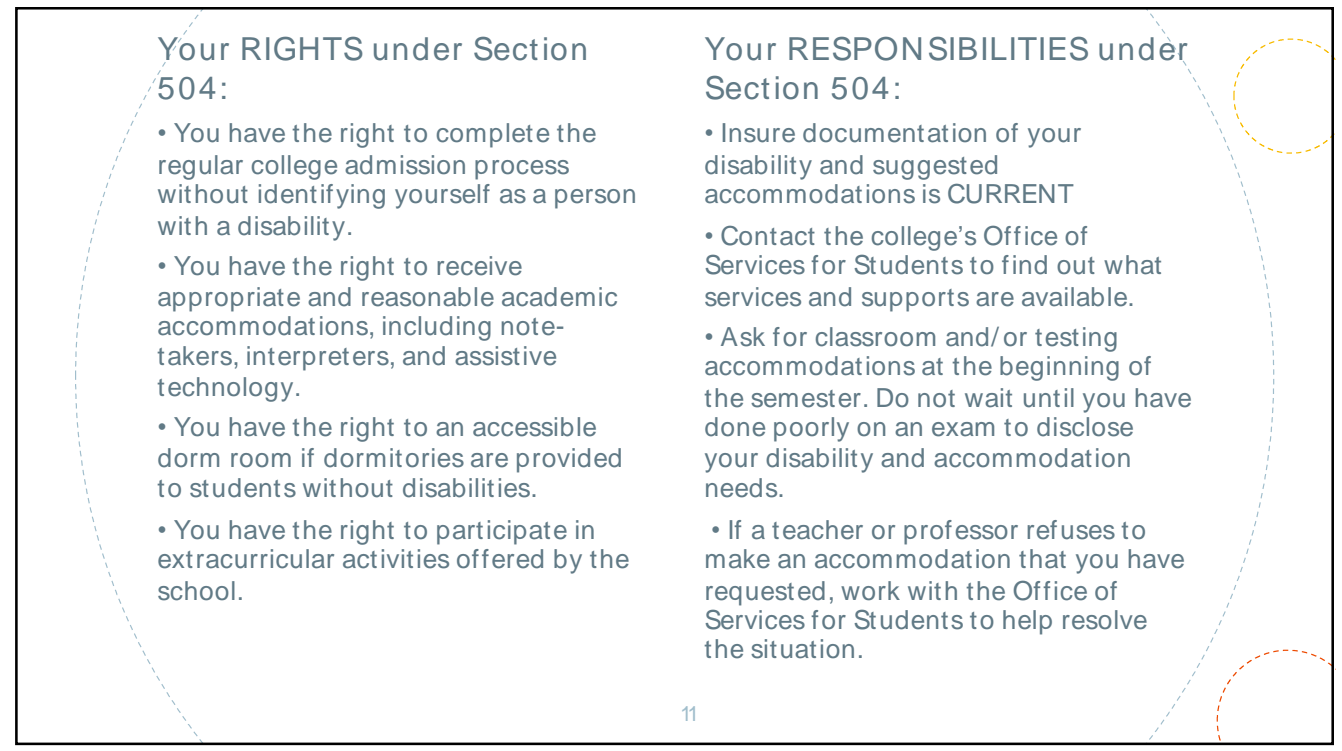

11
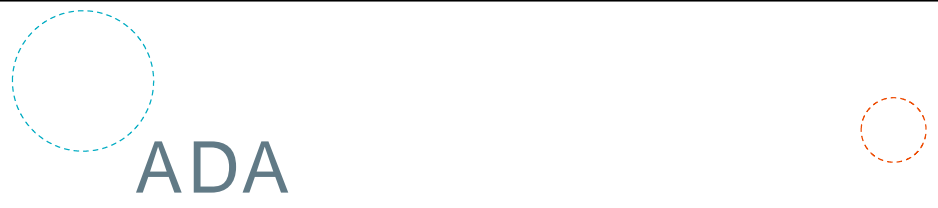

(2) American with Disabilities Act

(2) ADA is a civil rights law that protects people with disabilities by requiring places to be accessible to people with disabilities.

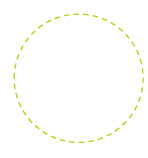

(a) ADA is different than Section 504 because it applies to more places, such as transportation (public buses), telecommunication, as well as schools.

(a) Both Section 504 and ADA are antidiscrimination laws that focus on access. 


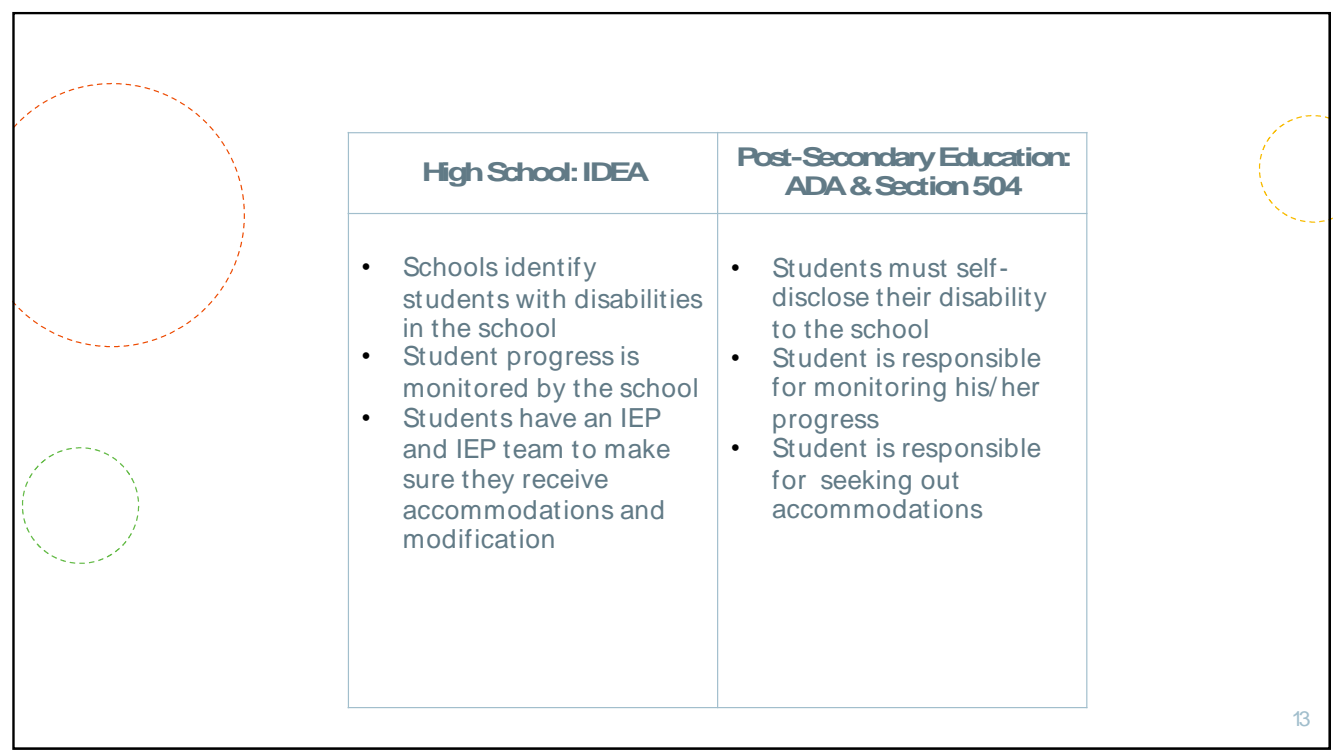




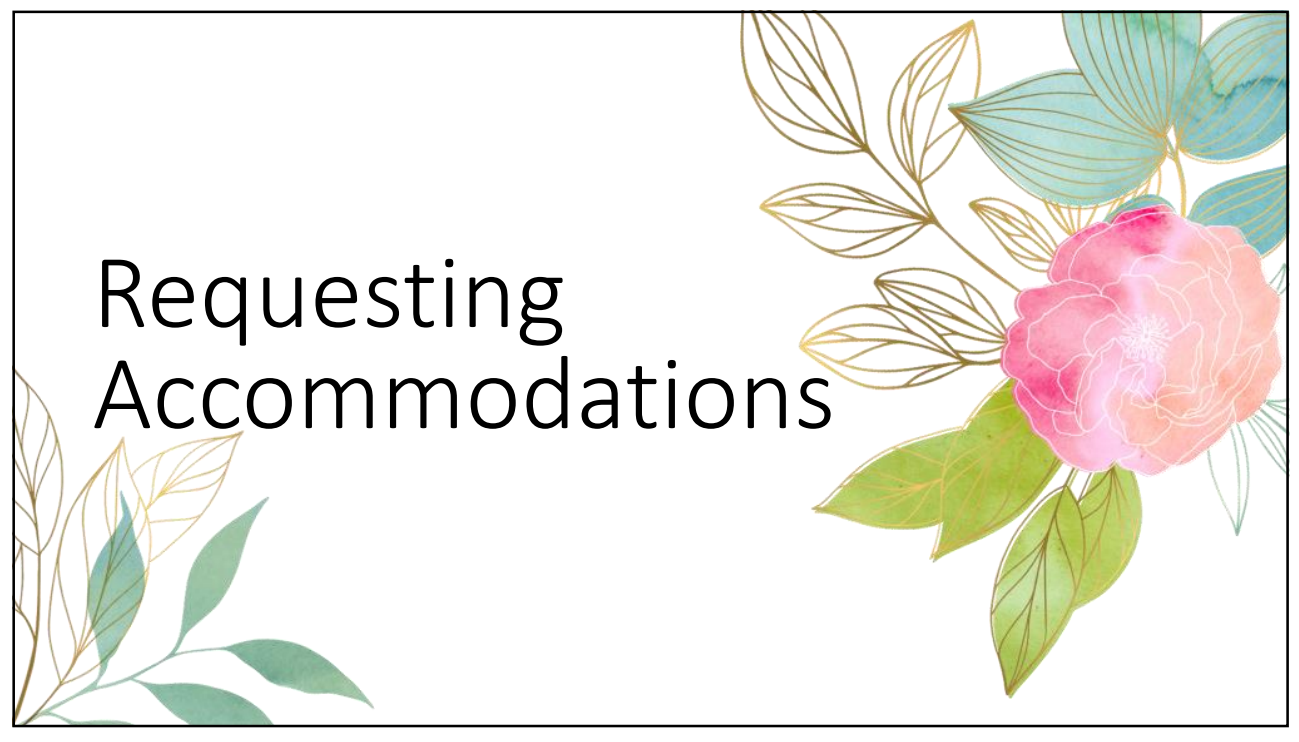

1

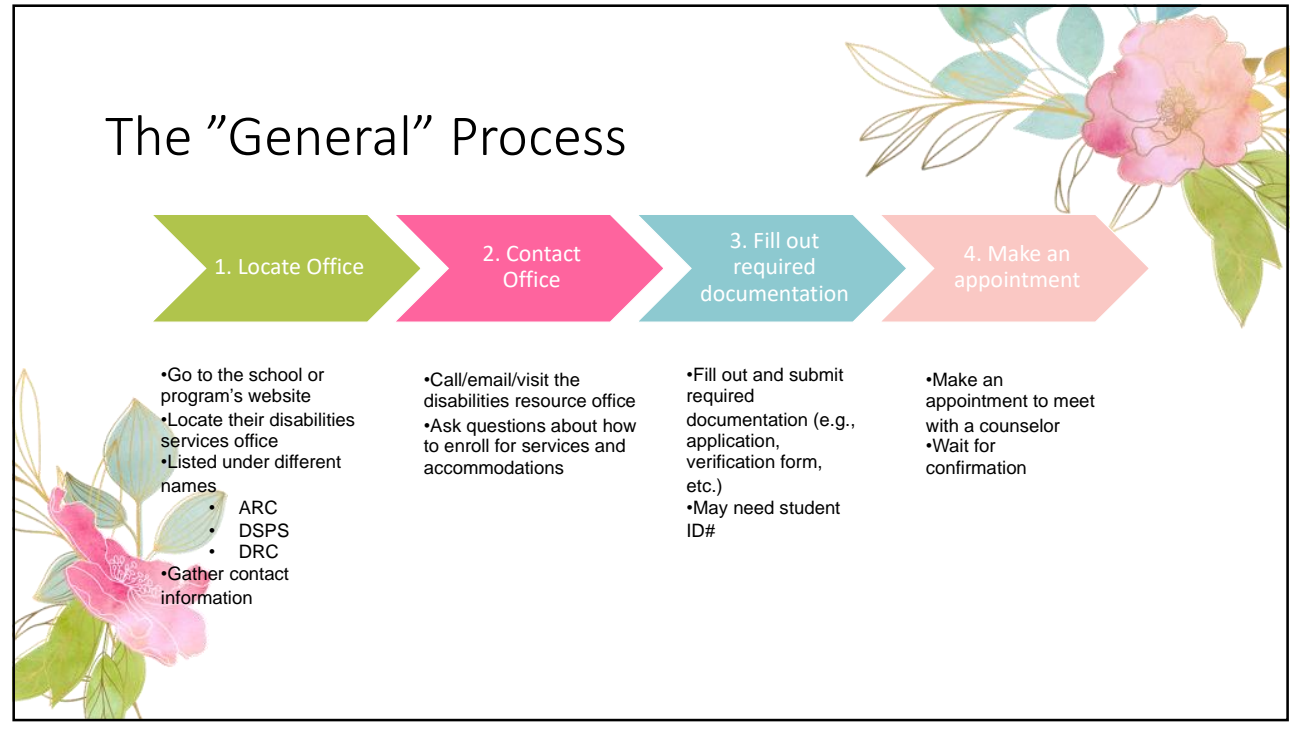

2 


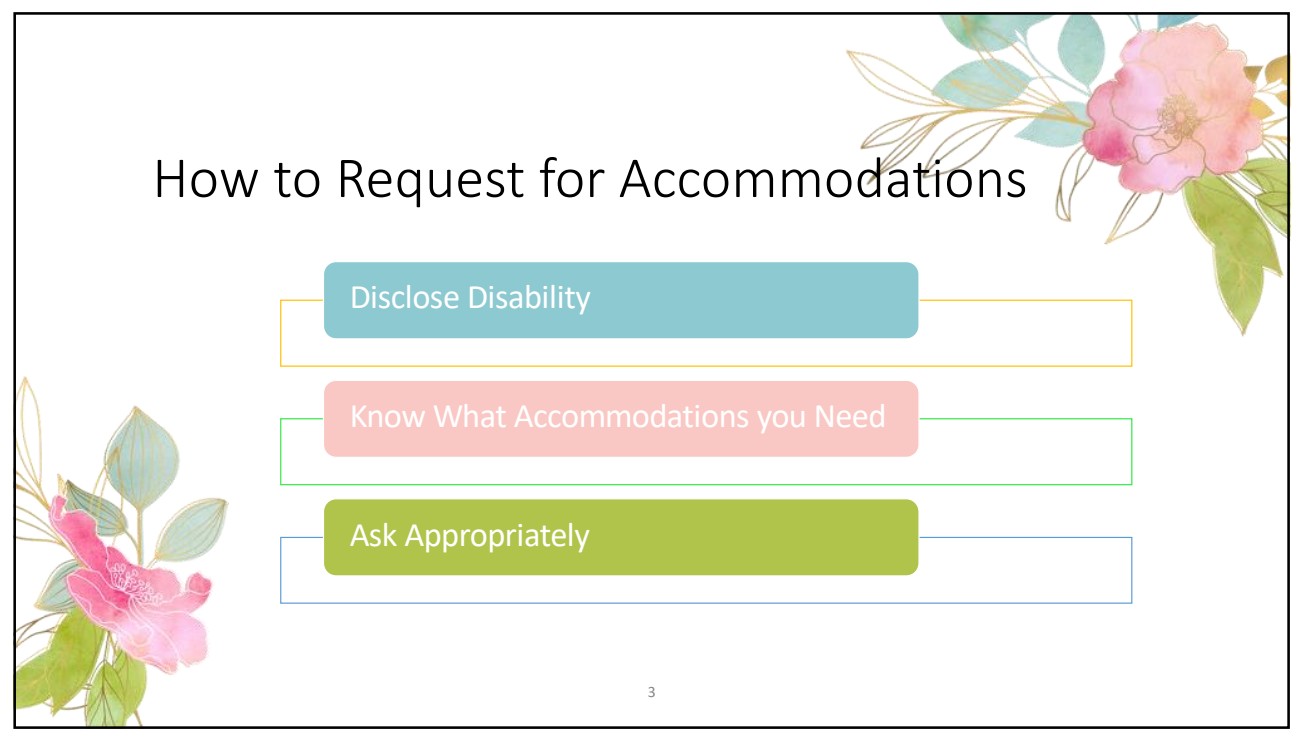

3

\section{Disclose Disability}

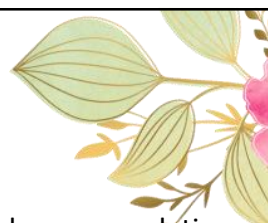

Need to disclose disability to receive needed accommodations to both disability service office as well as your professors

- Disclosure means that people with disabilities share personal information about their disability for the specific purpose of receiving accommodations

Evidence shows that one of the main reasons why students with disabilities do not receive support services is because they are unwilling to disclose that they have a disability. 


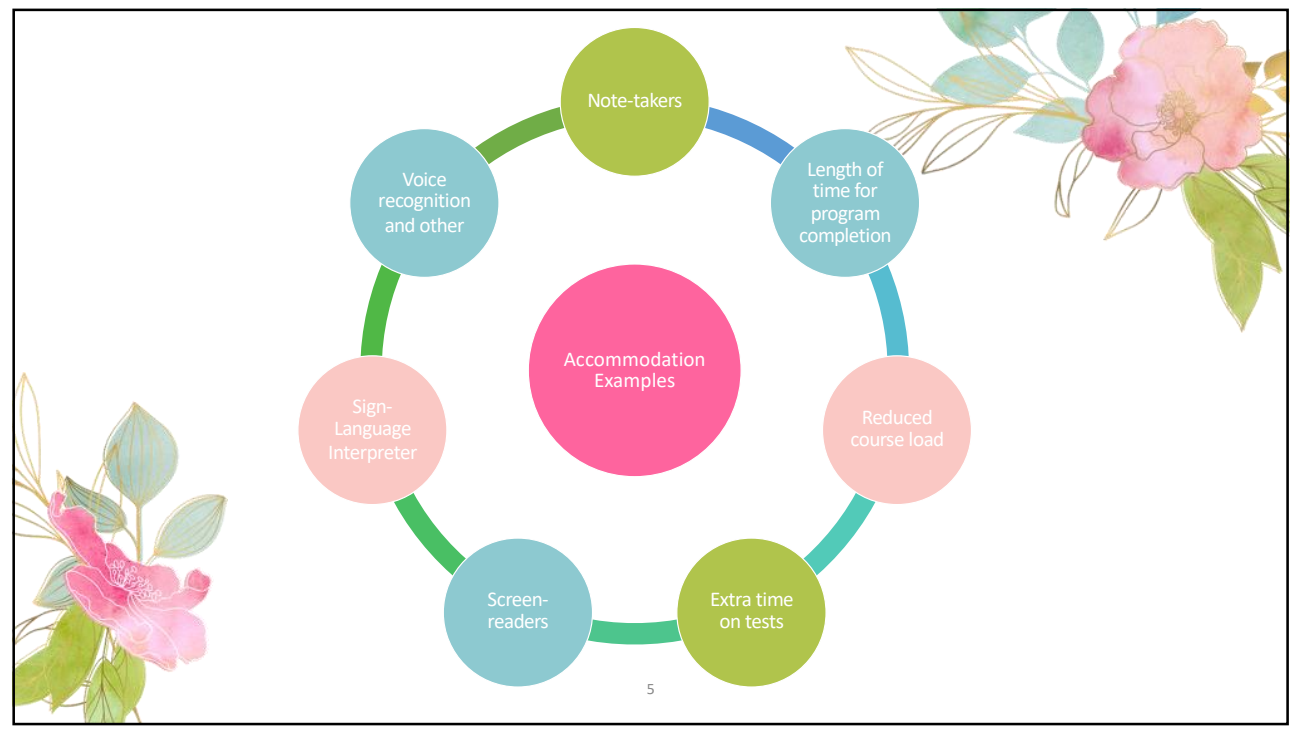

5

Asking Appropriately
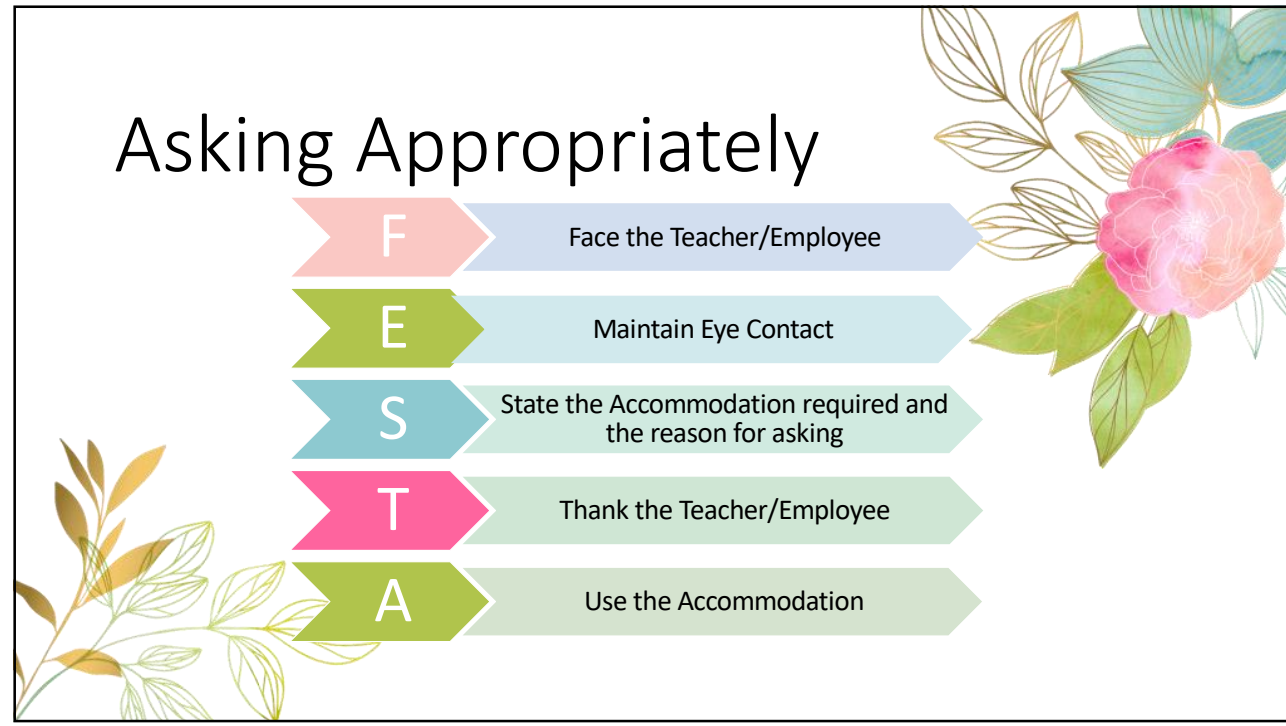

6 

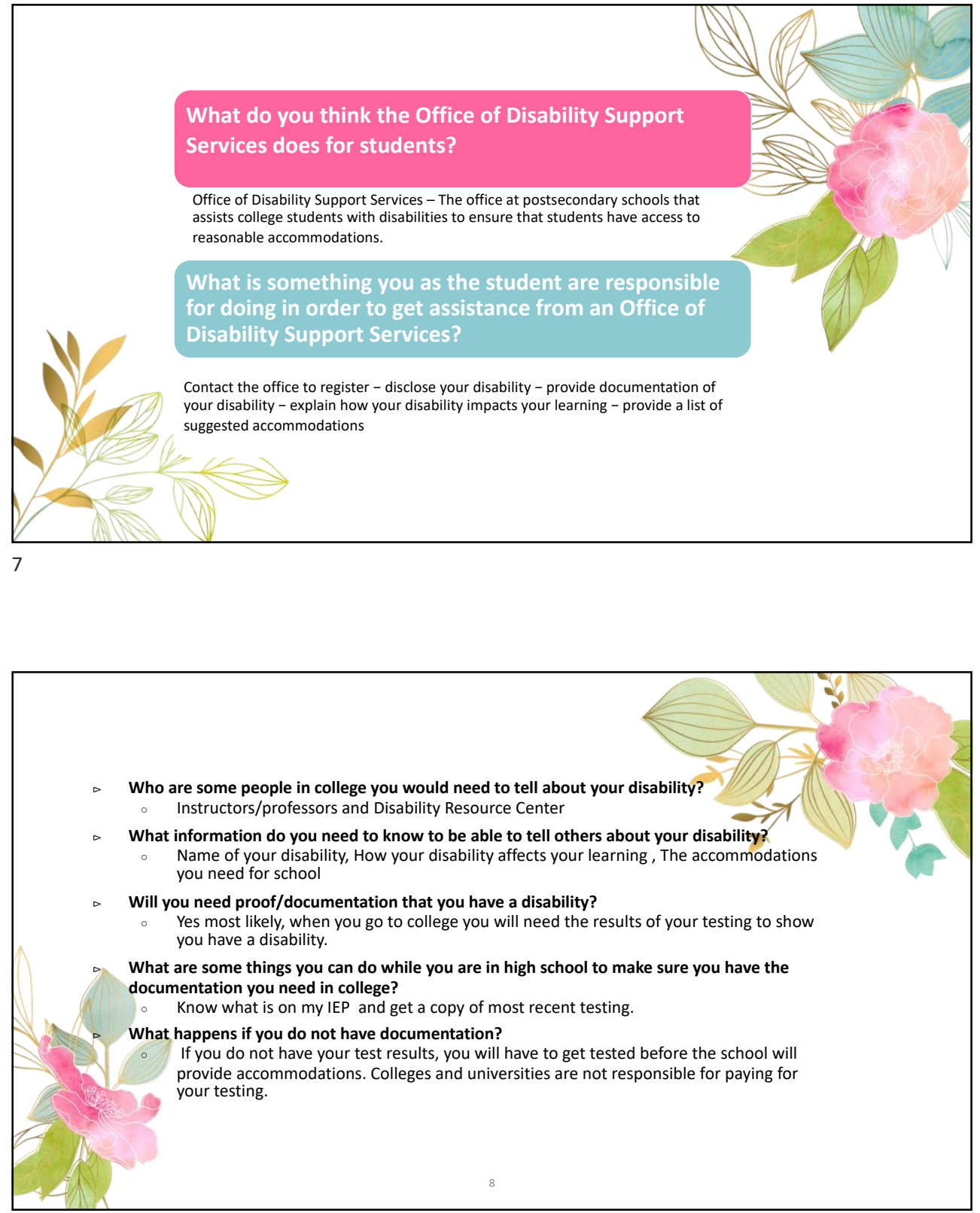

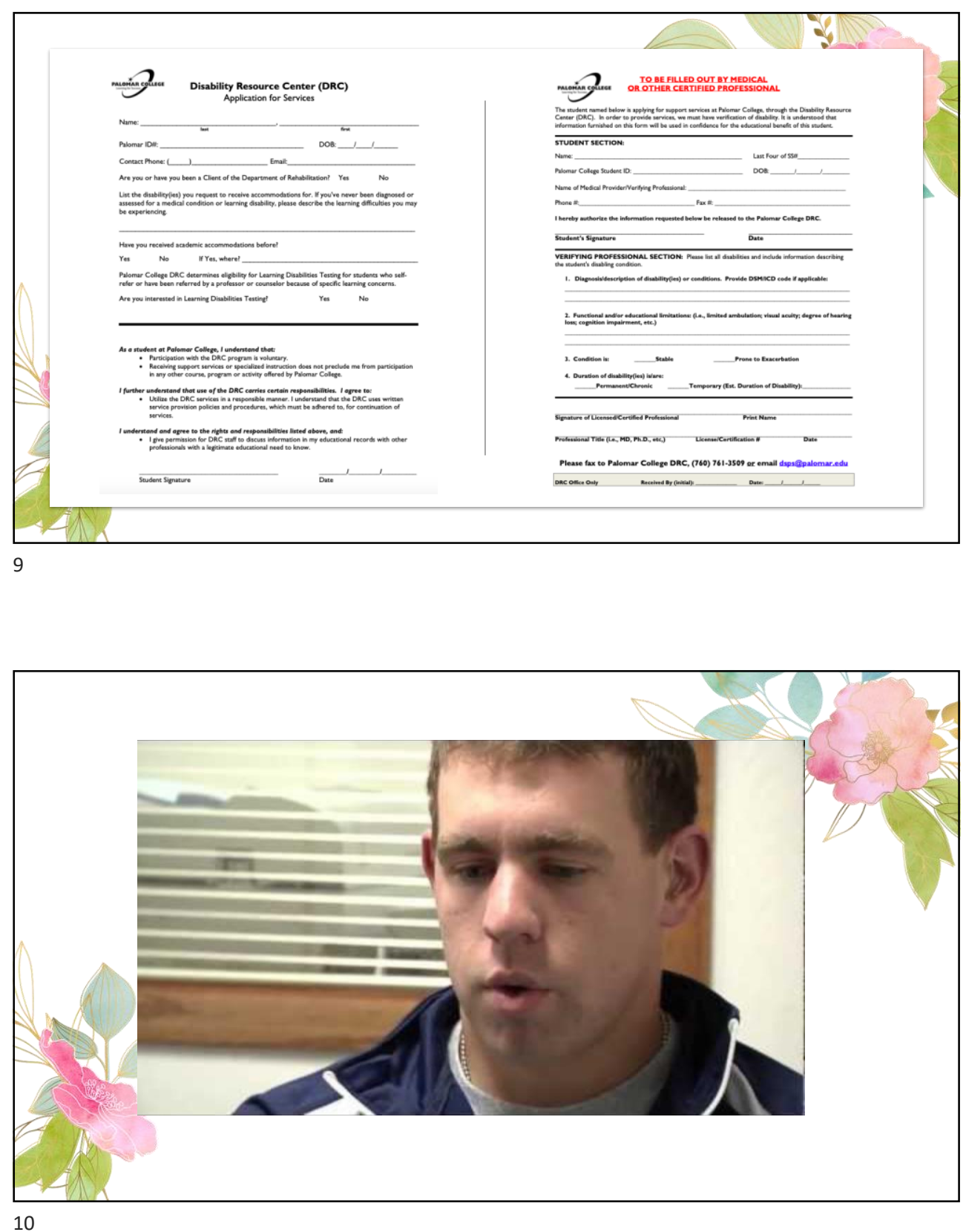


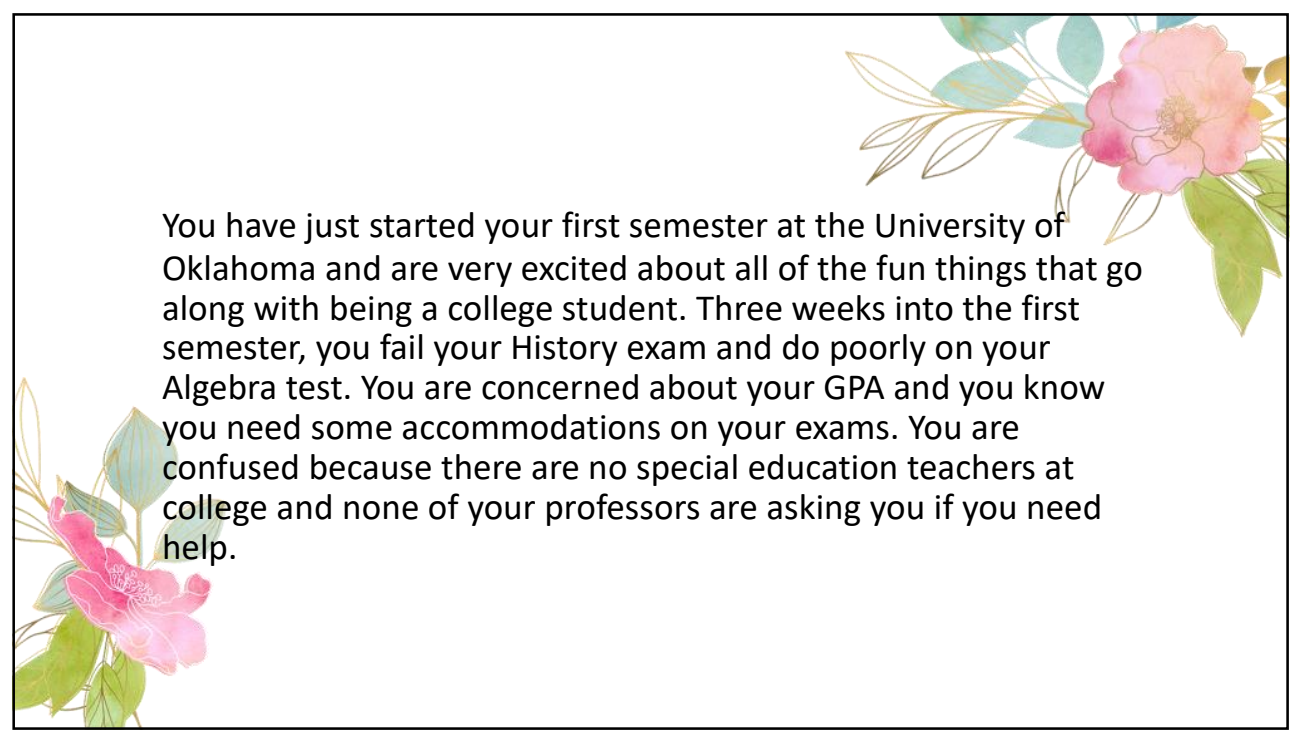

11

\section{Role Play Activity}

You have a learning disability that makes you process information slower. Due to this, taking exams and writing notes during lectures are difficult. You researched which accommodations would work best for your learning style and found that you need extra time on exams and need a note taker or to be able to record the class lecture. You need to speak to disability services first and then with your professor in order to receive those accommodations.
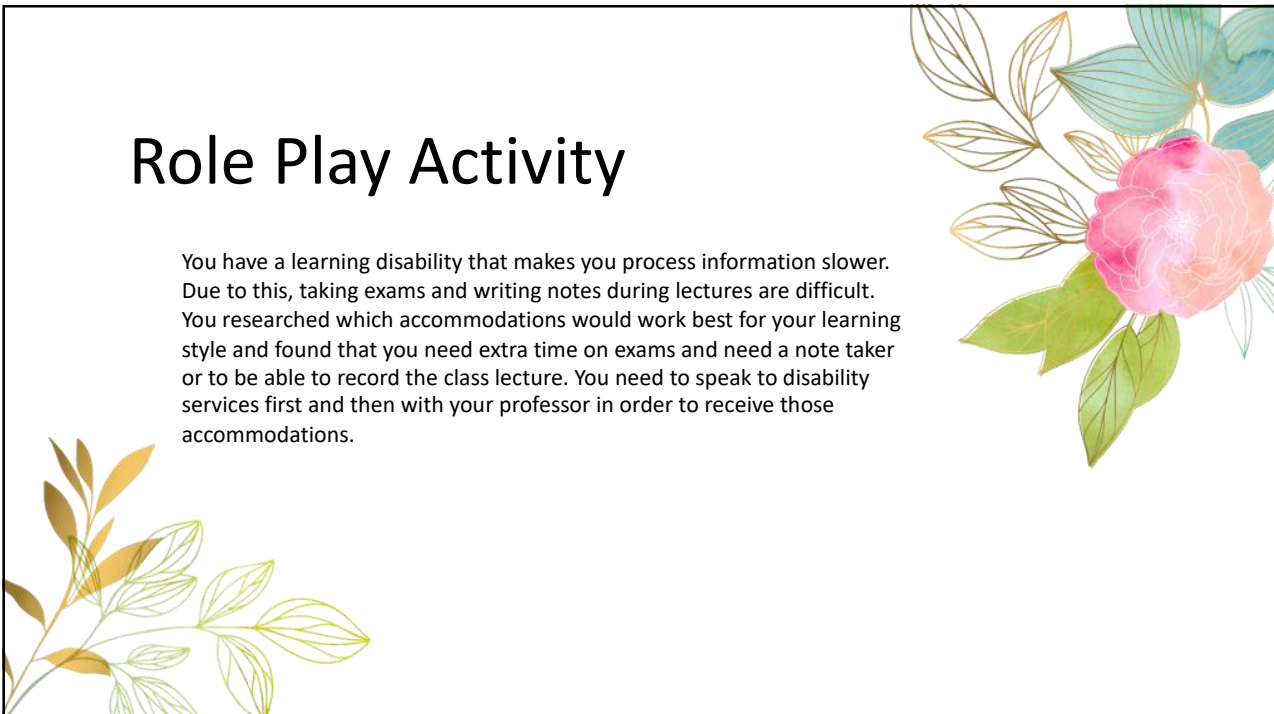


\section{Appendix F \\ Lesson Plans $8^{\text {th }}$ Graders}

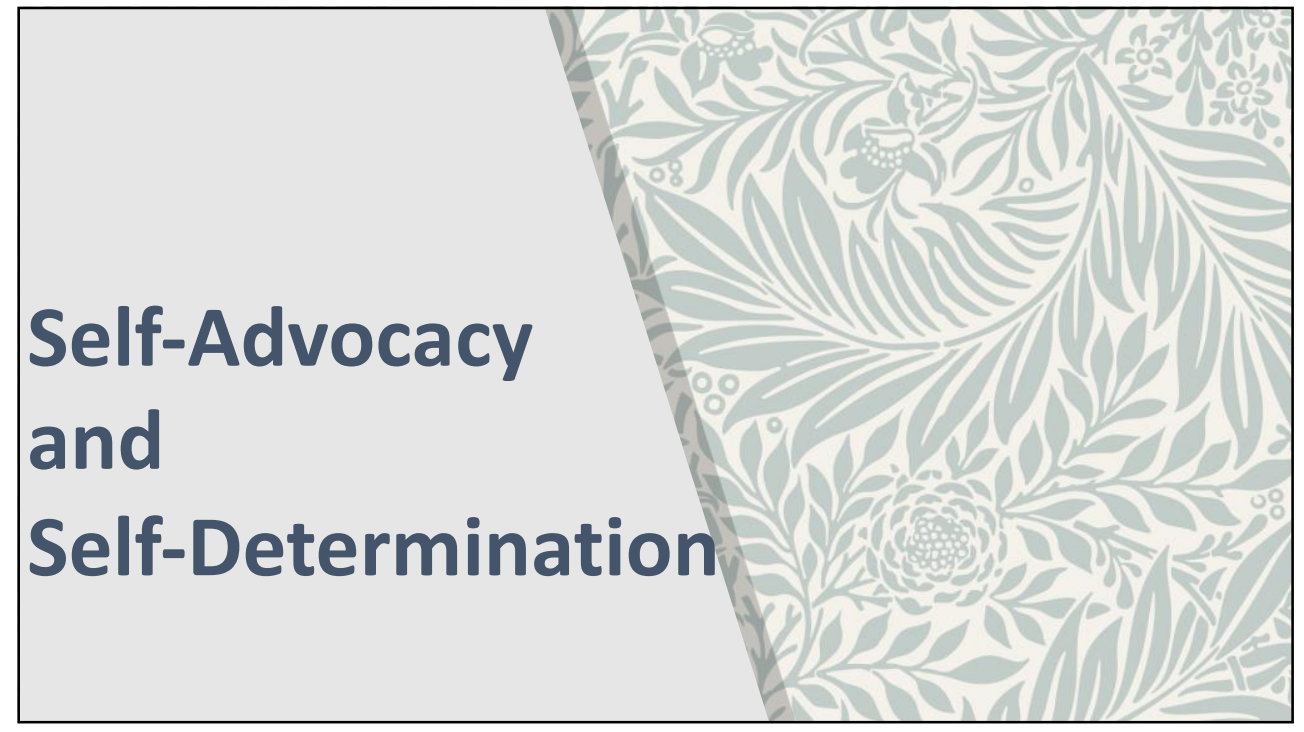

1

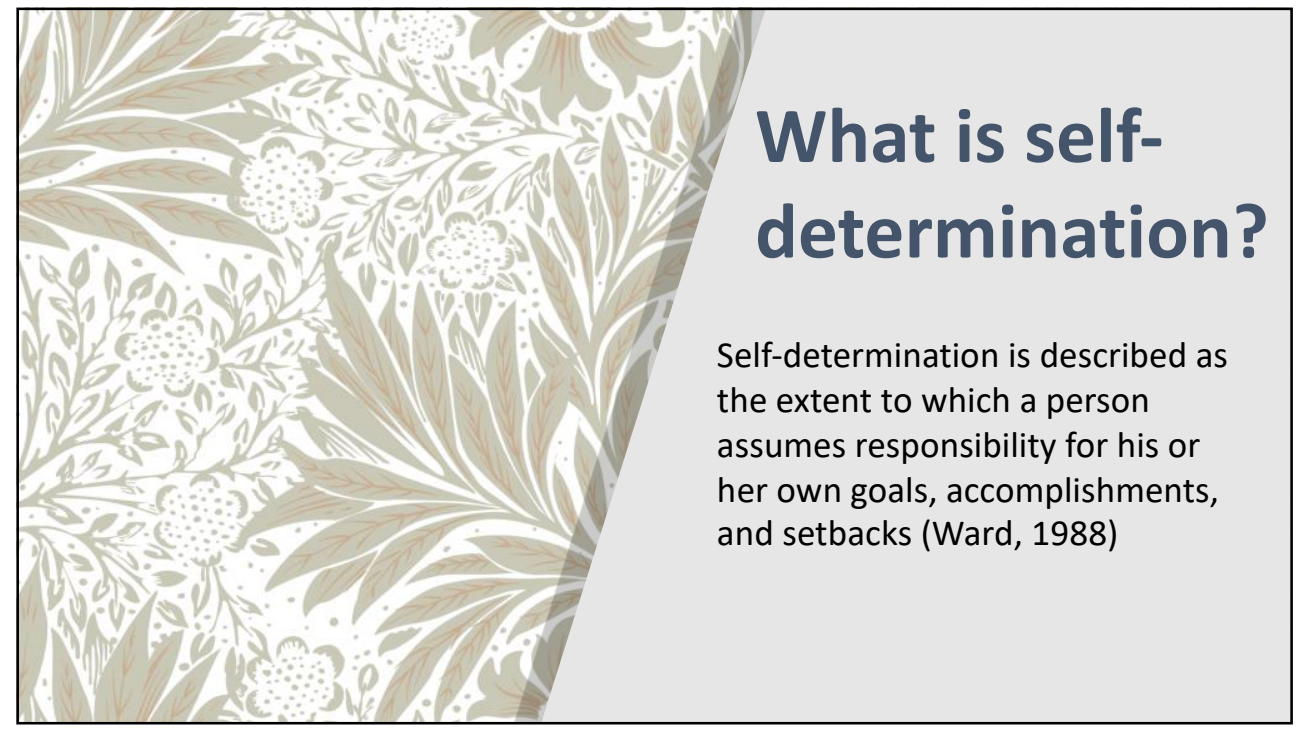




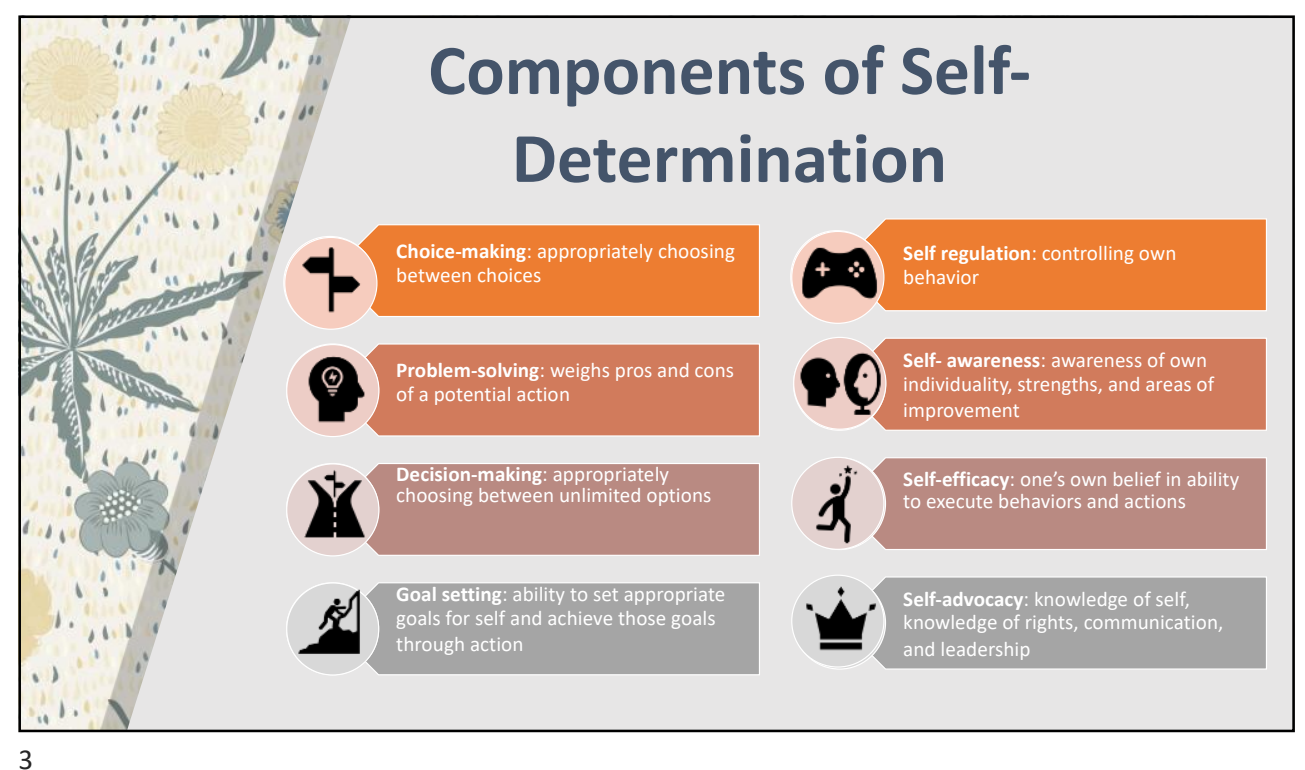

Self-advocacy is defined as the ability to speak on one's behalf and represent personal needs and interests (Kotzer and Margalit, 2007).

What is selfadvocacy?

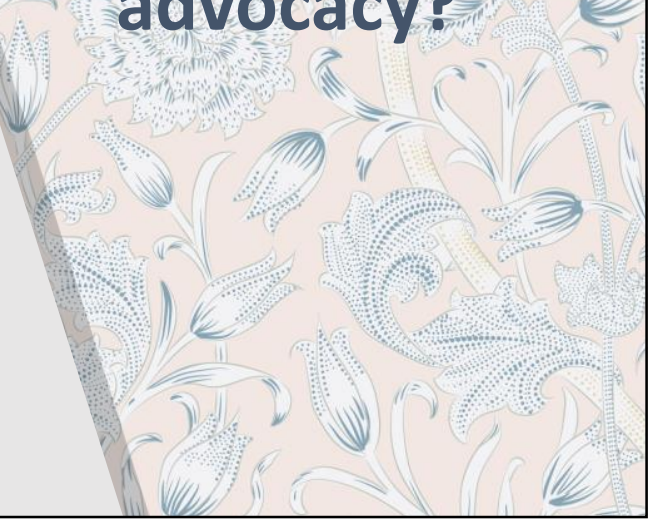




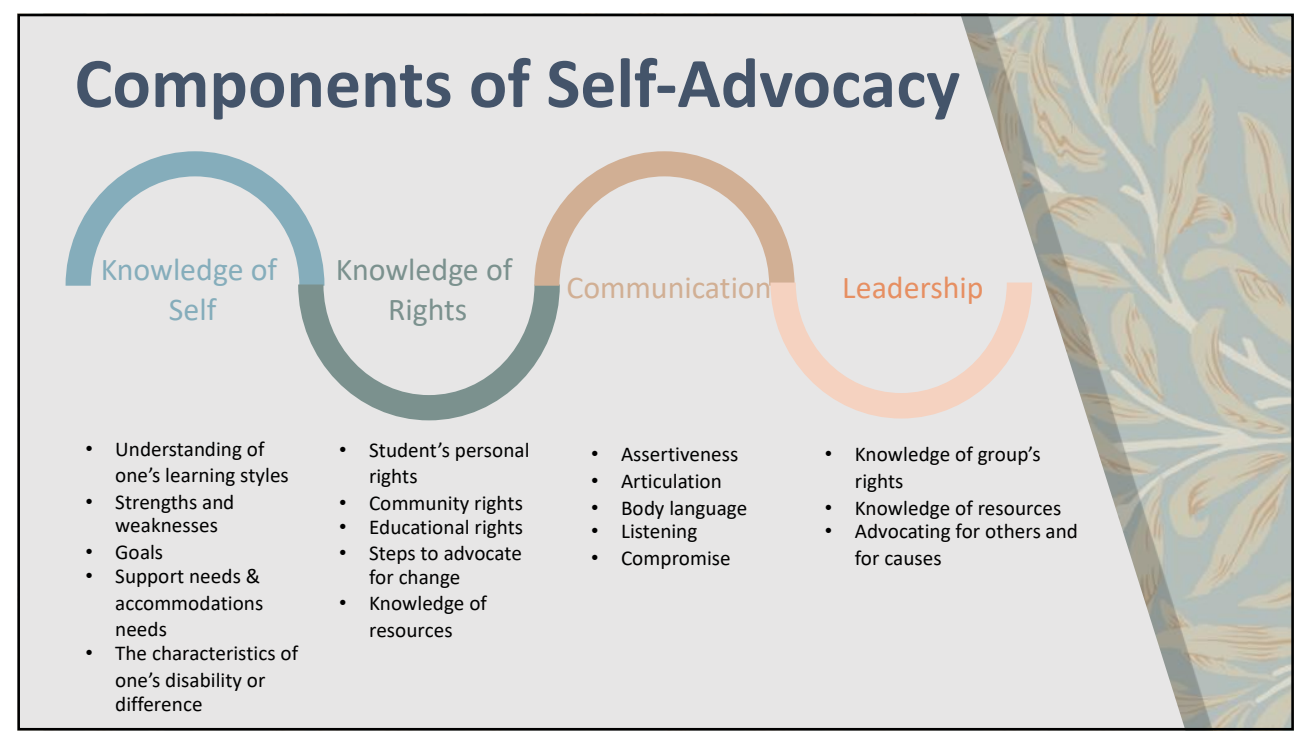

5

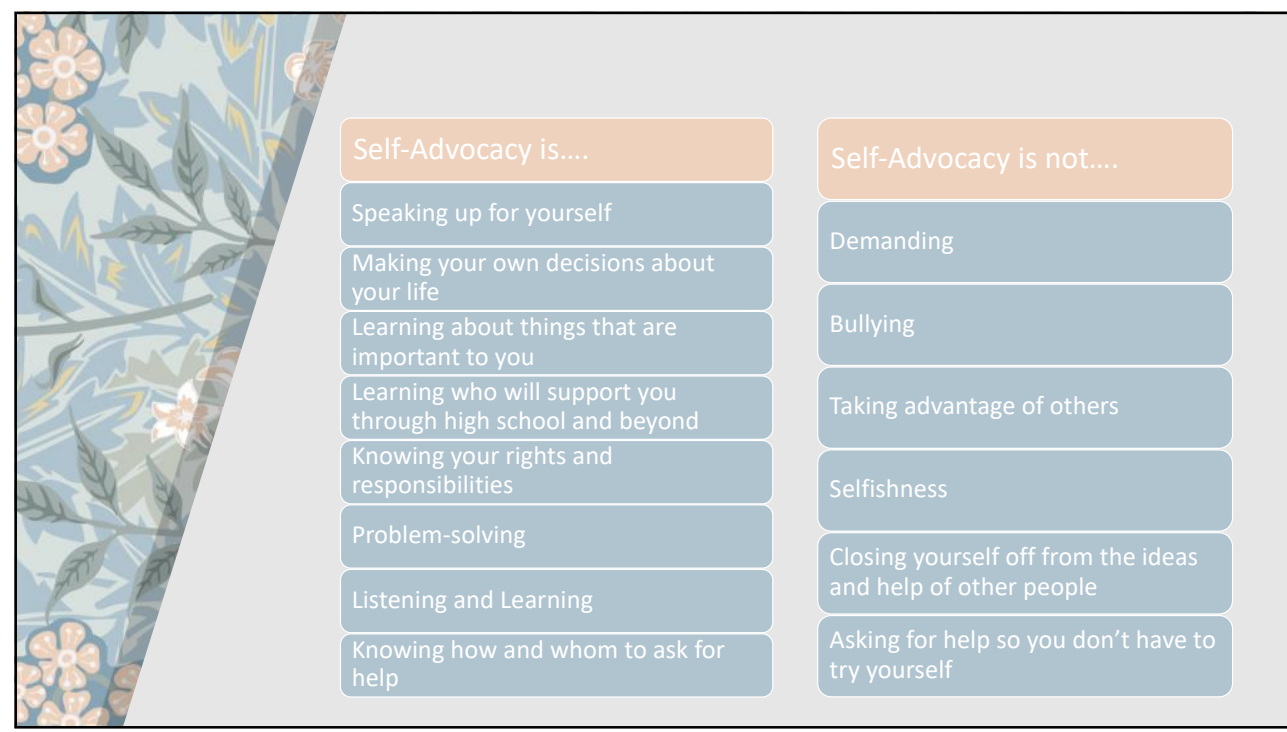




\section{Benefits of Self-Advocacy and Self-Determination Skills}

\section{Increase problem solving skills}

Improve self-confidence

Feeling of control over choices and life

Increase independence

Self-empowerment

Health \& Wellness

7

Not only will these skills help you with postsecondary education, but it will also help with general adulthood as well...

Such as:

- Choosing a college

- Requesting needed accommodations

- Choosing a job

- Asking for a raise

- Choosing a hobby 


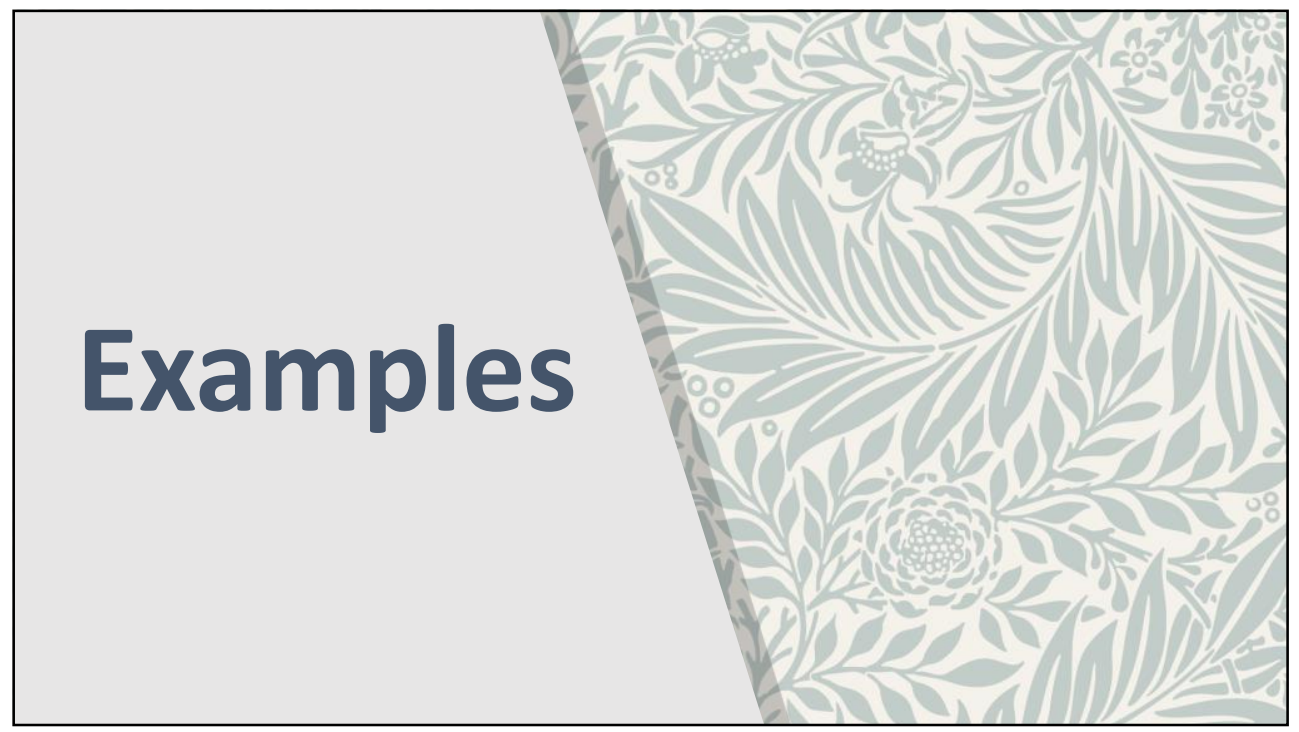

9

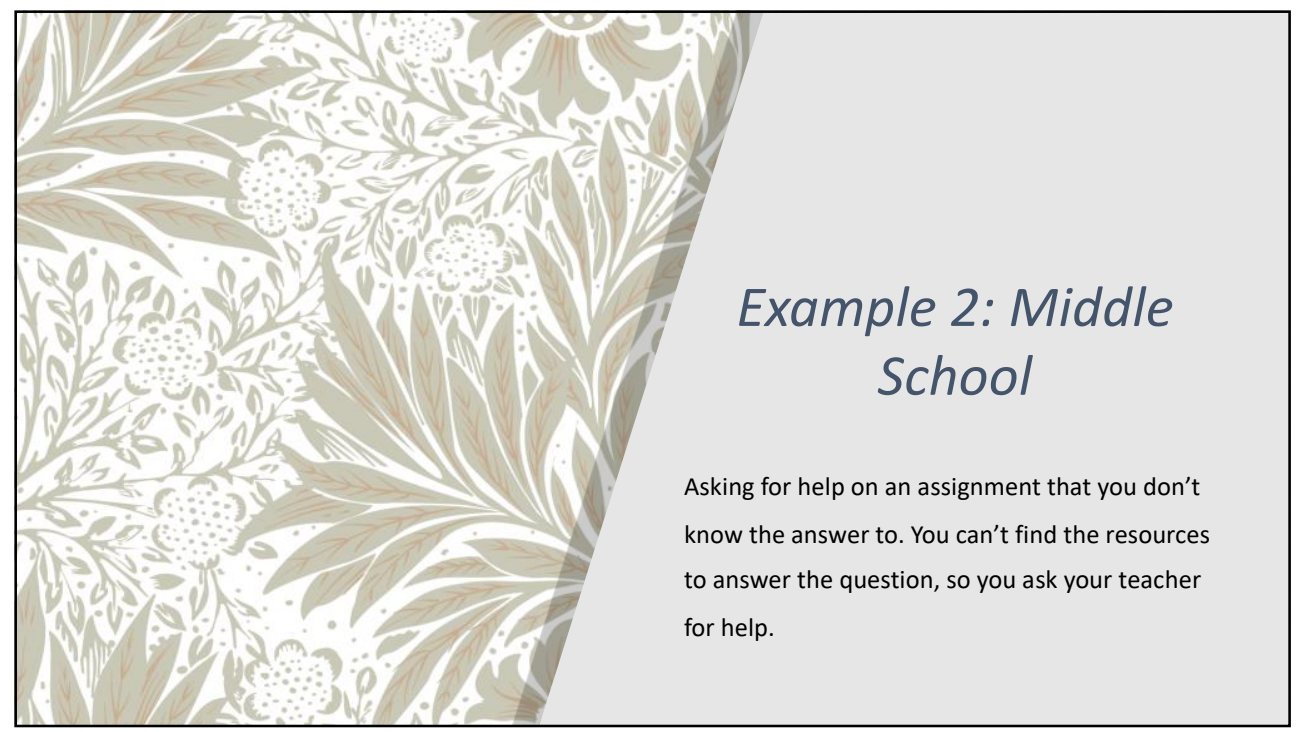

10 


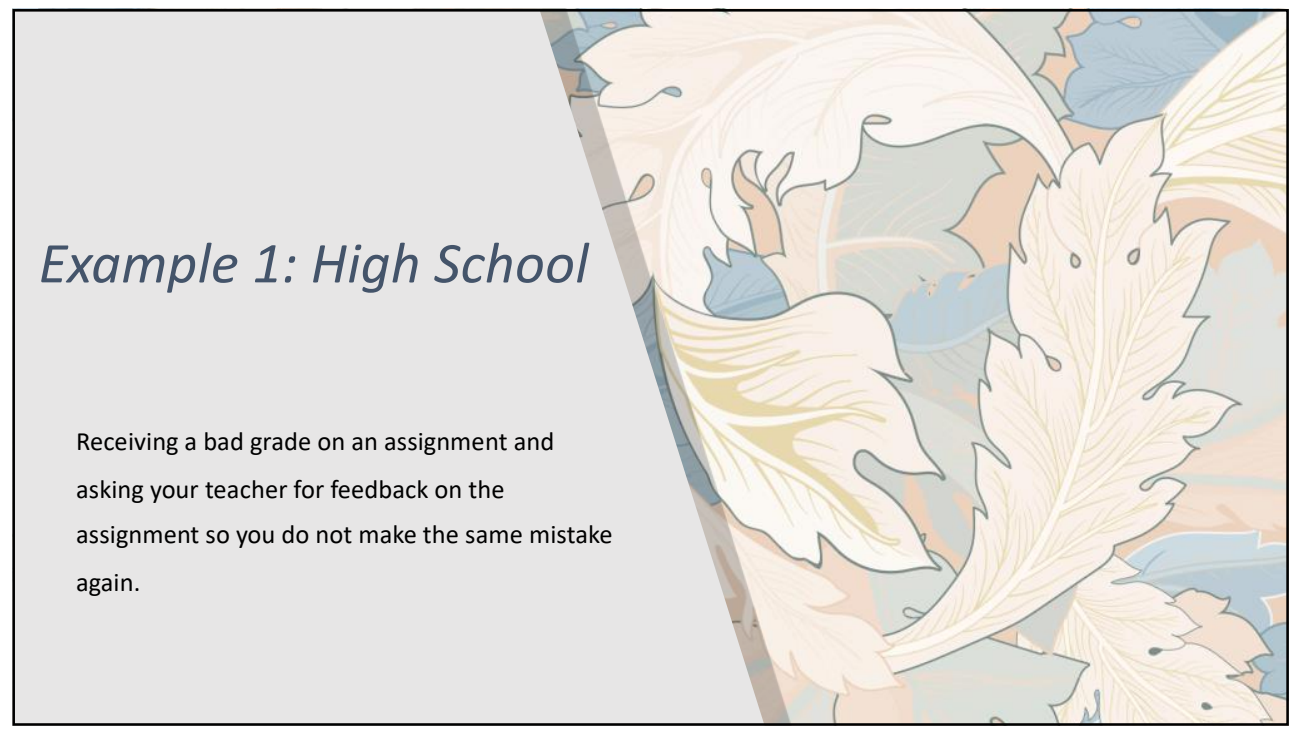

11

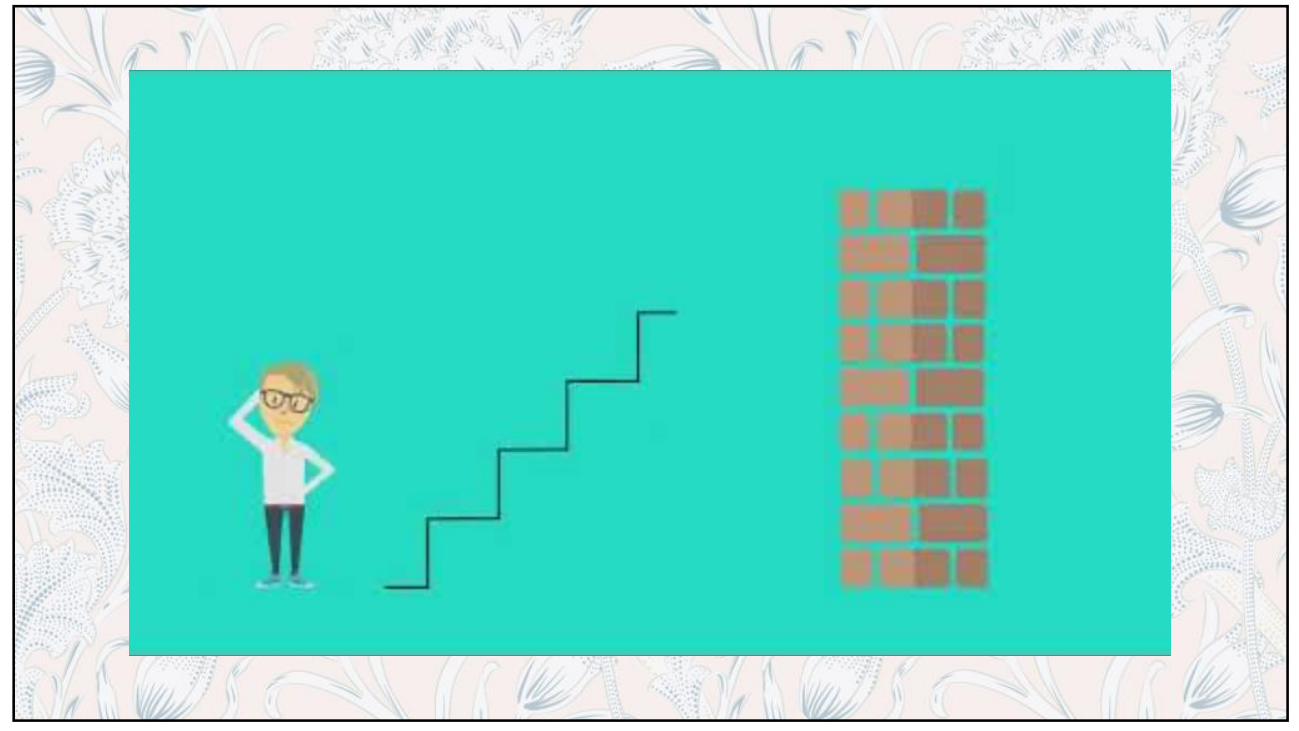

12 


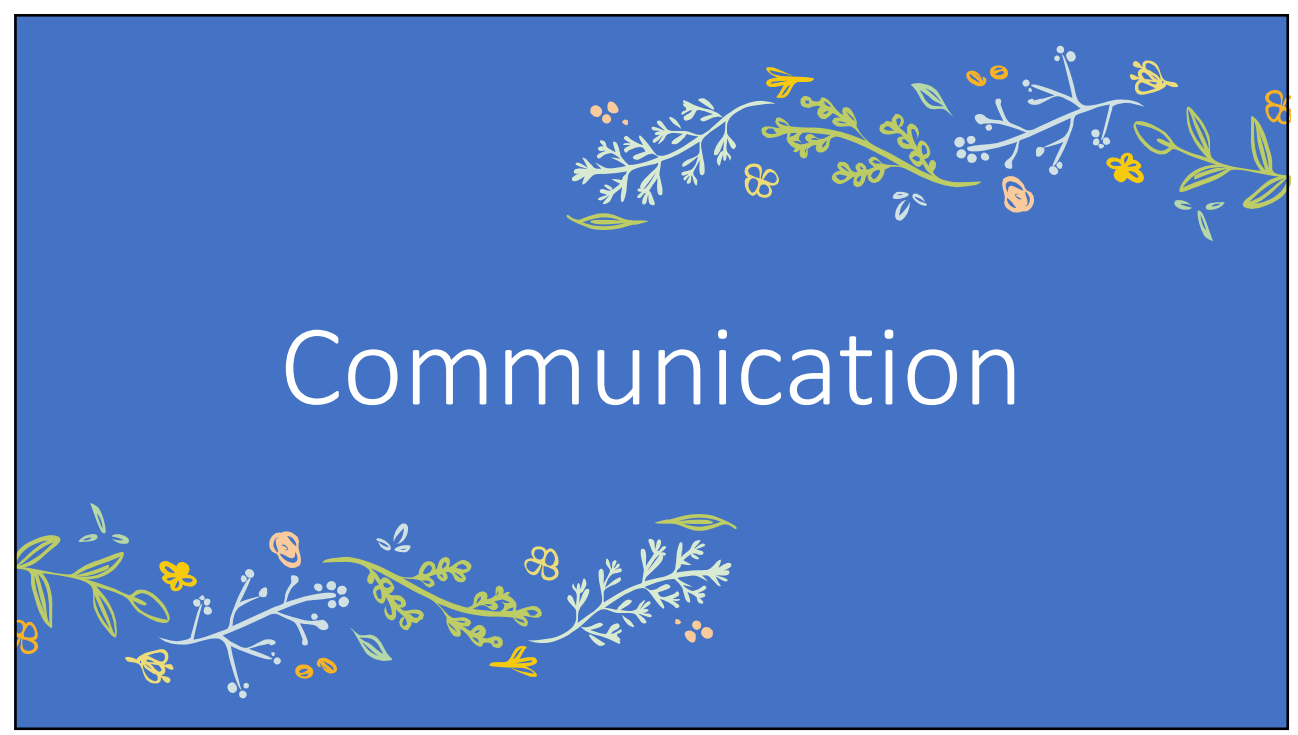

1

\section{Importance of Communication} when advocating

+ It is important to always use appropriate communication skills when advocating.

+ If you are rude or belligerent, people will likely not listen to you.

+ You must be able to explain why your need is important.

+ If you cannot explain your need, you cannot expect the other person to understand why it is important.

+ This applies to school, work and all other aspects of life.

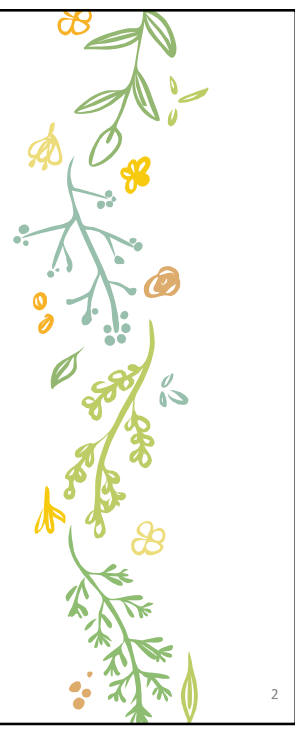




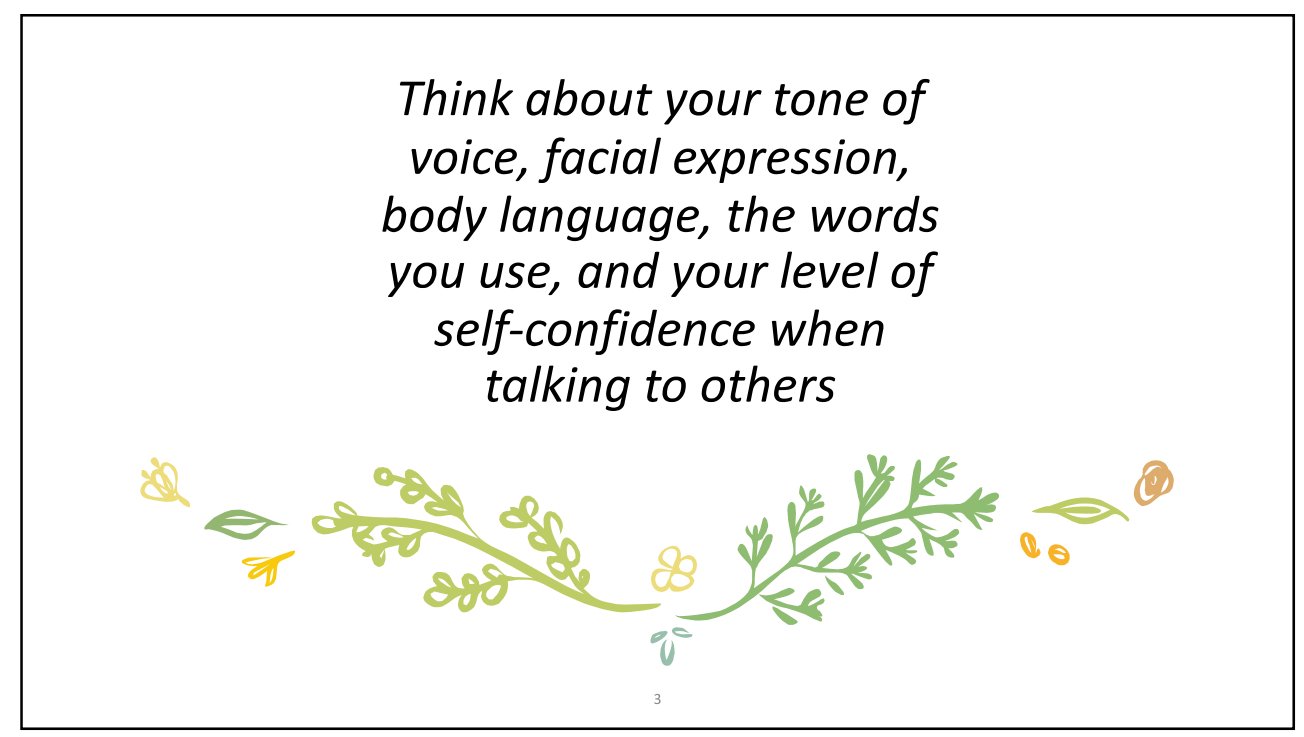

3

\section{-Respectful communication}

+ Respect is the foundation of effective communication, especially in the classroom.

+ Teachers and students demonstrate respectful communication in the following ways:

- Use a tone that is honest and tactful, choosing words that are appropriate to the situation

- When taking on a listening role, make eye contact and focus on the speaker.

O Speak in turn, never interrupting the speaker

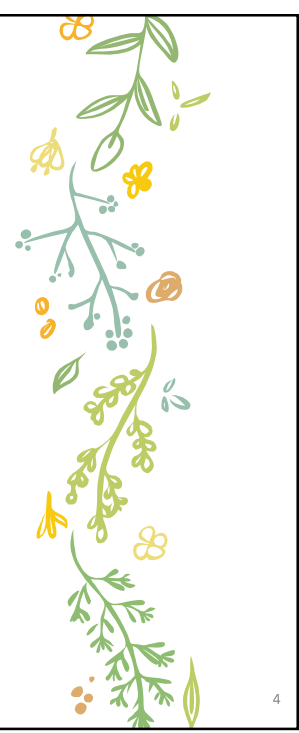


Sit/stand up straight

Have a pleasant tone of voice

Activate your thinking

Relax

Engage in eye contact

5

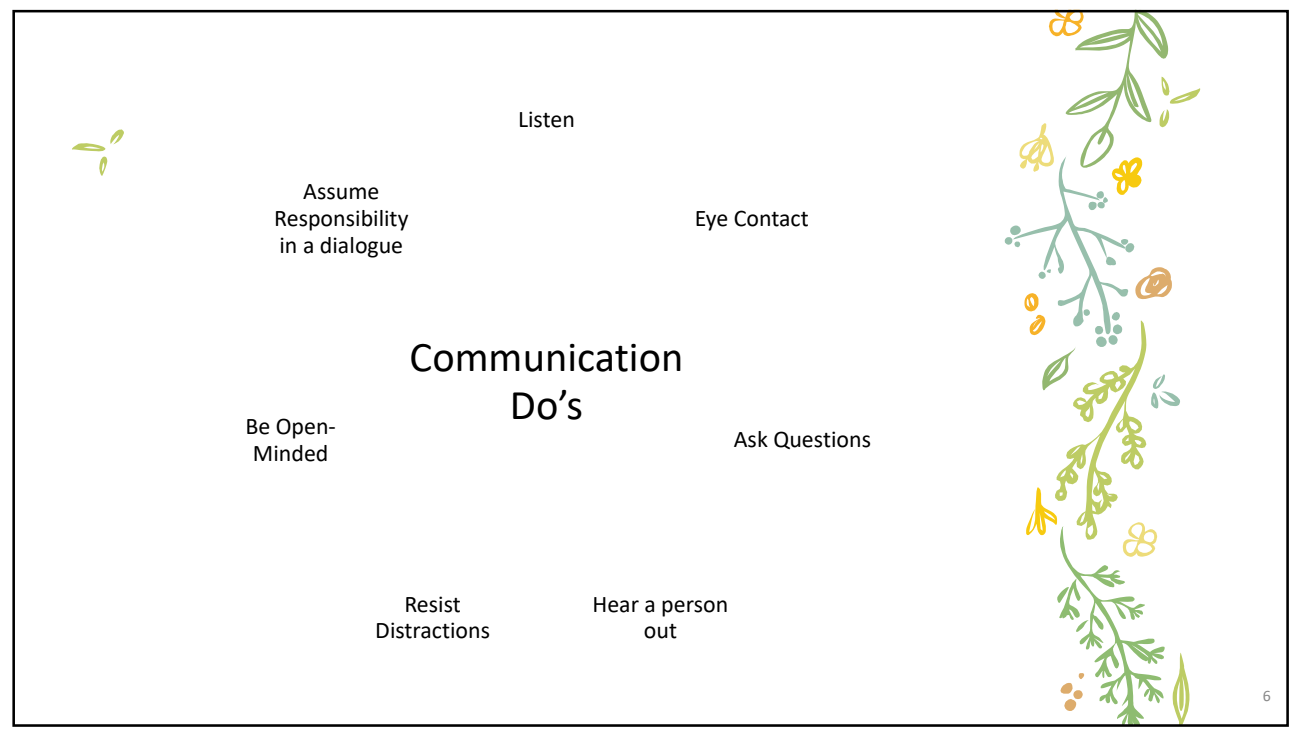

6 


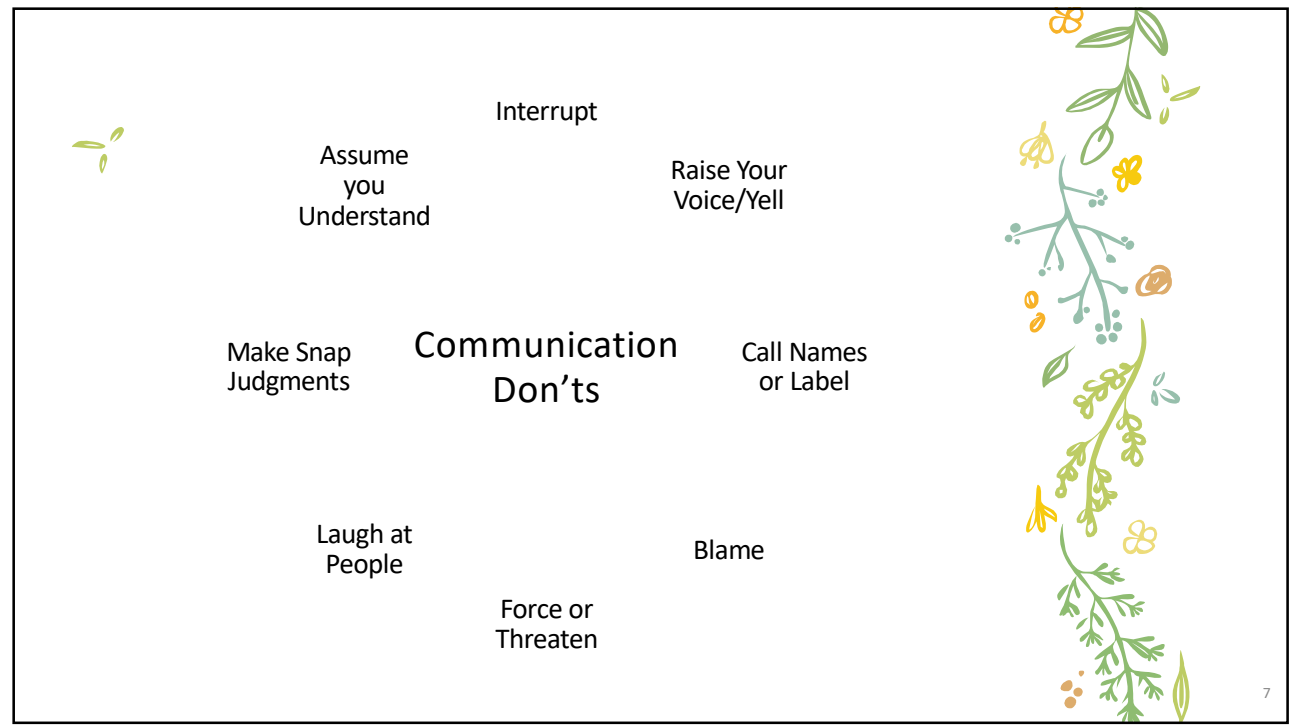

7

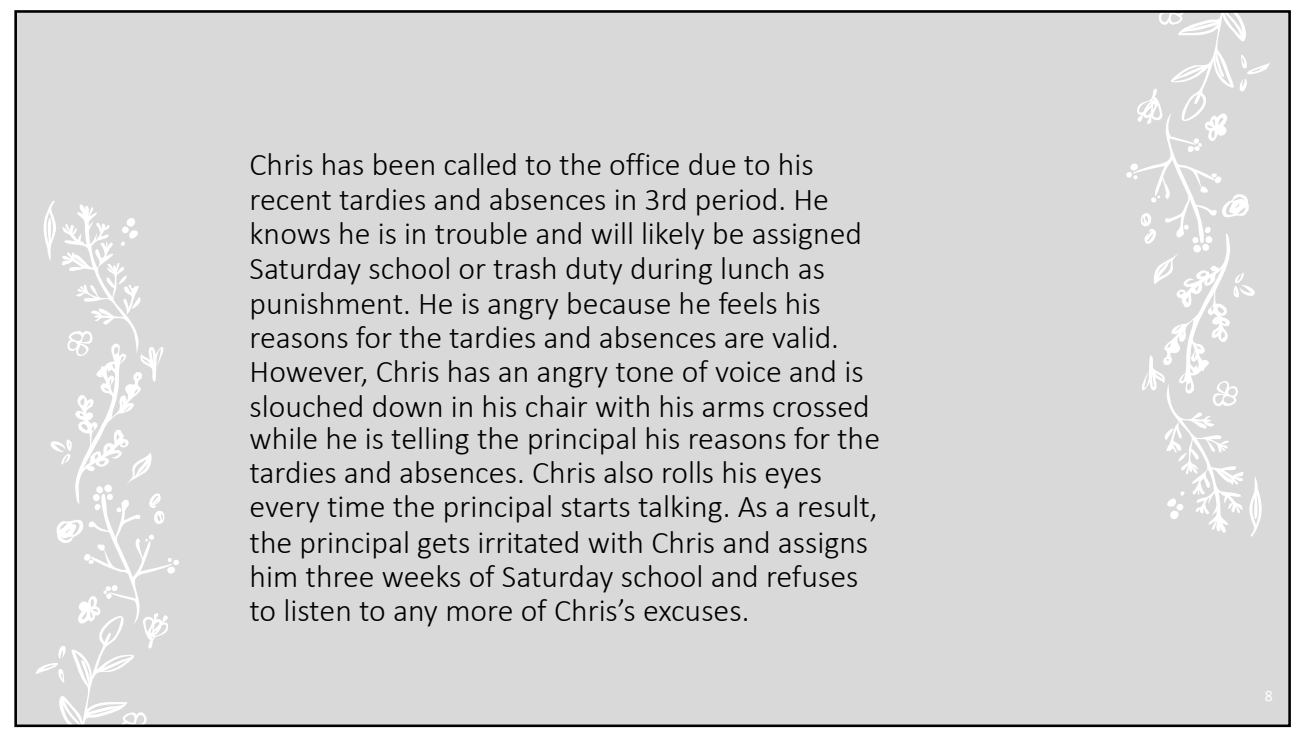




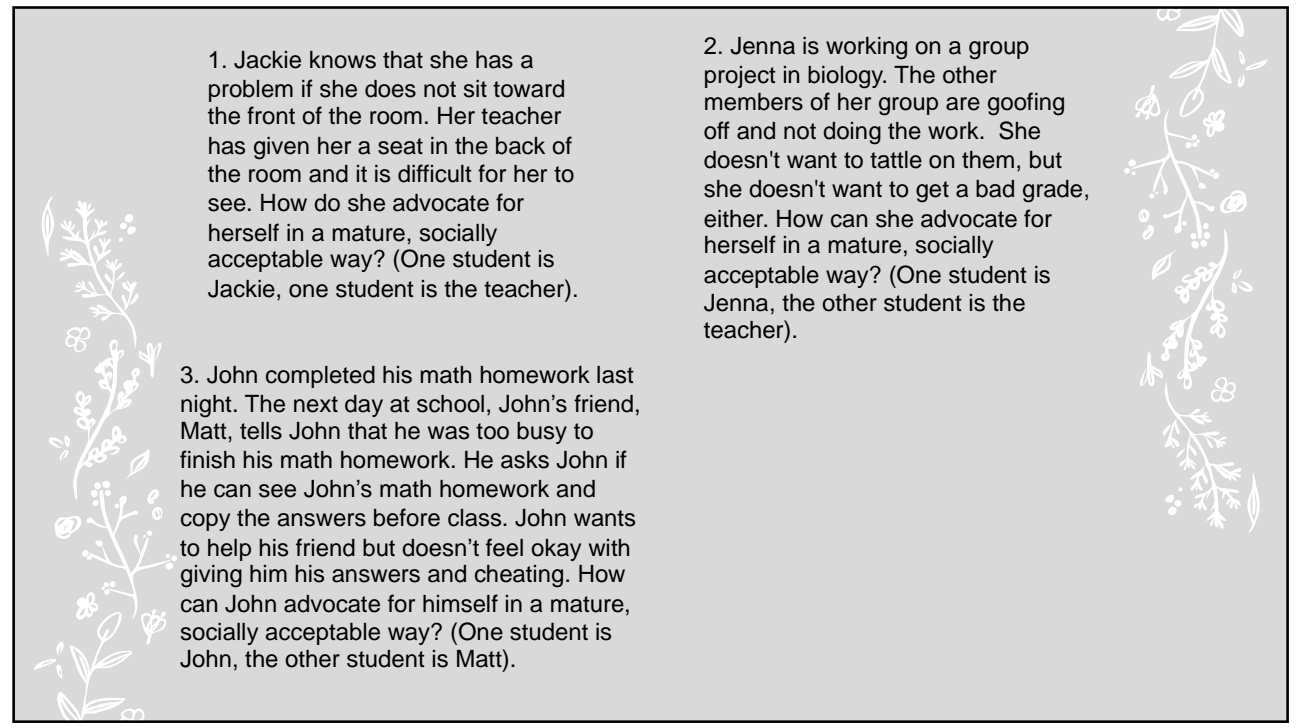




\section{Appendix G}

\section{Staff Survey}

8 responses

Publish analytics

1. What grade level do you teach?

8 responses

$10-12$

9 th and 12 th

10 and 11

9 th and 11 th grade students

Middle School 6-8 and 9th grade Integrated math

High School

10 th, 11 th, and 12 th

I assist Kristen in the 6 th - 9 th grade math classes 
2. What are some areas students need to work on prior to the transition to post-secondary education? Click all that apply

8 responses

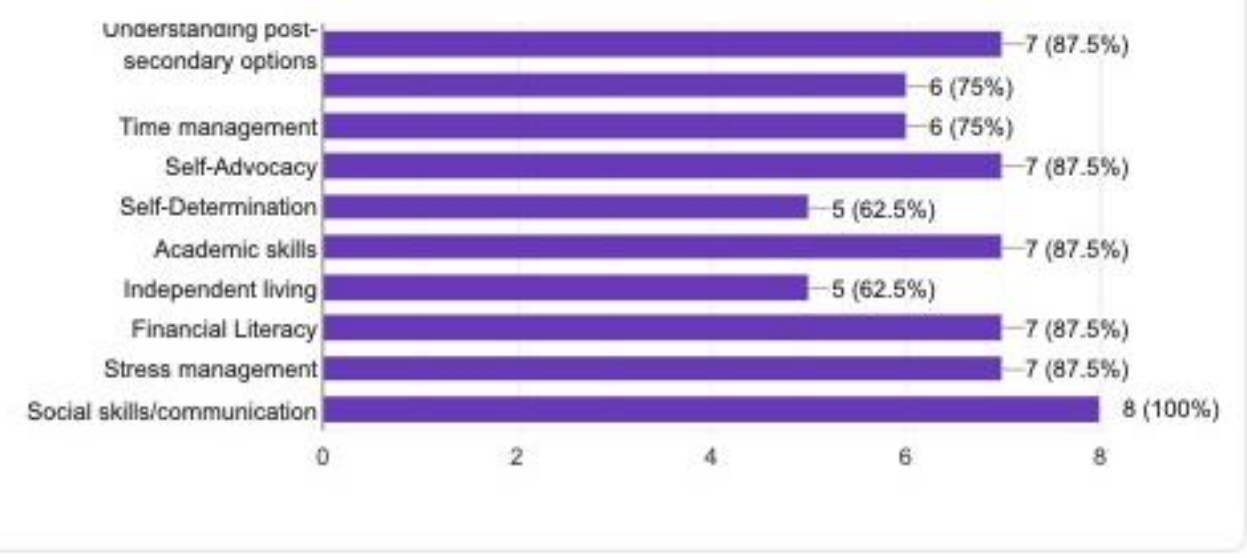

3. Do the students know what self-advocacy is?

8 responses

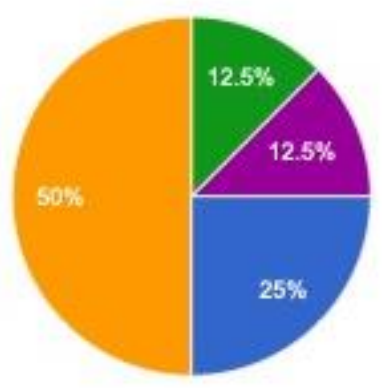

- Some do - others do not.

- Some students do. We talk about it in class, but there is a lot of leamed-helplessness. 
4. In general, how would you rate the students' overall self-advocacy and self-determination skills?

8 responses

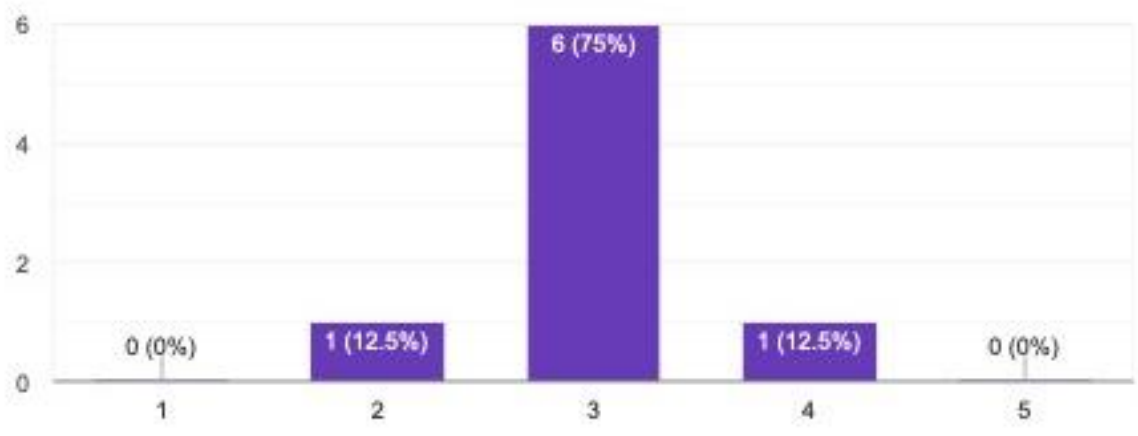

5. Do students ask for help when needed on assignments and projects?

8 responses

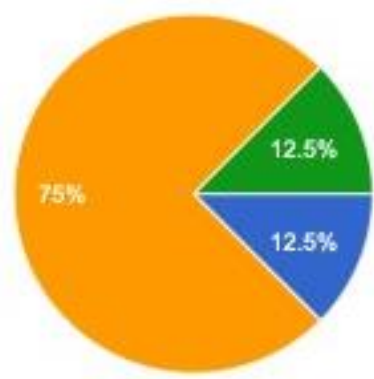

Of course it depends on the student. Many of our students will just say to themselves that they don't "get it" and write down any answer. It is more of our questioning and sitting close to when we get more verbal $f$... 
6. When the students ask for help, is it done appropriately?

8 responses

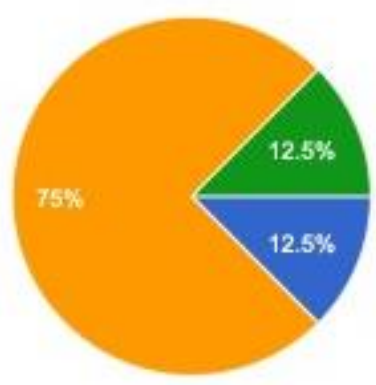

- Yes

- No

- Sometimes

- In some cases, yes. Some don't know how to ask or what they are asking for We also get questioned in unacceptable "tone of voice" as they become frustrated

7. If no, what do they do that is inappropriate when asking for help? (Is it too often, not at the right time, not asking politely, etc)

2 responses

interrupting or yelling

All of the above and tone of voice and not raising hand.

8. Do the students ask for clarification or feedback when they do not understand why they received the grade they did?

8 responses

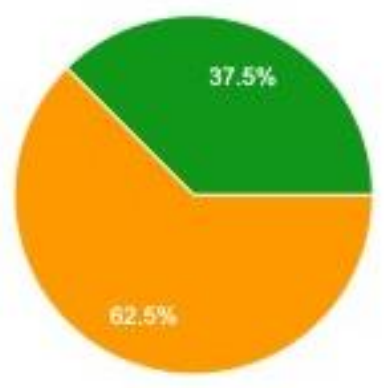

Too often

C Yes, an appropriate amount

No

Sometimes 
9. Do the students have an opportunity to disclose of their disability on their own and in their own words?

8 responses

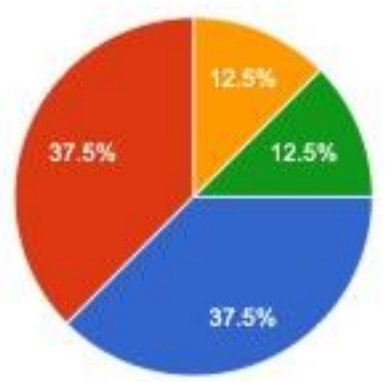

Yes

- No

Yes, but this almost never happens

Depends on student. Some are very articulate.

10. Are the students aware of their disability, their strengths, and weaknesses?

8 responses

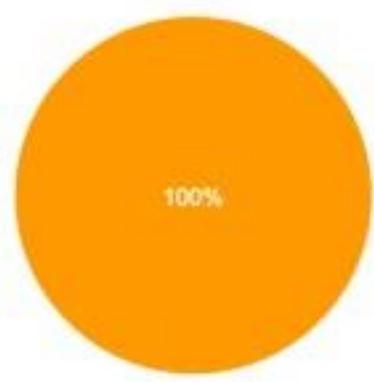

Yes

C No

Sometimes 
11. Are the students taught about their rights as a student and laws such as ADA and IDEA?

8 responses

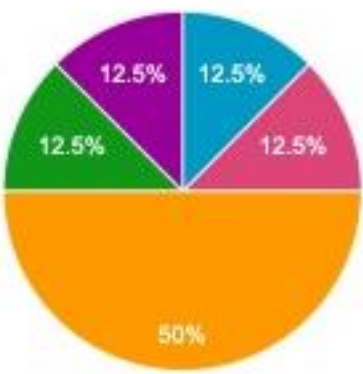

- Yes

- Yes they are taught but still do not understand

No

- I do not know

- I'm not sure

- I am not sure.

In the College/Career Class 


\section{Appendix $\mathbf{H}$}

\section{Self Advocacy Survey}

11 responses

Publish analytics

\section{Name}

6 responses

estefany gamino

Finian Aloy

Jonah Medel

Ella

Jacques

Lucas Klingsberg

1. What grade are you in?

11 responses

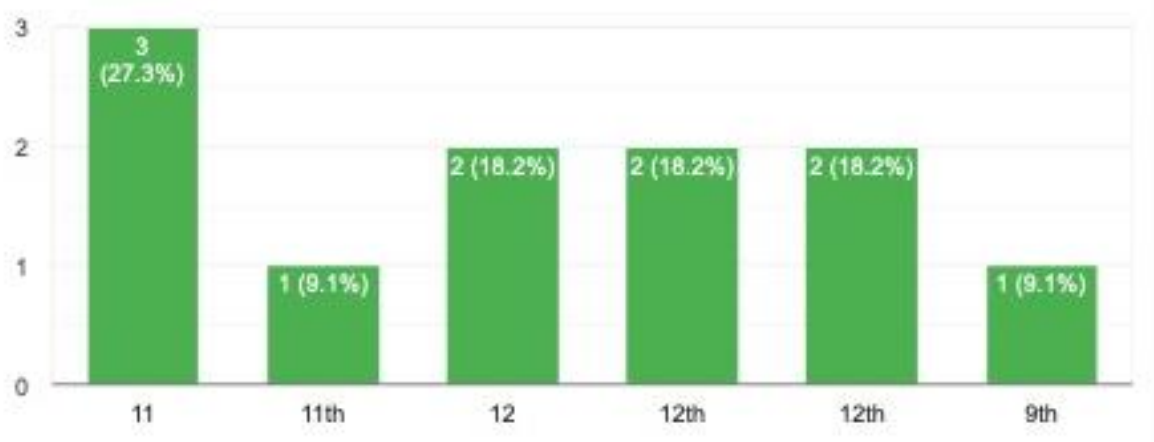


2. How well do you know your academic strengths?

11 responses

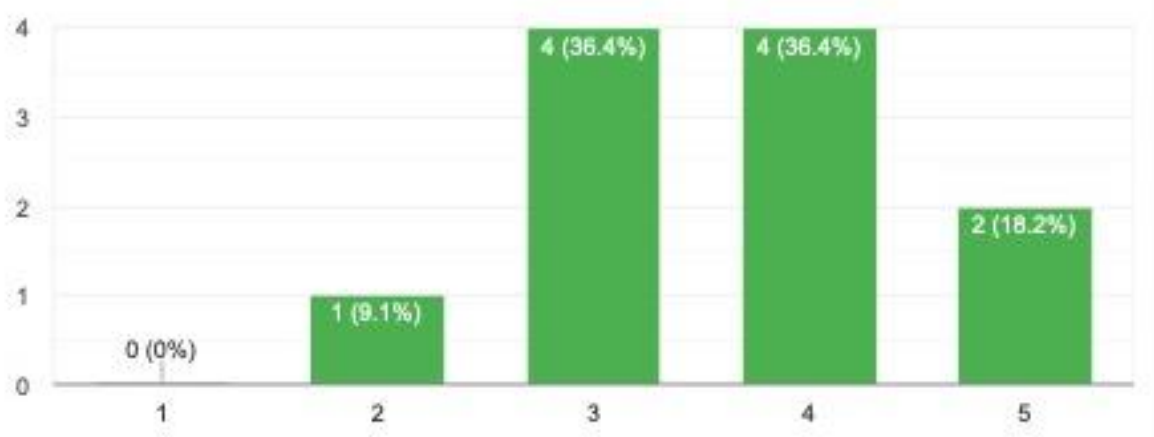

3. How well do you know which academic tasks give you the most difficulty 11 responses

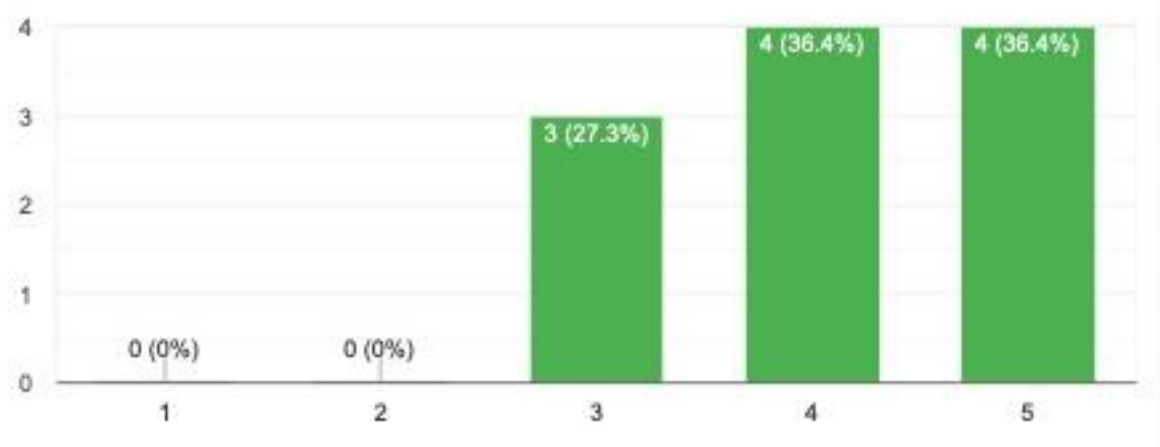


4. How well can you identify the academic supports you need to be successful

11 responses

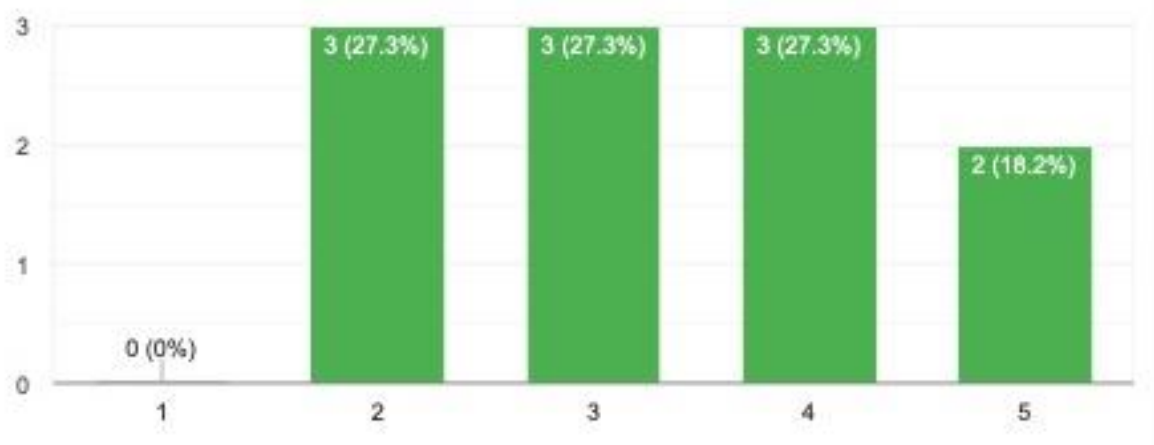

5. How well do you know your legal rights as a student 11 responses

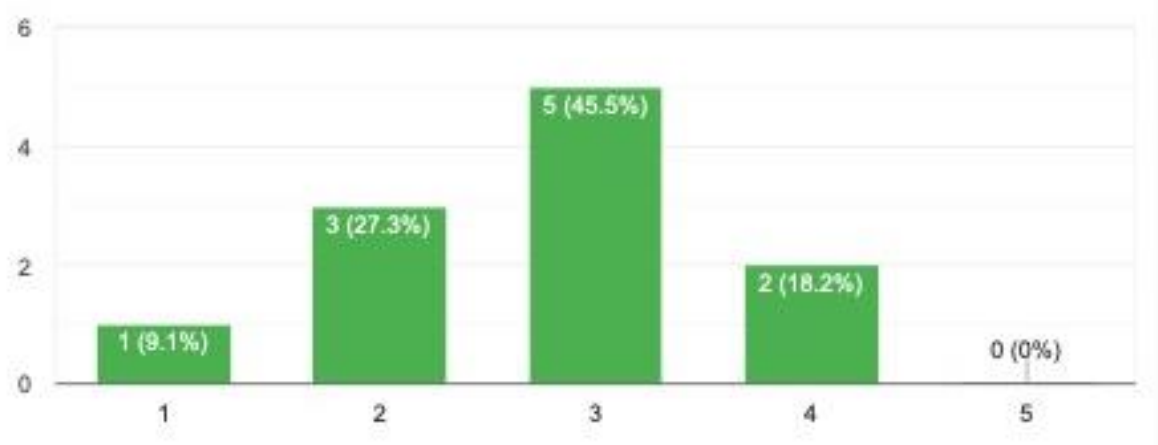


6. How often do you ask for help when you run into difficulty

11 responses

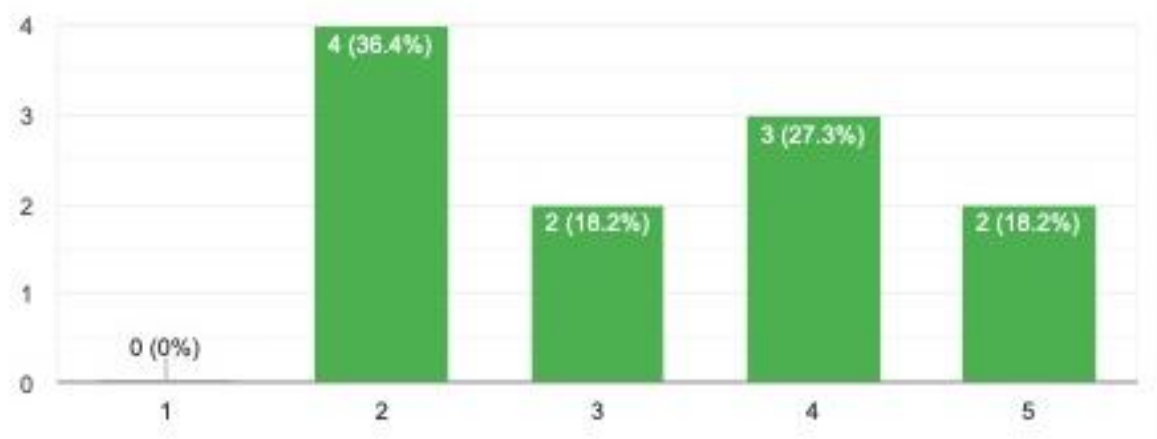

7. How often do you schedule your own appointments with doctors, advisors, and counselors

11 responses

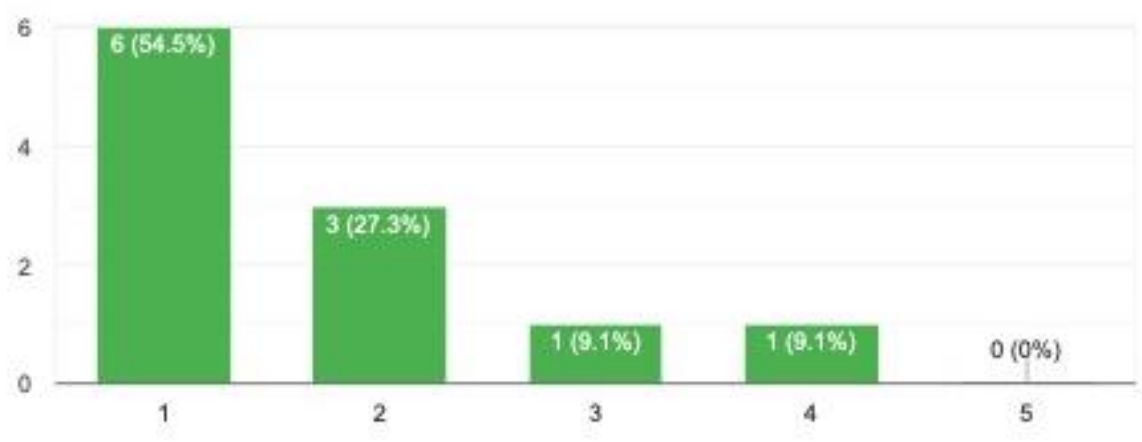


8. If a school or college refused to provide you with an appropriate accommodation, how likely are you to dispute the decision 11 responses

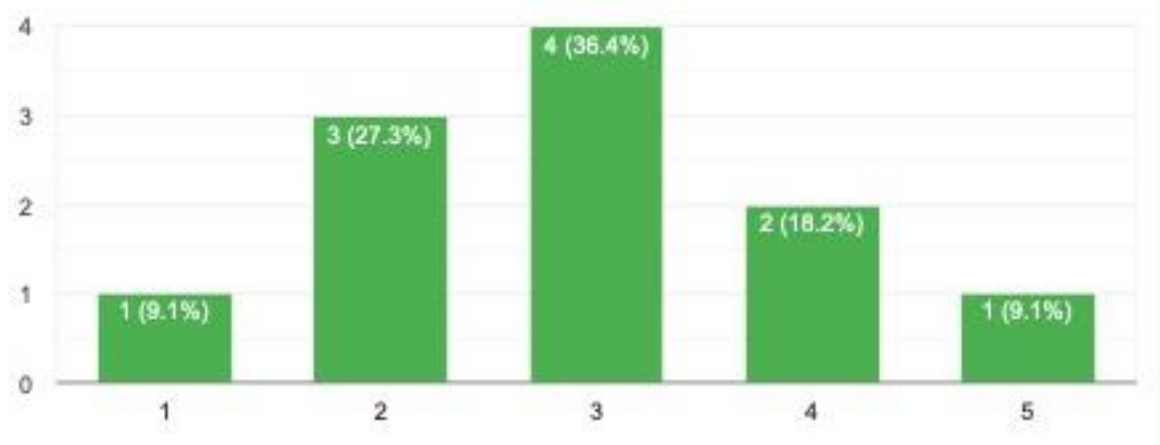

9. How would you rate your system of keeping organized?(Example: keeping track of projects, books, and papers)

11 responses

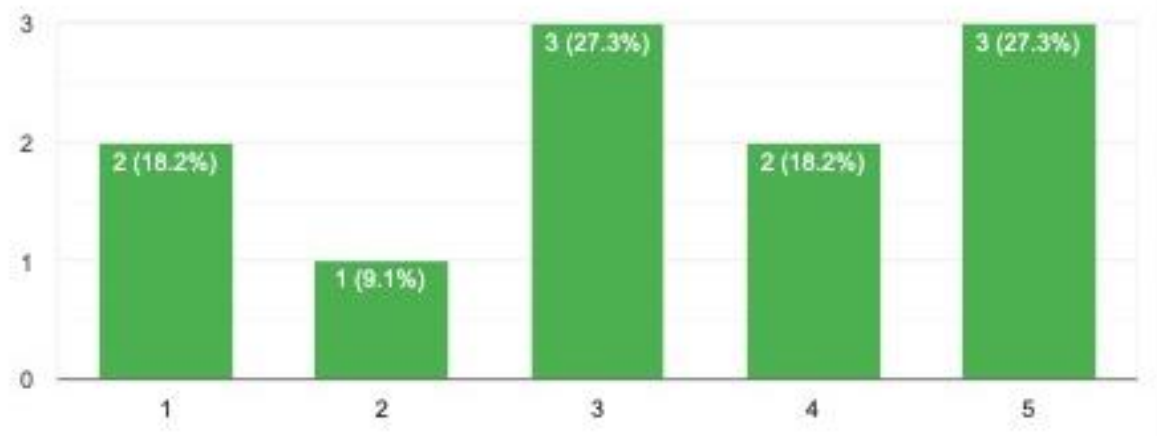


10. How well are you at ignoring distractions and focusing on the task at hand

11 responses

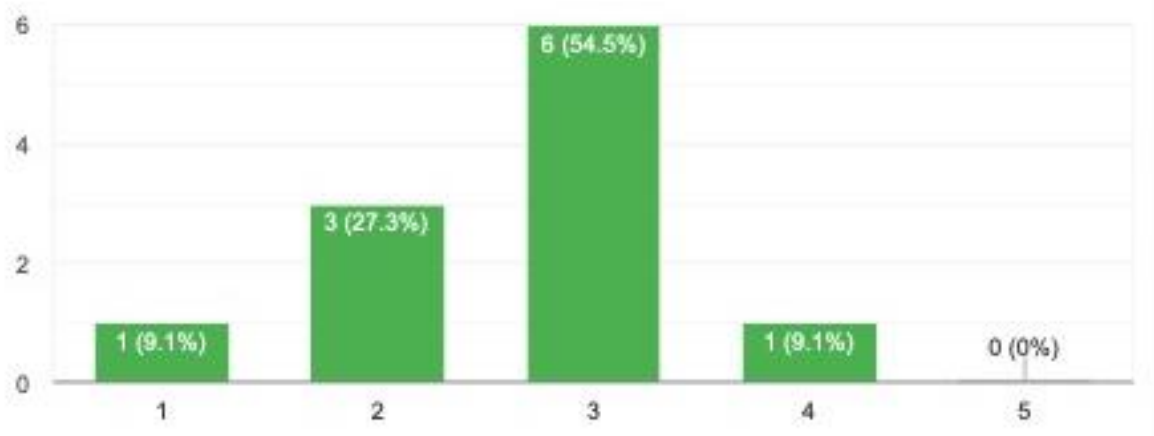

11. How well are you able to complete all steps of a project in a timely manner

11 responses

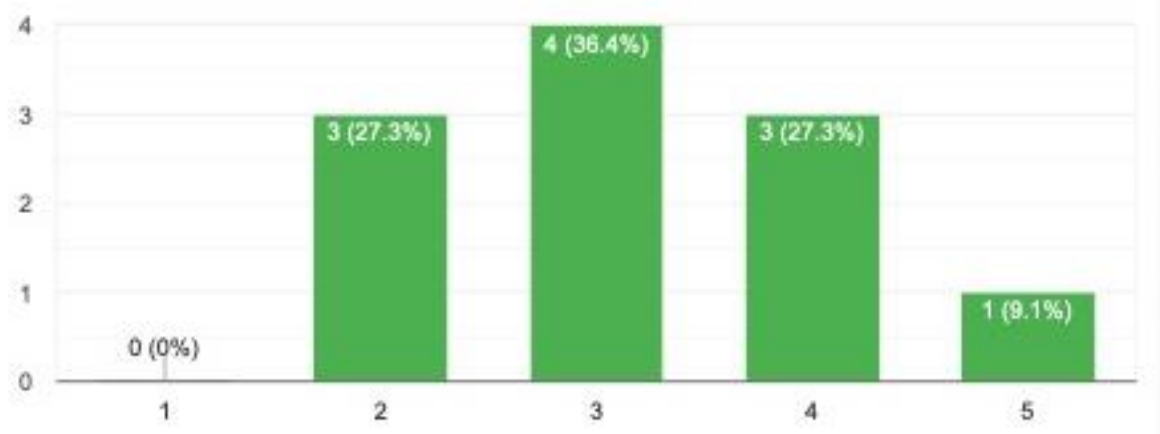


12. How would you rate your ability to complete tasks that you find boring 11 responses

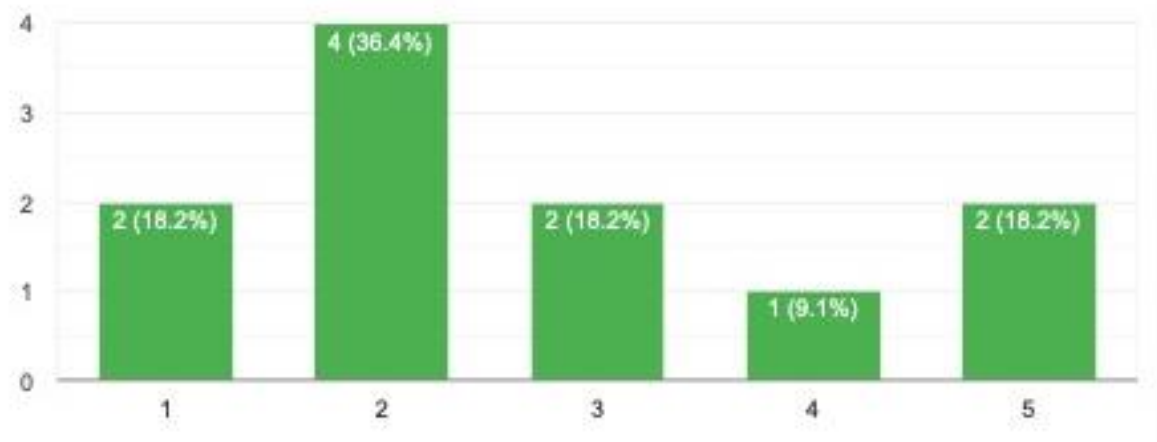

13. How would you rate your perceived ability to succeed? 11 responses

6

4

2

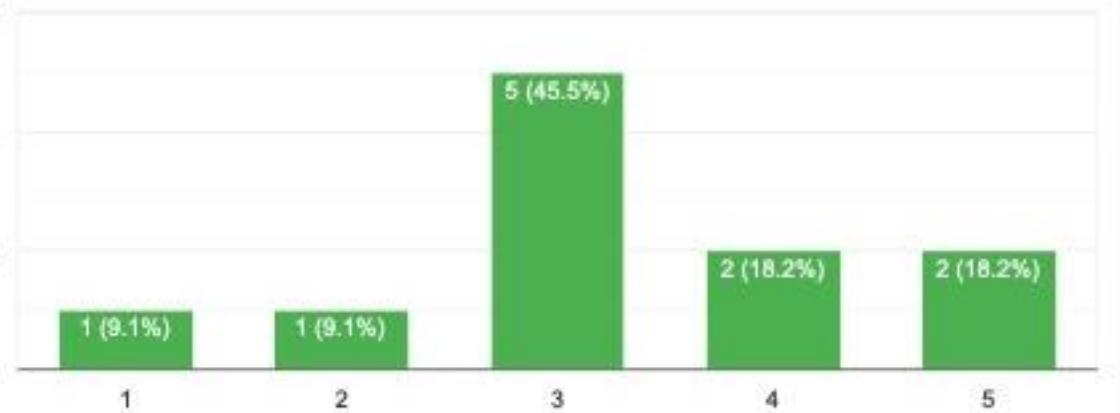

$0+1$ 
14. When you think about what you have to do in college are you excited?

11 responses

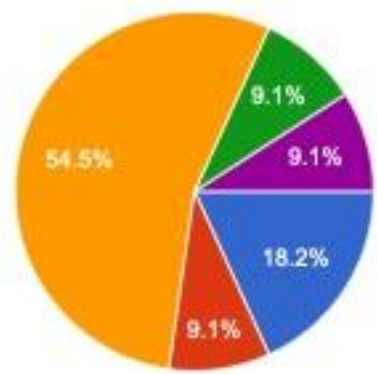

- Yes

- No

Not sure yet

- I don't want to go go college, so this doesn't apply to me. Even if I did, I would not be overly excited, as some people have made college seem feartul to me.

But also really nervous

15. Can you imagine your life in 10 years?

11 responses

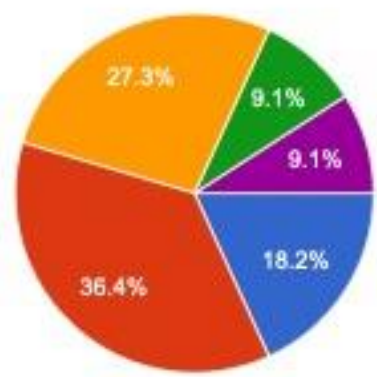

Yes

- No

Not sure yet

- I envision myself doing a job as HVAC/R service technician, hopefully planning to start my own business.

- Not really I know I want to be a teacher but I don't know everything else. 
16. How often do you make your own snacks and meals?

11 responses

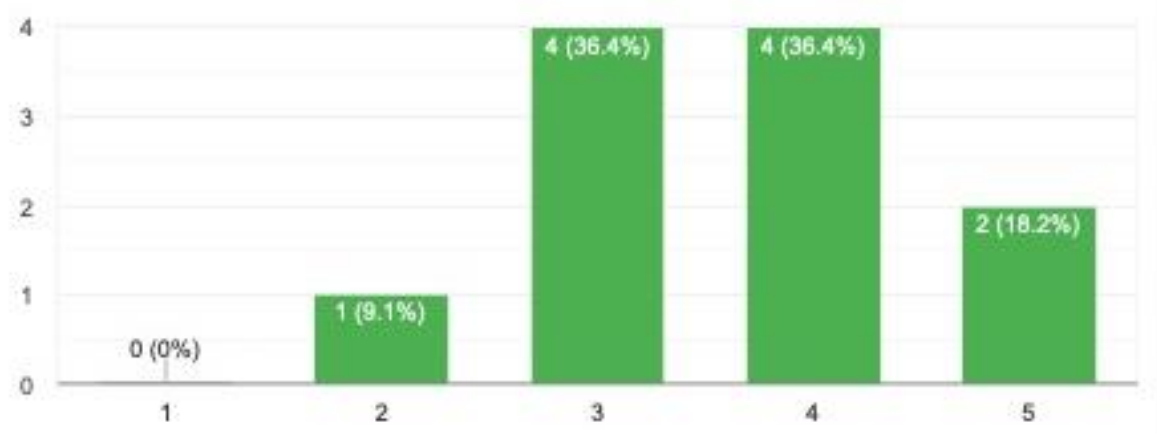

17. How often do you make friends with other kids your age

10 responses

6

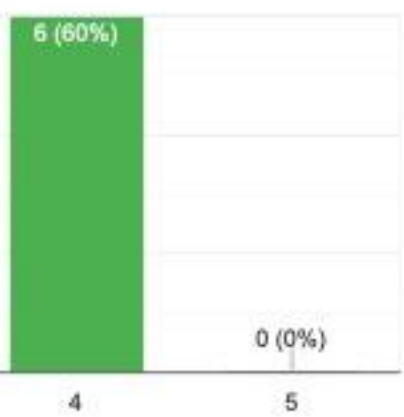

4

2

0

$1(10 \%)$

2

3

4

5 
18. How often do you plan weekend activities that you like to do 11 responses

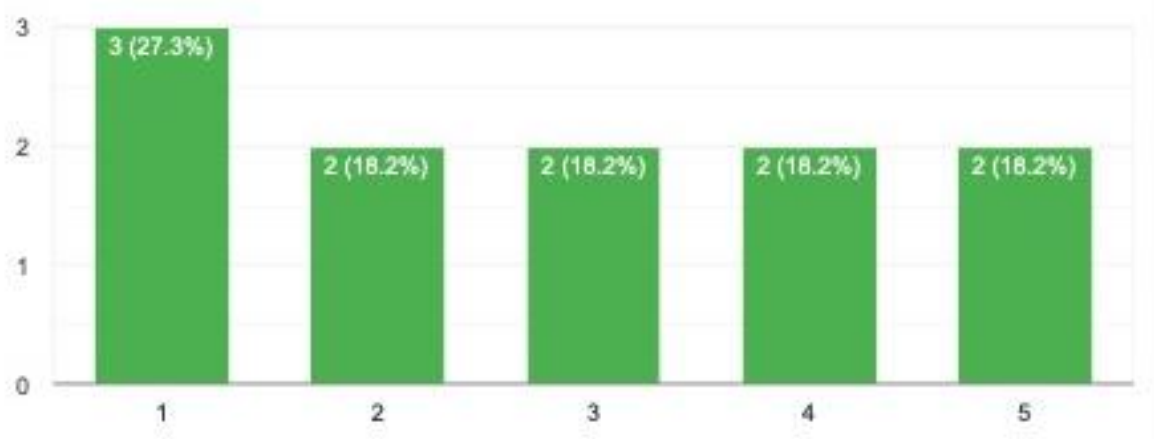

19. How often do you choose your own hair and clothing style 11 responses

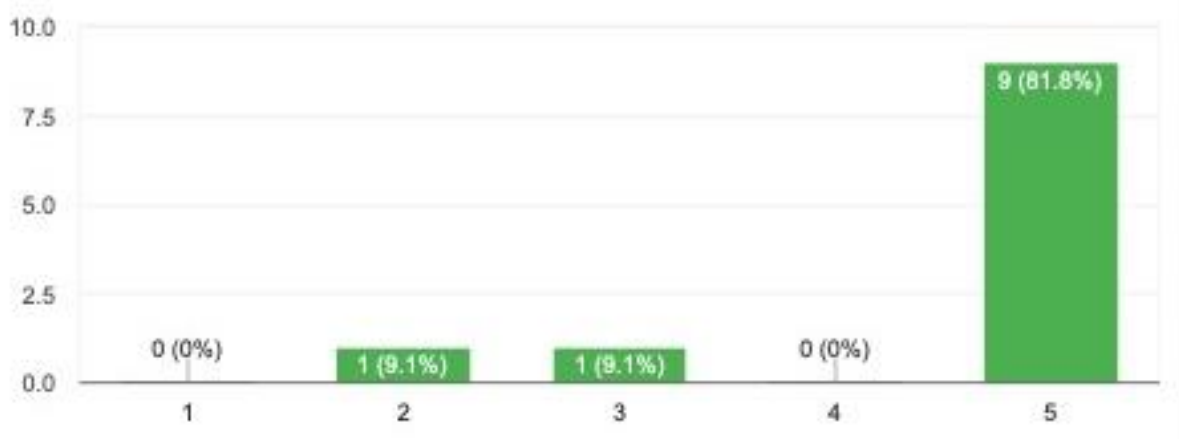


20. Do you make long term career plans?

11 responses

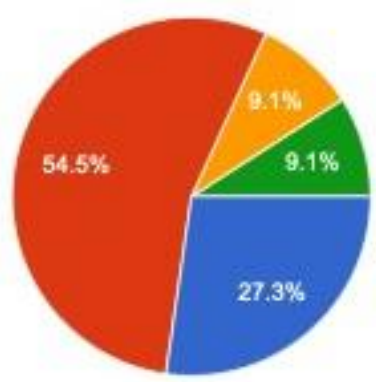

Yes

C No

i dont know i really dont plan too much. although I do have some plans but I'm not changing them that much.

- sometimes

21. Do you have an academic subject that you find interesting? If so what is it? 10 responses

Science kind of. animals also.

not particularly

Math

Yes, science

IT

Biology, Geology, Paleontology, Archeology, Photography

Math or art

I really like all the subjects except math. However, I find history and english to be the ones I learn the most in.

Viden Fditina 
22. Is there anything else you would like to say or share with me?

8 responses

If you haven't gotten the message already, I don't want to go to college. I think that the typical idea of going to college and then getting a job you work at until you retire is not for most people, but they do it because they think there's no other option. Starting a business and working in the trades are great ways to be successful in life without going to college.

nope

Sorry I got nothing

Nope

I have taken some college classes so I kind of know how to get my accommodations in a college setting.

ITS SPOOKTOBER!! AAAAAAAAAAAAAAAA *RATTEL EM BOIS*

not to my knowledge. 


\title{
Appendix I
}

\section{Self-Advocacy Post-Survey}

5 responses

Publish analytics

\author{
1. Name \\ 5 responses \\ Ella \\ estefany \\ Finian Aloy \\ Jonah Medel \\ Jacques Szakvary
}

2. In your own words, what is Self-Advocacy?

5 responses

It is when you advocate your needs and or questions for yourself.

tell people how you are feeling and expressing yourself

Self-Advocacy is the act of standing up for yourself, or seeking tools that can make your life easier.

Reaching out for help or asking for accommodations.

Self Advocacy is when your able to stand up for your self and figure out what you need and get the things you need. 
3. In your opinion, how important is it to learn self-advocacy skills?

5 responses

6

$5(100 \%)$

4

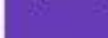

2

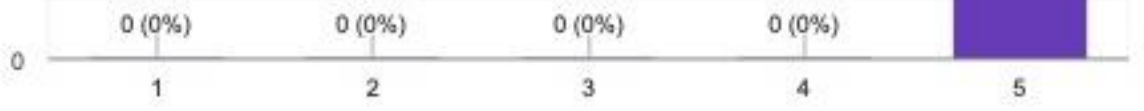

4. Did you find it helpful to learn about self-advocacy and selfdetermination?

5 responses
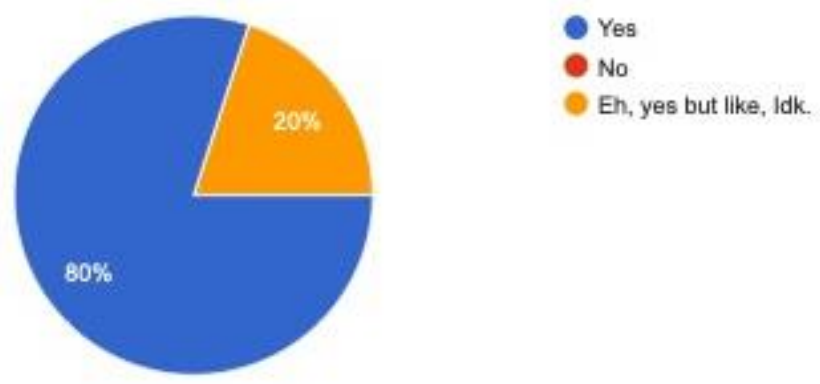
5. In your opinion, when would be the best time to learn about selfadvocacy?

5 responses

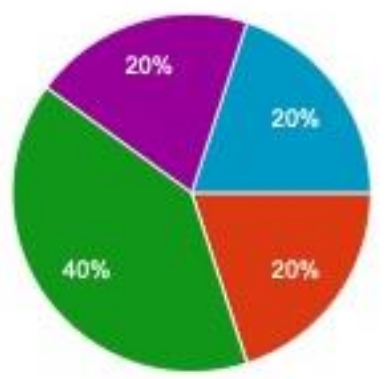

Senior year of high school

Junior year of high school

- Sophomore year of high school

- Freshman year of high school

- Middle school

It does not need to be taught at all

6. What was most beneficial to your learning of self-advocacy and selfdetermination skills?

5 responses

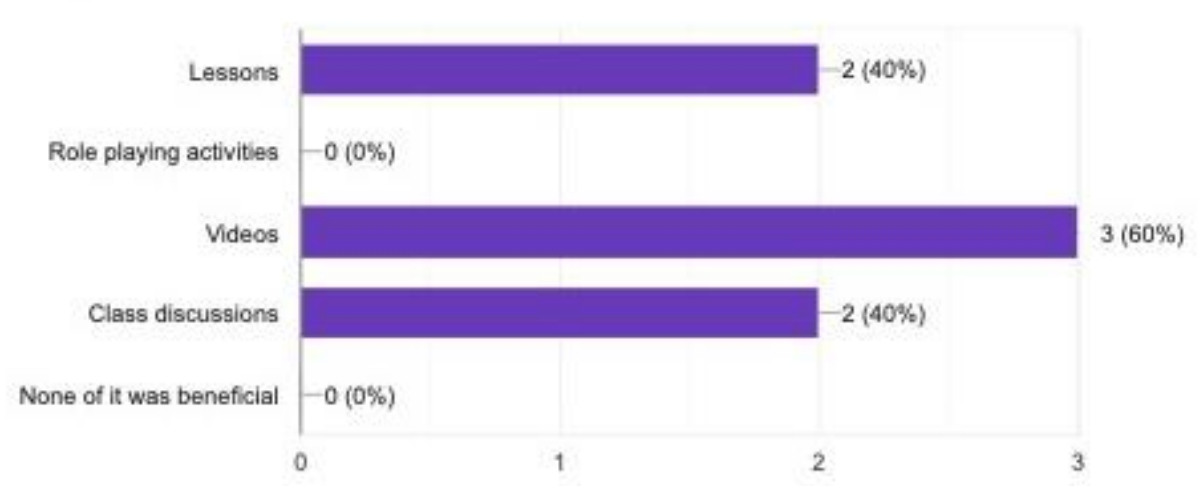


7. Did you enjoy learning self-advocacy and self-determination skills? 5 responses

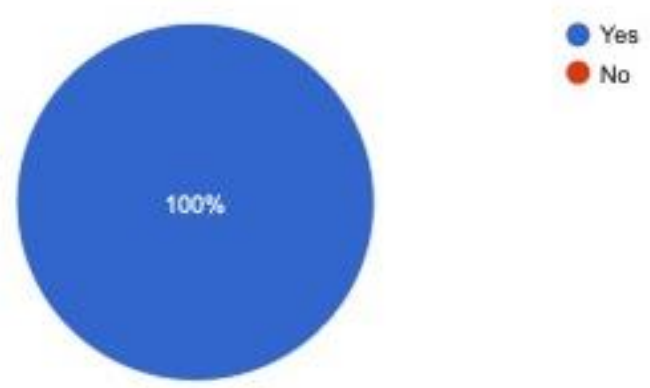

8. Did you enjoy the role playing activities?

5 responses
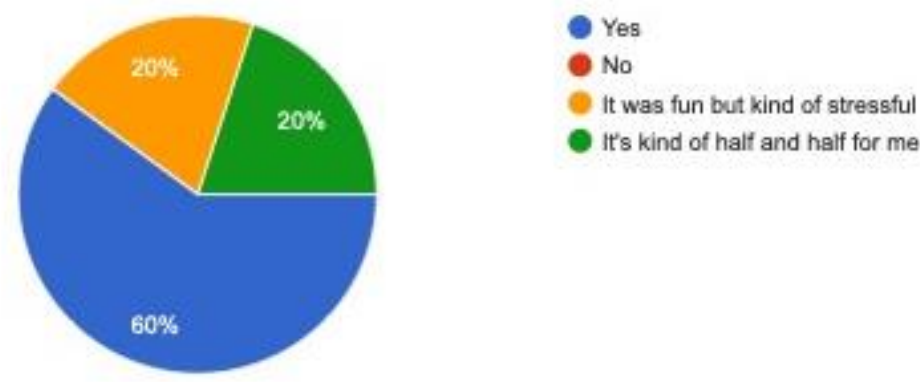
9. How comfortable do you feel asking your teacher/professor for help? 5 responses

3

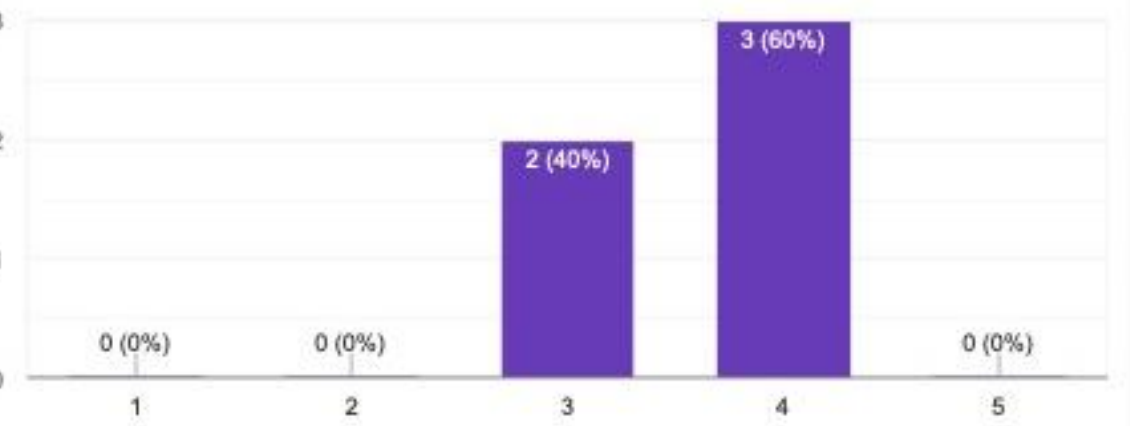

10. How comfortable do you feel requesting for accommodations in postsecondary education?

5 responses

2

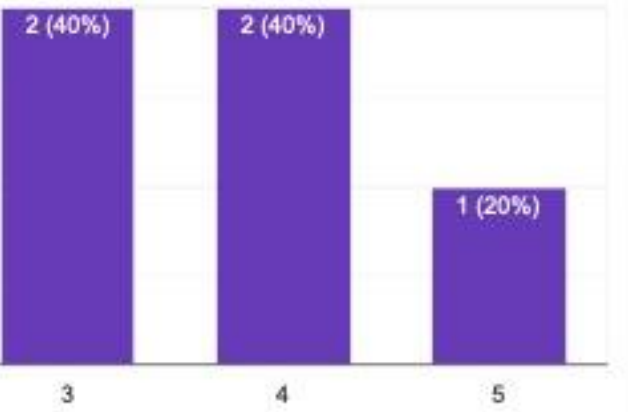

0

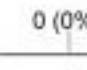

$0(0 \%)$ 
11. If you have a disability, how comfortable do you feel disclosing your disability to receive academic accommodations?

5 responses

3

2

1

0

$0(0 \%)$

$0(0 \%)$

3

12. Do you know the process of how to request for accommodations in post-secondary education?

5 responses

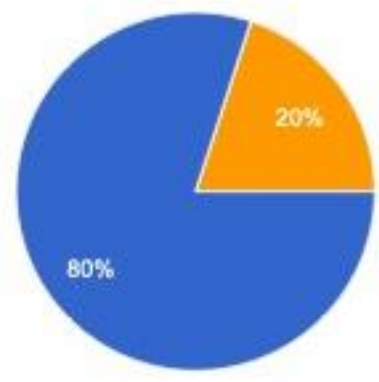


13. How well do you know your student rights and laws?

5 responses

2

2

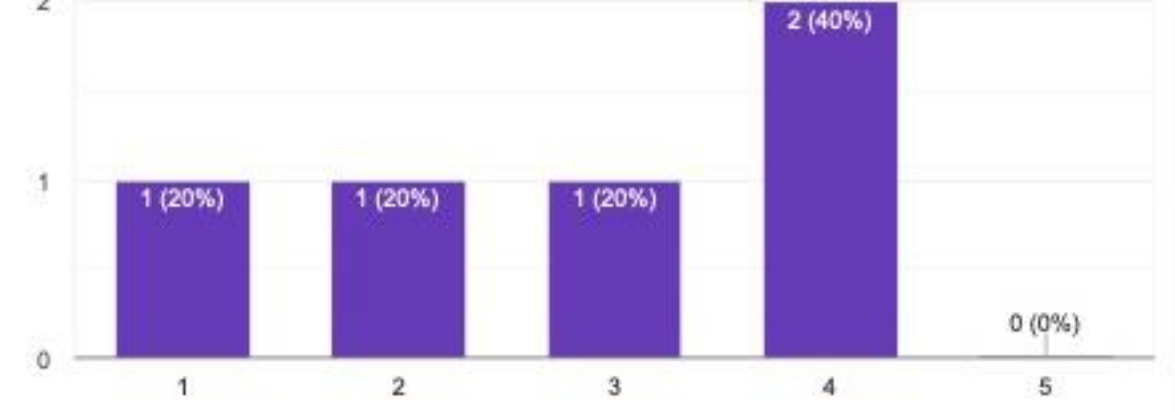

14. What are some differences between high school and post-secondary education?

5 responses

Post-secondary education is way more independent, no one's going to come up to you like high school in and ask if you need help.

post secondary you going to go to do a career

In post-secondary education you're completely on your own to ask for help

You have to self advocate way more, since teachers aren't going to reach out to you to help.

Secondary education will help you get a specific job. 
15. Would you recommend the self-advocacy lessons to other students?

5 responses

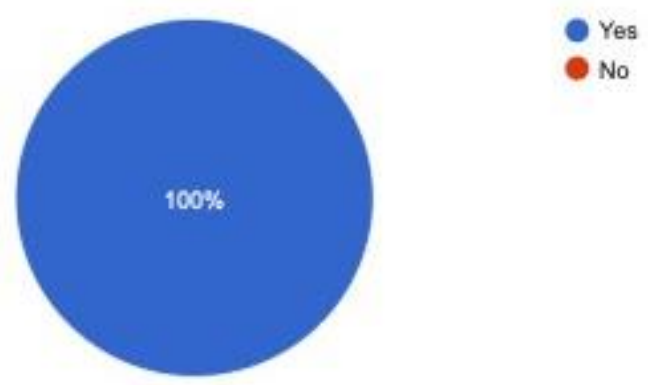

16. What was one thing you liked about the self-advocacy and self-determination lessons/activities?

5 responses

I really liked that we talked about ways to ask for help. Like you don't have to ask during class, you can email or wait for office hours.

role play

If they deny your request, it can be a huge deal

We were able to cover what to do to get accommodations for post secondary education.

I liked the material it taught. 
17. What is one thing you would change about the self-advocacy and selfdetermination lessons/activities?

5 responses

I think one thing I would add, not change, is describe in more detail what happened in the meetings you have with the accommodation department for your accommodations.

nothing

Nothing! They seem good to me

nothing

I cant really think of anything. 


\section{Appendix J}

\section{College Readiness Survey}

3 responses

Publish analytics

1. What grade are you in?

3 responses

8 th

7

8

2. How well do you know your academic strengths?

3 responses

2

1

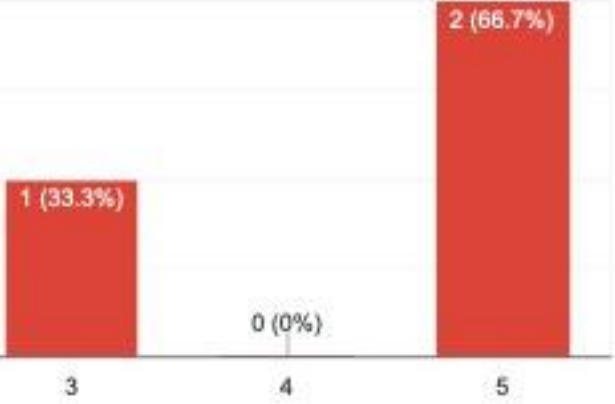

0

$0(0 \%)$ 
3. How well do you know which academic tasks give you the most difficulty 3 responses

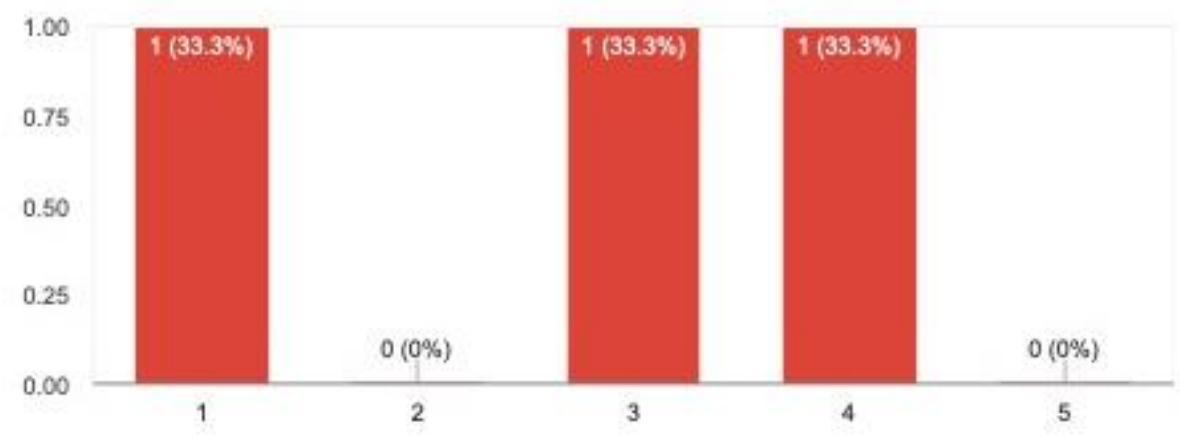

4. How well can you identify the academic supports you need to be successful

3 responses

2

1

0

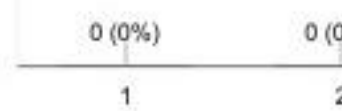

$0(0 \%)$

$0(0 \%)$

3

45 
5. How well do you know your legal rights as a student 3 responses

3

2

1

0

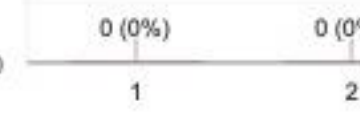

$(0 \%)$

$0(0 \%)$

$0(0 \%)$

3

4

5

6. How often do you ask for help when you run into difficulty 3 responses

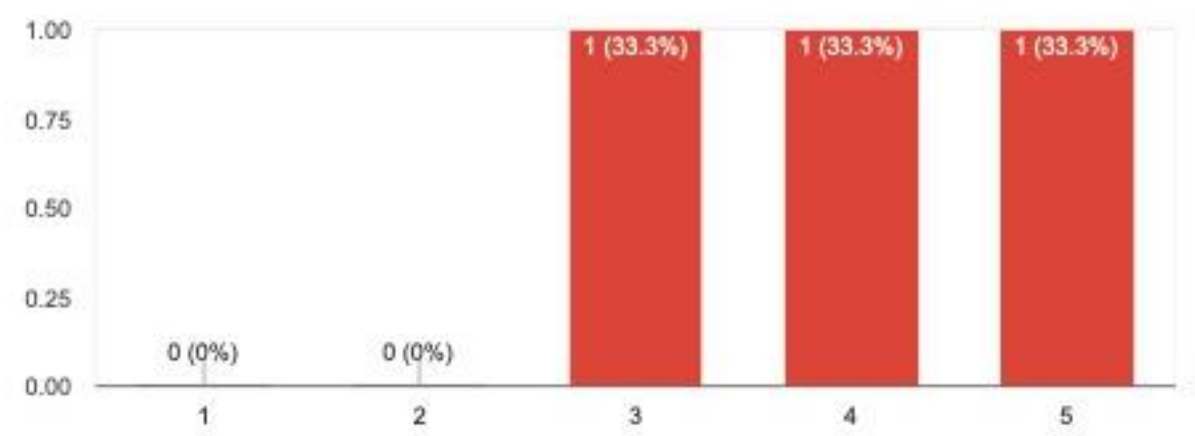


7. How would you rate your system of keeping organized (Example: Keeping track of projects, books, and papers)

3 responses

2 $2(66.7 \%)$

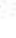

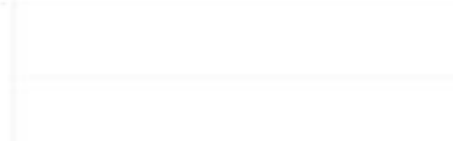

1

(1)

0

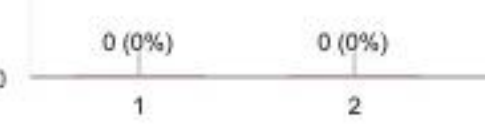

3

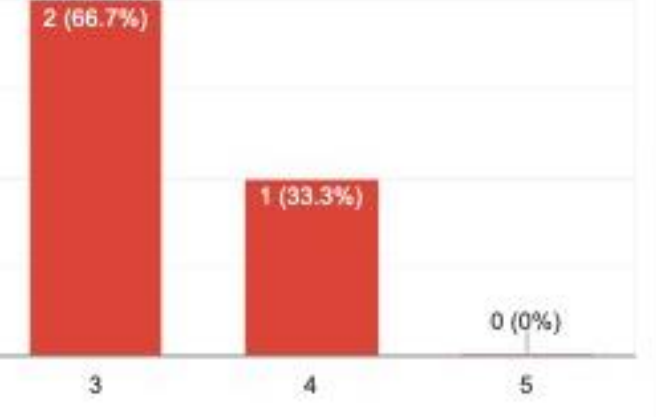

8. How well are you at ignoring distractions and focusing on the task at hand

3 responses

2

1
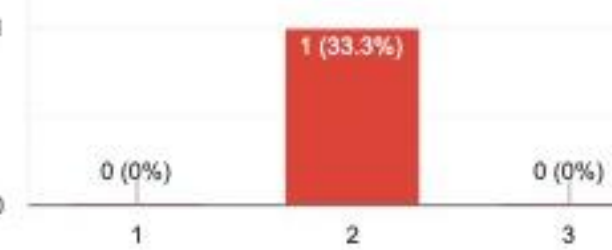

$0(0 \%)$

3

4 
9. How well are you able to complete all steps of a project in a timely manner

3 responses

2

2

1

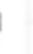

0

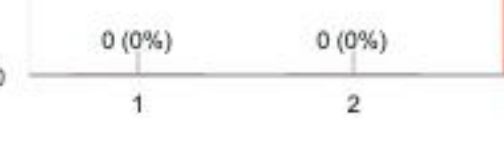

3

10. How would you rate your ability to complete tasks that you find boring 3 responses

2

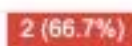

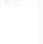

1

0

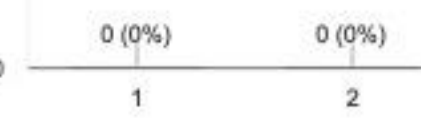

$0(0 \%)$

3

4

5 
11. How would you rate your perceived ability to succeed?

3 responses

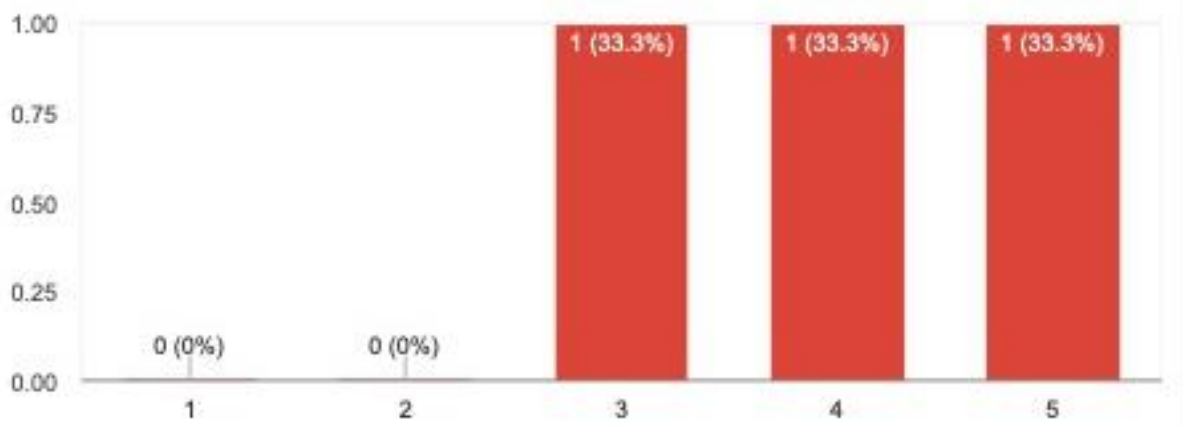

12. When you think about what you have to do in college are you excited? 3 responses

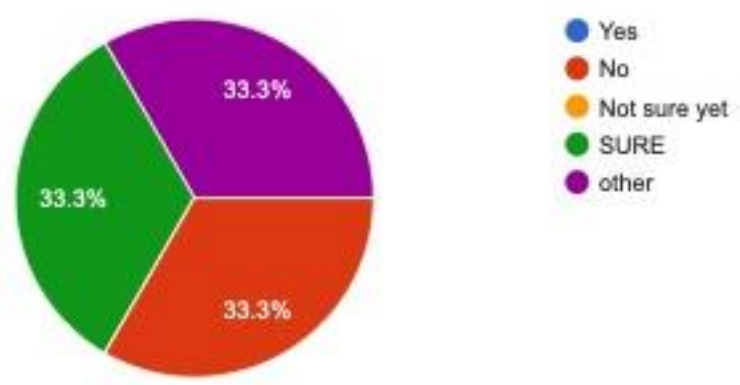


13. Can you imagine your life in 10 years?

3 responses

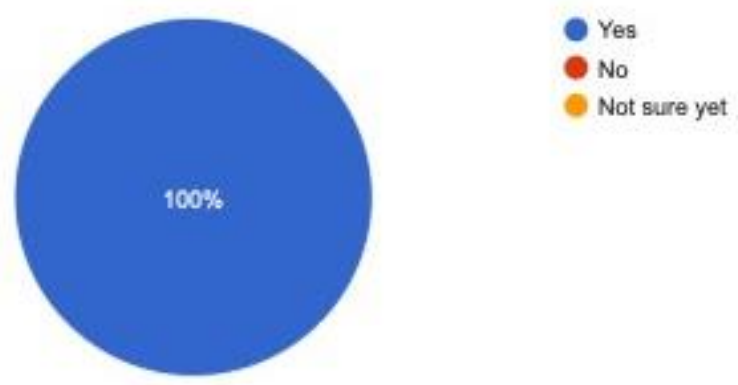

14. How often do you make your own snacks and meals?

3 responses

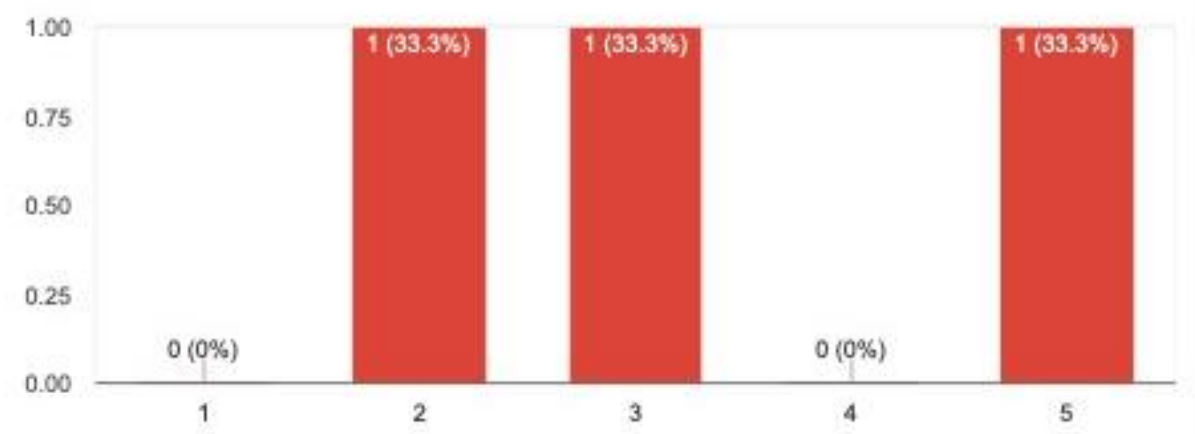


15. How often do you make friends with other kids your age

3 responses

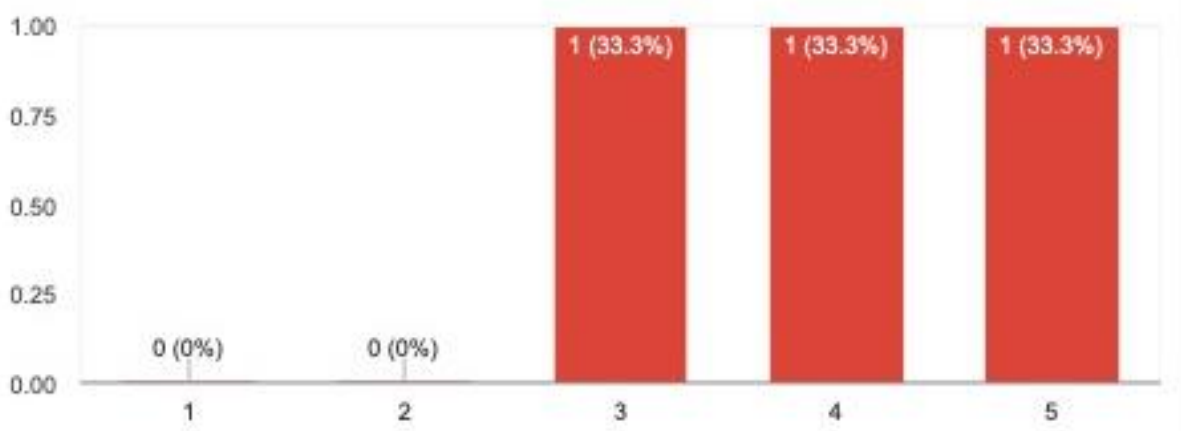

16. How often do you plan weekend activities that you like to do

3 responses

2

1

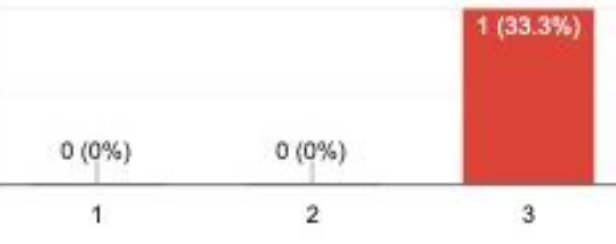

0

$0(0 \%)$

4 
17. How often do you choose your own hair and clothing style 3 responses

2

1

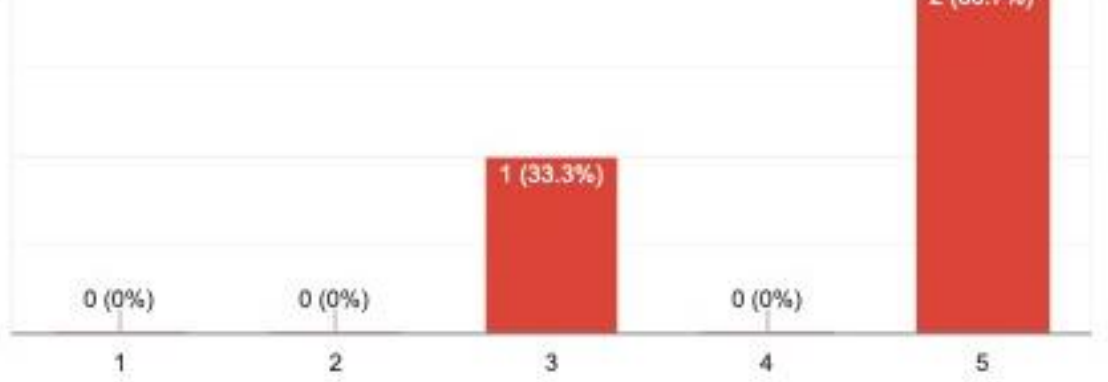

18. Do you have an academic subject that you find interesting? If so what is it? 3 responses

I have therapy animals and it is very fun.

math

Idk

19. Is there anything else you would to say or share with me?

3 responses

no

yes

No 